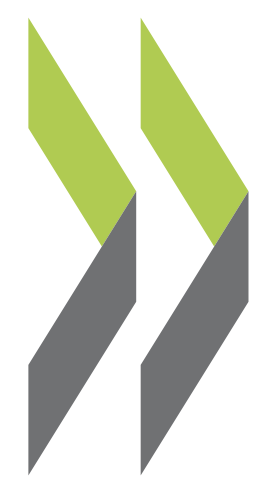

OECD Local Economic and Employment Development (LEED) Papers 2011/05

\title{
Gabriela Miranda,
}

Climate Change, Employment and Local Development in London, UK
Mads Greaker,

Kris Krasnowski,

Bettina Schaefer, Andy Westwood 


\section{Climate Change, Employment and Local Development in London, UK}
A REVIEW BY THE LOCAL ECONOMIC AND EMPLOYMENT DEVELOPMENT (LEED) PROGRAMME OF THE ORGANISATION FOR ECONOMIC CO-OPERATION AND DEVELOPMENT (OECD)

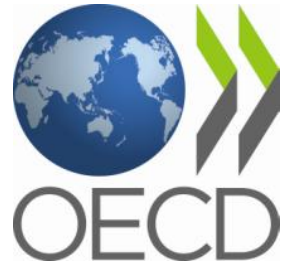





\section{CLIMATE CHANGE, EMPLOYMENT AND LOCAL DEVELOPMENT IN LONDON, UK}

A review by the Local Economic and Employment Development (LEED) Programme of the Organisation for Economic Co-operation and Development (OECD)

\section{FINAL REPORT}

March 2011 


\section{ORGANISATION FOR ECONOMIC CO-OPERATION AND DEVELOPMENT}

The OECD is a unique forum where governments work together to address the economic, social and environmental challenges of globalisation. The OECD is also at the forefront of efforts to understand and to help governments respond to new developments and concerns, such as corporate governance, the information economy and the challenges of an ageing population. The Organisation provides a setting where governments can compare policy experiences, seek answers to common problems, identify good practice and work to co-ordinate domestic and international policies.

The OECD member countries are: Australia, Austria, Belgium, Canada, Chile, the Czech Republic, Denmark, Estonia, Finland, France, Germany, Greece, Hungary, Iceland, Ireland, Israel, Italy, Japan, Korea, Luxembourg, Mexico, the Netherlands, New Zealand, Norway, Poland, Portugal, the Slovak Republic, Slovenia, Spain, Sweden, Switzerland, Turkey, the United Kingdom and the United States. The European Commission takes part in the work of the OECD.

This work is published on the responsibility of the Secretary-General of the OECD. The opinions expressed and arguments employed herein do not necessarily reflect the official views of the Organisation or of the governments of its member countries.

You can copy, download or print OECD content for your own use, and you can include excerpts from OECD publications, databases and multimedia products in your own documents, presentations, blogs, websites and teaching materials, provided that suitable acknowledgment of OECD as source and copyright owner is given. All requests for public or commercial use and translation rights should be submitted to rights@oecd.org. Requests for permission to photocopy portions of this material for public or commercial use shall be addressed directly to the Copyright Clearance Center (CCC) at info@ copyright.com or the Centre français d'exploitation du droit de copie (CFC) contact@cfcopies.com. 


\section{FOREWORD}

The OECD is defining a Green Growth Strategy aimed at providing a policy framework to worldwide efforts to manage the greening of the economies. Within this context, the OECD Local Economic and Employment Development (LEED) project on "Climate Change, Employment and Local Development" seeks to assess the challenges and opportunities ahead for governments in the context of sustainability. Most national and local governments have made ambitious commitments to mitigate climate change and to adapt to the new environmental and regulatory conditions, while combating unemployment. London is not the exception.

This project with the London Development Agency has offered a unique opportunity to analyse an outstanding example of leadership in supporting the development of a low-carbon economy in one of the most dynamic cities across the OECD. London is putting a lot of efforts into achieving its ambitious emission-cutting targets while regenerating its labour market. On the one hand, the Mayor of London has developed a range of programmes that will stimulate activity and demand for the low-carbon economy within London. On the other hand, large scale initiatives such as the 2012 Olympic Games put London in the global scene as one of the forerunners of the transition to a low-carbon economy. The challenge is immense.

London has many assets in which it could create support for its programmes to facilitate the emergence of a low-carbon economy. State-of-the-art infrastructure like CEREB, large well-established enterprises, strong economic sectors, leadership and democratic participation are some of the key resources that characterise London. But some important challenges remain as top priorities, such as the regeneration of the most socio-economically challenged area of the city and the integration of Londoners into the lowcarbon labour market.

This report provides London with an in-depth analysis of its labour market, its "green" policies and of the barriers hindering the development of the low-carbon economy. The report includes a set of policy recommendations for London to overcome those obstacles and support the creation of jobs in this new context. This report and work stream is led by Gabriela Miranda, LEED Policy Analyst. The project has benefitted from the participation of Extremadura (Spain), London (UK), Podlaskie and Pomorskie (Poland), Sydney (Australia) and the European Commission. The findings of the various case studies will be synthesised in an OECD report expected to be finalised by the end of 2011.

With this work, LEED once again contributes to ensuring that policies and programmes are more socially-inclusive, more environmentally-friendly, and more economically-sound. I am confident that this work will provide a valuable contribution to London, and to other OECD countries and regions that are looking at alternative ways of thinking to achieve economic growth and job creation in a more sustainable economy.

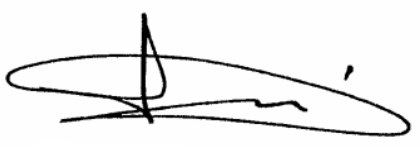

Sergio Arzeni

Director, OECD Centre for Entrepreneurship

Head, OECD LEED Programme 


\section{ACKNOWLEDGEMENTS}

The study on "Climate Change, Employment and Local Development in London", UK, has been undertaken by the Local Economic and Employment Development (LEED) Programme of the Organisation for Economic Co-operation and Development (OECD) in collaboration with the London Development Agency. The work was supervised by Gabriela Miranda of the OECD LEED Programme, who also prepared the report.

The OECD is grateful to Ms Jacqui Wordsworth and Mr. Kris Krasnowski from the London Development Agency for their continuous support and interest in this review. The work would not have been possible without the engagement of Ms Ami Diaby, London Development Agency, for her assistance in preparing the study visit and ensuring quality meetings. Additional thanks go to the various actors in London that took the time to meet with the OECD international expert team during the study visit and provided invaluable insights to this study.

In addition to Gabriela Miranda from the OECD Secretariat, the international expert team consisted of the following experts: Mr. Andy Westwood, chairman of the OECD Forum on Social Innovations; Ms Bettina Schaefer, founding member of Ecoinstitut Barcelona; and Mr. Mads Greaker, Head of research for the Section for Economic Growth and Environmental Economics at the Research Department in Statistics Norway.

Special thanks to Debra Mountford and Joe Huxley from the OECD Secretariat, for providing very valuable insights in relation to previous LEED work with London on the 2012 Olympic Games. Lucy Pyne from the OECD Secretariat was very helpful in the preparation of additional learning models to illustrate some of the recommendations and in revising Chapter 6. Kay Olbison provided editorial assistance for Chapter 5. Damian Garnys from the OECD Secretariat drafted additional learning models and prepared this report for publication. 


\section{TABLE OF CONTENTS}

FOREWORD

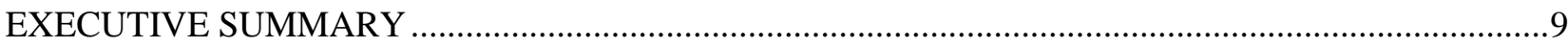

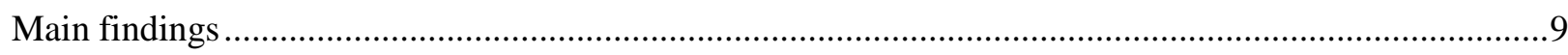

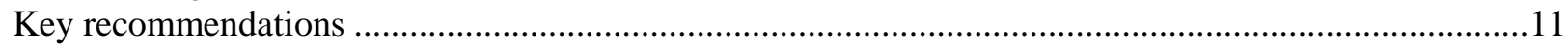

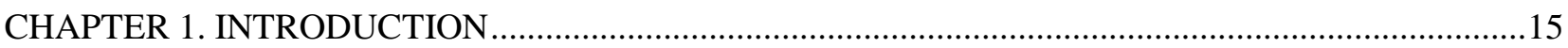

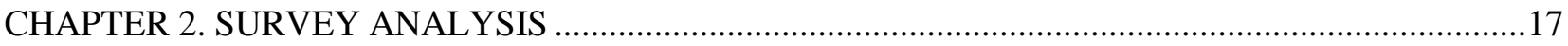

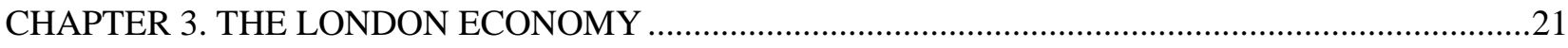

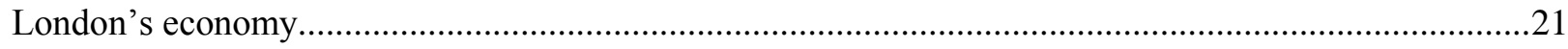

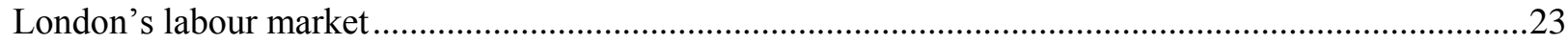

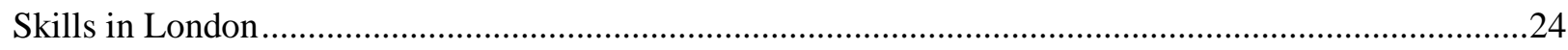

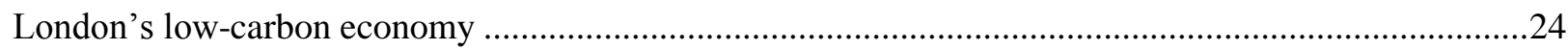

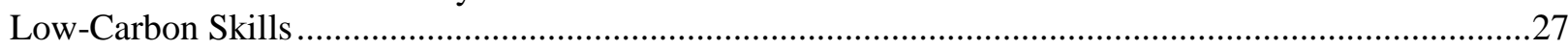

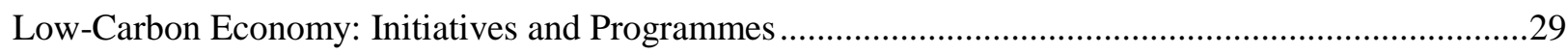

CHAPTER 4. THE LONDON LABOUR MARKET IN THE GREEN ECONOMY .................................37

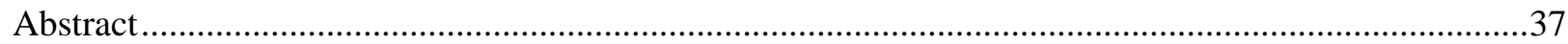

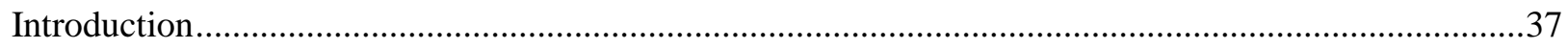

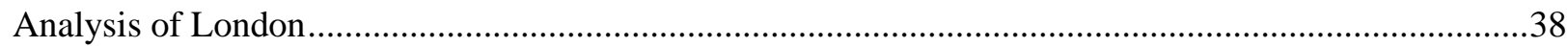

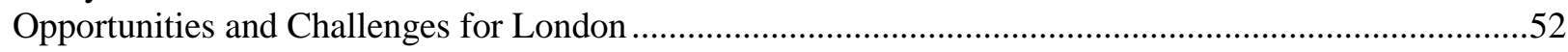

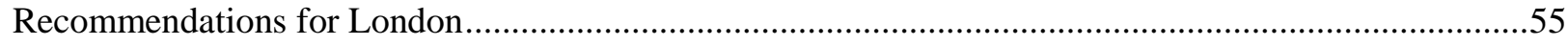

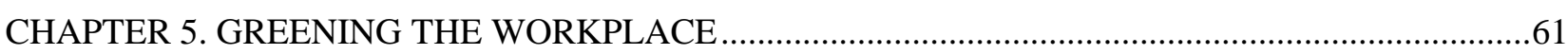

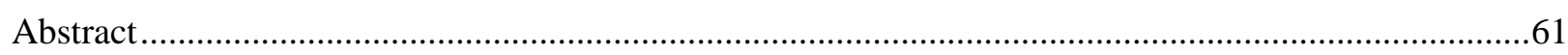

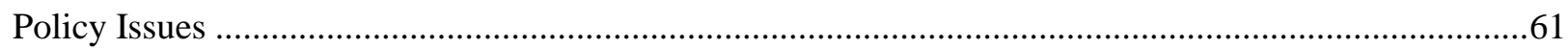

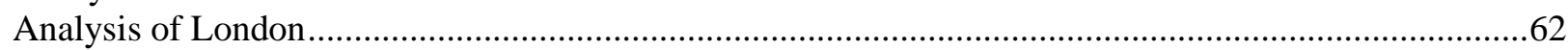

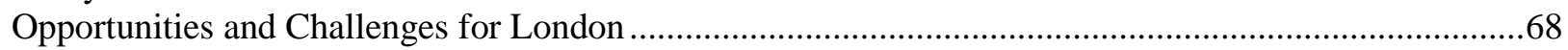

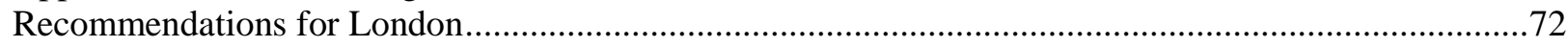

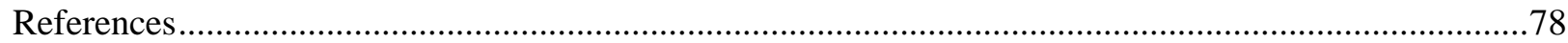

CHAPTER 6. ENABLING GREEN GROWTH IN LONDON ..............................................................

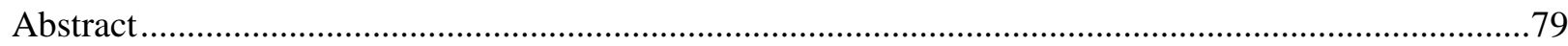

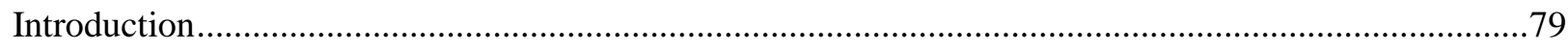

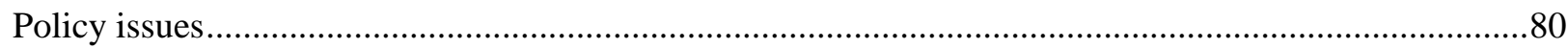

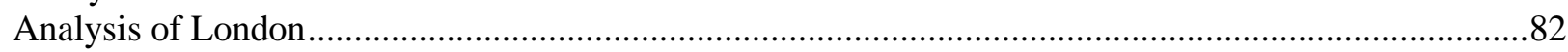

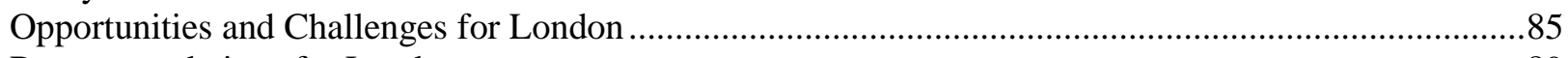

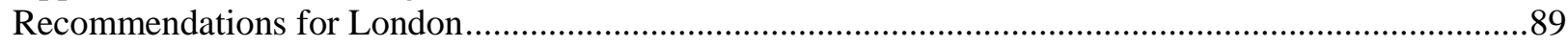

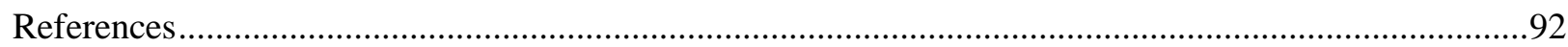




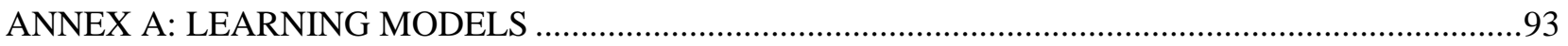

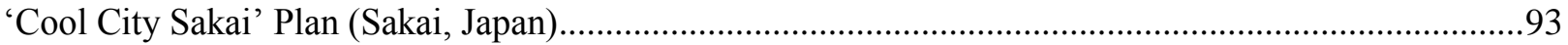

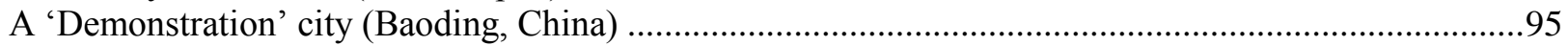

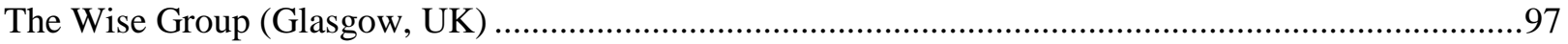

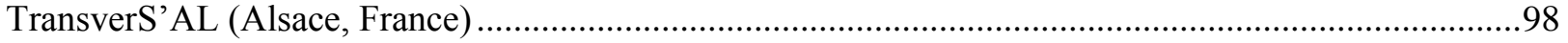

Green Public Procurement (Basque Country, Spain)............................................................................ 101

Green Skills in Vocational Education and Training, TAFE (NSW, Australia) ....................................... 104

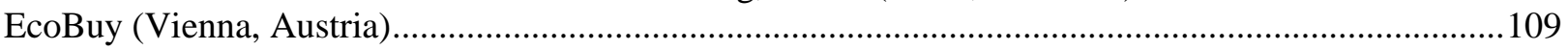

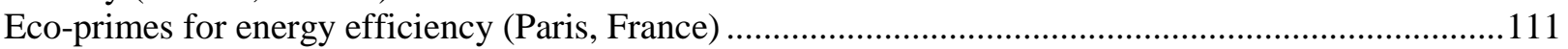

Using market instruments instead of direct controls (Norway and United States) .................................113

Flexible approach to GHG emission reduction targets (Norway)........................................................115

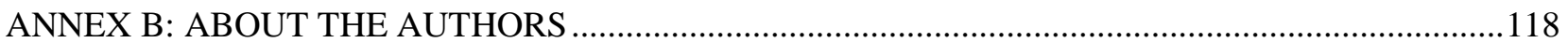

\section{Boxes}

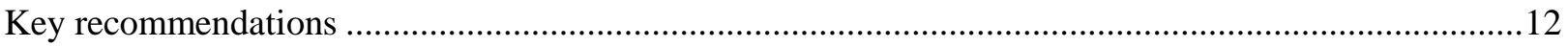

Box 4.1. London 2012 Summer Olympics: The Greenest Games Ever?...............................................40

Box 4.2. The Mayor's Carbon Reduction Targets and Ambitions .....................................................46

Box 4.3. Cycling revolution and low-carbon transport solutions in London ...........................................48

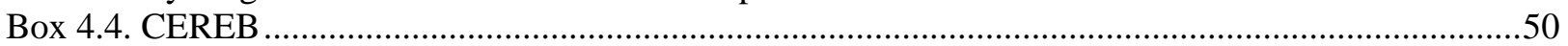

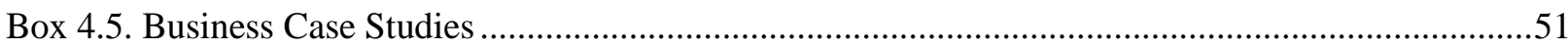

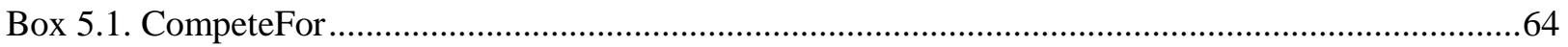

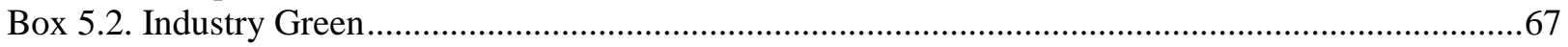




\section{EXECUTIVE SUMMARY}

London and the UK are far from immune from the impacts of climate change. The UK is already experiencing the effects of climate change in the form of increased sea-surface temperature and rising sea levels. If global GHG emissions continue unabated, the UK is expected to experience progressively warmer and drier summers, wetter and milder winters and more frequent extreme weather. London, in particular, will be vulnerable to floods, droughts and heat waves. The Mayor of London has committed to reducing the city's $\mathrm{CO}_{2}$ emissions by $60 \%$ on 1990 levels by 2025 . To achieve this, the Mayor has developed a range of programmes that will contribute to his ambitious climate change targets whilst stimulating demand for the low-carbon economy in London. However, some challenges still need to be addressed in order to ensure that enough jobs will be created and that those jobs created in the low-carbon economy will be accessible for Londoners.

How can London exploit its capacities to broaden the employment basis while moving to a lowcarbon economy? What actions and priorities should the London authorities take into account to move an economic development and employment agenda forward in this new context? How can London authorities contribute to stimulate the demand of lower-carbon products and services? How can London ensure that the jobs created will be for Londoners? This study sought to provide guidance and policy recommendation to London on these and other issues related to the transition of the labour market to the low-carbon economy.

This OECD project with the City of London examines the impacts of climate change (including through its effect on policy and regulations) on the London labour markets, with a focus on the creation of jobs and the development of a skilled workforce to meet the needs of the greener economy. In particular, the project identifies areas in which the authorities can have a more important role to play to enable green growth, as well as the barriers that are hindering the expansion of business activities in the low-carbon economy. This report provides a set of policy recommendations for London to meet the Mayor's ambitious low-carbon agenda while creating jobs.

\section{Main findings}

The new jobs that London's economy will create over the next decade are likely to be increasingly highly skilled. By 2020 more than one half of the jobs in London will require degree level qualifications, compared to $40 \%$ in 2009 . To avoid this mismatch, London needs to look at the broader picture. This implies an assessment of London's skills availability, the contribution of HE and FE institutions to the labour market, the performance of the businesses in the low-carbon sector as well as the role that the public sector can play to stimulate the demand of "greener" products and services. Various good practices were identified in London, while some challenges still need to be addressed in order to support the low-carbon agenda. A summary of the analysis is presented below.

\section{Opportunities for London}

London has a clear focus on the long-term economic labour market and broader economic opportunities offered by the shift to a low-carbon economy. Long-term targets and policies are in place that mutually support and reinforce overall objectives for meeting environmental standards and carbon reduction targets as well as the generation of new opportunities in the green economy. London also 
benefits from strong leadership with specified and clear green ambitions - the London authorities understand how they can use their policy, funding and regulatory powers and resources to practically drive green objectives.

Key economic sectors and expertise are already in place in London, from established sectors to centres of research expertise and businesses expanding to offer more green jobs in the green economy. The Centre for Efficient and Renewable Energy in Buildings at London Southbank University is a state-ofthe-art facility that provides a practical approach to learning and research. London has a reputation for innovative products and emerging green markets, and is well position in the carbon finance sector.

The UK and London as the "Low-Carbon Capital" are without any doubt global leaders in developing projects, methodologies, standards and certification schemes for the low-carbon economy. The development of the Olympic Village provides a good example where the carbon footprint has been calculated for the construction work. From an international point of view, there are few examples of urban development projects with a similar level of environmental and energy efficiency auditing, both in the project and the construction phase.

There are 5500 companies working in the low-carbon sector. This is a good starting point and presents an opportunity for the further development of the low-carbon economy. There are low-carbon jobs that do not involve radical changes in qualifications or skills. Only some new learning or apprenticeship models are needed because the main skills already exist. Moreover, London has a highly innovative and well educated population which could generate the new ideas needed for the transition to a low-carbon economy.

London has a very strong position in carbon finance, that is, facilitating buying and selling of emission permits in the EU Emissions Trading System (EU ETS), in joint implementation (JI) projects and in Clean Development Mechanisms (CDM) markets. These instruments are seen as essential for a global solution to the climate problem.

Evidence was gathered in London on the economic benefits of greening the workplace and the development of the low-carbon economy, but more visibility should be given to the benefits in order to enhance its outcome. Also, there is an opportunity for London to make the most out of the Olympics site to strengthen the workforce base for the low-carbon economy and to set the criteria of a low-carbon site.

Green businesses in London with large growth potential have not yet been thoroughly identified. Clearly, specialised firms will be in demand for eco-improvements such as heat insulation, installation of energy efficient equipment, and even for small scale electricity production. However, there is room for more opportunities such as firms who provide systems for so-called intelligent homes and buildings where all energy usage is monitored.

\section{Challenges ahead for London}

London is part of complex skills and employment system with limited and declining local power for the Mayor and the GLA group. This makes it increasingly difficult for direct intervention and investment.

Continuous research and development requires continuous adjustments to the skills needed by the sector. It is difficult to match up the professionals with the required skills to the emerging low-carbon activities at the right time and in the right place. This requires leadership and flexibility to adapt rapidly to the new low-carbon paradigm well ahead of society and client demand.

Market-based skills and training systems also focus both on current and past needs and it is therefore not easy to capture future trends or future demand. The slow development of new frameworks and 
qualifications for the low-carbon curriculum may lead to sub optimal outcomes for green industries as a whole and also for the Mayor's ambitions to get more London residents into new green jobs.

Behavioural changes are processes which take time. The lack of skills or awareness is also applicable to the end-users. Indeed, the fact that consumers do not have the ability to use smart building technology has also been identified as a barrier to good energy performance. In contrast to some initiatives put in place to up-skill the public sector and businesses, individual consumers are expected to make a behavioural shift in a very short time frame. London's challenge is therefore the end-user; in how to up-skill them to change their behaviours.

London suffers from a lack of entrepreneurial capacity. There is little business creation in the lowcarbon economy and business support agencies have not shown any adjustment to the emerging needs of businesses in the low-carbon economy. Moreover, there are weak links between job placement and vacancy matching and broader business support and development.

Venture capital markets and financial institutions may not be backing new innovation in firm support or lending due to 'myopia' or because lending is restricted by post recession banking targets. There may also be an information failure as such firms may not see the short to long-term benefits of such investment because they are lacking knowledge of regulatory and policy changes.

There is a lack of clarity in the market prospective for green businesses. Thus, businesses may lack the necessary confidence to start investing or expand in the low-carbon sector. There may also be too many different funds, institutions, and so on, such that businesses find it hard to afford the costs of finding the information and going through the application process.

The link between the current green firms located in London and the demand for new green solutions in London may be weak. That is, the current green firms in London may be geared towards demand from the sectors outside London, that is the rest of the UK and internationally. Information on the opportunities and possibilities within the low-carbon economy (nationally and internationally) should be clearly presented, market-oriented and condensed to facilitate its uptake.

In London, there is a large number of ongoing projects and programmes showing similar objectives, but with a different focus or definitions. As a consequence of the arbitrary definition of "green", "responsible" or "sustainable" procurement in parallel projects, no clear GPP strategy nor GPP criteria for strategic contracts have been defined, and London's public procurement activities are not as visible as they could be.

Finally, information gathered during the study visit demonstrated the relatively weak implementation of GPP both in London's and in government departments. The identification of future "low-carbon" procurements would be necessary to support the expansion of the low-carbon sector. This implies the early identification of procurement opportunities based on a prospective analysis of future public spending, leading to the emergence of new markets or the expansion of existing ones.

\section{Key recommendations}

The report's analysis provides a basis for a set of policy recommendations to support the transition towards a low-carbon economy while creating jobs and supplying the skills required. Some of the policy recommendations are illustrated with practical examples (learning models) from approaches adopted in other regions across the OECD. The learning models can be found in the annex A. The main policy recommendations have been condensed in the list below. The details and analysis of each of them can be found in the report. 


\section{Key recommendations}

- Make use of the existent powers to build a green economy.

This could be achieved by:

- Working through partnerships

- Encouraging democratic participation

- Promoting private investment and behaviour change

- Maximising outcomes

- Enhance your leadership.

This could be achieved by:

- Communicating effectively

- Pursuing demonstrative leadership

- Using the London 2012 Olympics as a platform to pursue a green growth strategy

- Focus on both 'evolution' and 'revolution' jobs and businesses.

This could be achieved by:

- Deploying support for adaptation and flexibility

- Promoting science, research and technology transfer

- Supporting innovative firms and market development

- Innovation in public sector delivery.

This could be achieved by:

- Making better use of social enterprises

- Supporting market-oriented funding systems

- Undertake a skills audit for London.

This could be achieved by:

- Identifying transferrable skills

- Making faster and more flexible response from FE and HE institutions

- Gradual up-skilling of the population and the end-user.

This could be achieved by:

- Rising awareness among the population and the end-user

- Facilitating access to information on RE:NEW

- Improving the visibility and communication to the end-user

- Revise definitions and criteria.

This could be achieved by:

- Identifying Green Public Procurement criteria

- Re-defining the low-carbon sector

- Provide green training.

This could be achieved by:

- Building "green" capacities across the public sector

- Training the consumer 
- Support London's business sector.

This could be achieved by:

- Creating new businesses in the low-carbon sector

- Facilitating access to information to businesses

- Targeting businesses in the building sector

- Positioning London as a low-carbon building area

- Supporting government actions through social enterprises and SMEs

- Work towards realising only profitable energy saving projects.

This could be achieved by:

- Unlocking inefficiencies in the economy

- Better identifying growth sectors and training needs

- $\quad$ Remove barriers to green growth.

This could be achieved by:

- Ensuring that the climate policy targets are realistic

- Considering realising projects abroad

- Providing business support in the long term 



\section{CHAPTER 1.}

\section{INTRODUCTION}

Among OECD countries, green growth is gaining support as a way to pursue economic growth and development, while preventing environmental degradation, biodiversity loss and unsustainable natural resource use. For the OECD, green growth implies decoupling economic and environmental performances, as well as making investment in the environment a driver of economic growth (OECD, 2010). Climate change is a reality now, and countries have to face several challenges to adapt and mitigate its effects on the economy and the employment base.

At the OECD Ministerial Council Meeting in June 2009, Ministers acknowledged that green and growth can go hand-in-hand and adopted the Declaration on Green Growth. At this occasion, Ministers asked the OECD to develop a Green Growth Strategy to provide guidance and recommendations on the programmes and initiatives required to facilitate the transition to a green economy. In developing this strategy, the OECD Local Economic and Employment Development (LEED) Programme proposed the project 'Climate Change, Employment and Local Development' to examine the impacts of climate change on labour markets and local development, as well as to assist participants manage the transition to a lowcarbon economy.

As analysed in the background report of this project ${ }^{1}$, there are a number of ways in which climate change can impact on the economy and on labour markets:

1. Direct impacts of climate change on economic activities - e.g. due to changes in climatic conditions and the occurrence of climatic events;

2. Indirect impact of climate change through new policy and regulations, affecting supply (enterprises) and demand (consumers);

3. Impact of the climate change debates on social conscience leading to a raise of awareness of sustainability. This "green" social conscience then drives policy, regulations, consumer choices, and therefore labour markets.

Whilst the first factor is potentially significant in the medium to long term and may affect some economic sectors in London; the primary focus of this study is on the second factor - in particular to identify and analyse the policy options available to the London authorities to maximise the economic opportunities arising from moving towards a low-carbon agenda, and minimise any adverse impacts on the economy and the jobs base.

The project 'Climate Change, Employment and Local Development' is the core contribution of the LEED Committee to the OECD Green Growth Strategy ${ }^{2}$. The analysis is underway in Extremadura (Spain), London (UK), Podlaskie/Pomorskie (Poland) and Sydney (Australia). As part of the project, a series of study visits to the four participating cities/regions are taking place. The aim of these study visits is to 'dig deeper' into the local challenges to the transition to the green economy and the consequences of this transition on the labour market, on jobs and on local development. Other valuable opportunities to 
interview local actors managing the transition to a green economy at the local level have arisen within the work carried out by the LEED Forum on Partnerships and Local Governance, notably on occasion of the capacity-building seminar in Trento (Italy) ${ }^{3}$ and during the study visit to Styria (Austria) ${ }^{4}$. The findings of the various case studies will be synthesised in an OECD report that will be finalised by the end of 2011.

The London review has been arranged around three thematic areas:

1. The London labour market in the green economy

2. Greening the workplace

\section{Enabling green growth}

One survey was prepared for the purposes of this study which was addressed to businesses in the lowcarbon sector in London. The OECD questions were integrated in the DTZ survey carried out in April 2010. This survey gathered evidence from 200 businesses on the impacts on jobs and skills requirements in the labour market from the transition to a low-carbon economy. An analysis of the survey is provided in more detail in the following section.

A three-day study visit to London was organised to deepen the understanding of the challenges and opportunities that are arising for the work of public services in the transition to a low-carbon economy. The study visit took place from 13 to 15 September 2010 in the city of London. The aim of the study visit was to confront the preliminary results of the surveys and the diagnostic analysis of London with key economic and social players in the city. The study visit was also the occasion to gather evidence of the challenges and opportunities for job creation and economic development in London in the context of the transition to a low-carbon economy. The study visit included a series of meetings with stakeholders from the public and private sectors in London, as well as other organisations involved in workforce and economic development.

The review panel was formed by three international experts, led by the OECD Secretariat. This review has been carried out under the supervision of Gabriela Miranda from the OECD Secretariat, who has also prepared this report. The Chapter 3 was drafted by Mr. Kris Krasnowski, Labour Market Analyst, London Development Agency. The Chapter 4 was drafted by Mr. Andy Westwood, Chief Executive Officer of GuildHE and Chairman of the OECD Forum on Social Innovations. The Chapter 5 was drafted by Ms Bettina Schaefer, Director of Projects, Ecoinstitut Barcelona. Lastly, Chapter 6 was prepared by Mr. Mads Greaker, Head of Research, Statistics Norway.

\section{ENDNOTES}

\footnotetext{
${ }^{1}$ Martinez-Fernandez C., Hinojosa C., Miranda G. (2010), Greening Jobs and Skills: Labour Market Implications of Addressing Climate Change, OECD

${ }^{2}$ See: www.oecd.org/greengrowth

${ }^{3}$ Capacity-building seminar on 'Local strategies for greening jobs and skills', Trento, Italy, 9-11 June 2010

${ }^{4}$ Study visit on 'Partnerships \& the green economy', Styria, Austria, 11-13 October 2010
} 


\section{CHAPTER 2.}

\section{SURVEY ANALYSIS}

The questions of the OECD survey enterprises were included in a DTZ survey in 2010. The results show changes in firms (due to climate change impacts on their processes and methods), in the creation, transformation or suppression of jobs, as well as in training and skills needs. The same survey was undertaken in Extremadura (Spain) and is currently running in Sydney as part of the LEED project.

The enterprises surveyed in London belong to the 'low-carbon' sector as defined by London (see Table 2.1). It is important to highlight that the OECD surveys aim at understanding the challenges and identifying the opportunities of the green economy in the local context. The LEED project seeks to reflect a broader illustration of the transition to the green agenda, while complementing the work that each of the participants is undertaking locally. The project is therefore adjusted to the participants' own agendas and to ensure that the final report is relevant to the different approaches pursued by mentor governments.

Table 2.1. London: surveyed enterprises by sector

\begin{tabular}{lcc}
\hline & Frequency & Valid Percent \\
\hline Energy Efficient - Building Technology & 49 & $24.5 \%$ \\
\hline Energy Efficient - Energy Managment & 23 & $11.5 \%$ \\
\hline Energy Supply + Renewable Energy & 11 & $5.5 \%$ \\
\hline Waste and waste to energy & 54 & $27.0 \%$ \\
\hline More than one of the sectors above & 63 & $31.5 \%$ \\
\hline Total & 200 & $100 \%$ \\
\hline
\end{tabular}

The survey respondents of the London survey were 200. Even though the OECD survey results are indicative only and do not represent the firms population in London, the study visit complement and confirm the analysis presented hereafter.

The first question of the survey was: Has your business made changes in the past 12 months in terms of introducing a new product/ service/ operation due to climate change adaptation or mitigation? Among the London businesses of the low-carbon sector the positive response rate was high (197 out of 200 firms).

For the firms having answered positively to the first question, it was asked whether these changes resulted in the creation, suppression or transformation of jobs in (their) enterprise? The answers show that jobs that have been created in the low-carbon sector firms as a result to changes/ adjustments due to climate change (43 out of 200 firms) have not been in large amounts. 
Table 2.2. Have these changes resulted in the creation, suppression or transformation of jobs in your enterprise?

\begin{tabular}{lcccc}
\hline & $\begin{array}{c}\text { Job } \\
\text { creation }\end{array}$ & $\begin{array}{c}\text { Job } \\
\text { loss }\end{array}$ & $\begin{array}{c}\text { Job } \\
\text { transformation }\end{array}$ & $\begin{array}{c}\text { No } \\
\text { change }\end{array}$ \\
\hline $\begin{array}{l}\text { London } \\
(197 / 200 \text { firms })\end{array}$ & $20.3 \%$ & $10.7 \%$ & $2.5 \%$ & $66.5 \%$ \\
\hline
\end{tabular}

As shown in Table 2.3, over $60 \%$ of the firms that responded having created a job, created 1-2 jobs. Only $9.3 \%$ of the firms created over 10 jobs. Even if the number of firms that have created jobs is only one fifth of the respondents, it is interesting to note that some jobs have been created in the low carbon sector in London over the past twelve months, despite the economic and financial crisis. Again, this analysis must be considered cautiously as the firms surveyed in London belong to the low-carbon sector only which is the target of this study.

Table 2.3. London: number of jobs created in the past 12 months as a result of changes/adjustments to climate change (including policies and regulations)

\begin{tabular}{rcc}
\hline $\begin{array}{c}\mathbf{N}^{\circ} \text { jobs } \\
\text { created }\end{array}$ & $\begin{array}{c}\text { Frequency of } \\
\text { responses }\end{array}$ & $\begin{array}{c}\text { Valid } \\
\text { Percent }\end{array}$ \\
\hline $1-2$ & 26 & $60.5 \%$ \\
$3-10$ & 13 & $30.2 \%$ \\
$>10$ & 4 & $9.3 \%$ \\
Total & 43 & $100 \%$ \\
\hline
\end{tabular}

It is important to take a look at the number of enterprises in the low-carbon sector in London that have actually increased their number of staff in absolute numbers. This means, those enterprises that have created jobs while not suppressing others. Table 2.4 shows that nearly all of the businesses that have created new jobs over the past twelve months have not had any job losses (36). In contrast, businesses that have reduced their number of workers in absolute terms (i.e. jobs lost and not created any jobs) account for half (18) of those that have augmented their number of workers. Further analysis is needed, but there seems to have actually been a net increase in jobs among the surveyed firms, despite the economic and financial turmoil.

Table 2.4. London: jobs created and lost (number of firms)

\begin{tabular}{|c|c|c|c|}
\hline & \multicolumn{2}{|c|}{ Reduction } \\
\hline & & Yes & No \\
\hline \multirow{2}{*}{ 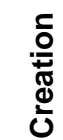 } & Yes & 1 & 36 \\
\hline & No & 18 & 50 \\
\hline
\end{tabular}

Moreover, Table 2.5 shows that for the majority of the surveyed firms there has been no real impact on jobs, and not much job transformation has taken place either. Yet, it is interesting to note that almost half of the firms (48\%) between 10-19 workers have created new jobs. A first analysis shows that in SMEs (firms < 250 employees) more jobs have been created than lost as a result of adjustments to climate change, while larger firms ( $>250$ employees) show the opposite trend. As the large firms group corresponds to only $12 \%$ of the sample, further analysis is needed to fully confirm the reasons for this shift. Preliminary hypotheses from the study visit point towards the internal restructuring of the larger companies 
due notably to the global financial crisis and not necessarily to climate change policies and regulations themselves, but further analysis is needed to confirm this.

Table 2.5. London: impact of climate change on jobs (\%)

\begin{tabular}{rcccc}
\hline $\begin{array}{c}\text { Firms by size } \\
\left(\mathrm{n}^{\circ} \text { workers }\right)\end{array}$ & $\begin{array}{c}\text { Jobs } \\
\text { created }\end{array}$ & $\begin{array}{c}\text { Jobs } \\
\text { lost }\end{array}$ & $\begin{array}{c}\text { Jobs } \\
\text { transformed }\end{array}$ & No change \\
\hline $1-9$ & 13.2 & 7.4 & 1.7 & 77.7 \\
$10-19$ & 48.0 & 4.0 & 12.0 & 36.0 \\
$20-49$ & 31.3 & 18.8 & 0.0 & 50.0 \\
$50-249$ & 33.3 & 8.3 & 0.0 & 58.3 \\
$250-499$ & 12.5 & 25.0 & 0.0 & 62.5 \\
$500-999$ & 16.7 & 50.0 & 0.0 & 33.3 \\
$>1000$ & 12.5 & 25.0 & 0.0 & 62.5 \\
\hline
\end{tabular}

Finally, for the purposes of this analysis, three periods were identified as milestones for the creation of enterprises in London: before 1990 (business as usual, peak for CO2 emissions), 1991-2000 (UNFCCC and Kyoto Protocol ${ }^{1}$ ) and 2001 onwards (Marrakesh Accords ${ }^{2}$ ). It is interesting to highlight that the most recently created firms, those that started in the context of the enter into force of the Kyoto Protocol, are the ones that have created more jobs due to climate change mitigation or adaptation (25 out of 43). Further analysis is needed, but hypotheses from the study visit point towards the positive effect on businesses of the initiatives put in place in London to reduce its greenhouse gas emissions, and the environmental awareness of the businesses.

\section{ENDNOTES}

${ }^{1}$ During the 1991-2000 period, international dialogue led to various agreements aiming at reducing greenhouse gas (GHG) emissions. The UK signed the United Nations Framework Convention on Climate Change (UNFCCC) in June 1992 and entered it into force in March 1996. The Kyoto Protocol was adopted in Kyoto, Japan, on 11 December 1997.

${ }^{2}$ From 2001 onwards, the international community put in place actions and national/local targets regarding climate change mitigation. The 'Marrakesh Accords' which are the detailed rules for the implementation of the Kyoto Protocol, were adopted at COP 7 in Marrakesh in 2001. The Kyoto Protocol entered into force on 16 February 2005. 



\title{
CHAPTER 3.
}

\section{THE LONDON ECONOMY}

\author{
by Kris Krasnowski
}

This chapter provides a short background on London, including information on London's people and its economy. It also presents a brief description of the key initiatives and programmes put in place by the London authorities to enable the emergence of the green economy and support the creation of jobs. This chapter is a summary of the diagnostic report which served as background material for the OECD expert team in preparation of the study visit to London. This chapter includes the analysis of some questions of the OECD survey that were included in an ongoing survey that the London Development Agency was undertaking in parallel.

\section{London's economy}

London is a global-focused knowledge and service economy. In 2009 London's economy generated approximately GBP 265 billion (GVA), a slight reduction on 2008 figures, but still making a dominant contribution to the UK economy, where London GVA accounts for around one-fifth of the UK's total GVA (see Figure 3.1).

Figure 3.1. London's output (GBP billions) and London's share of UK output

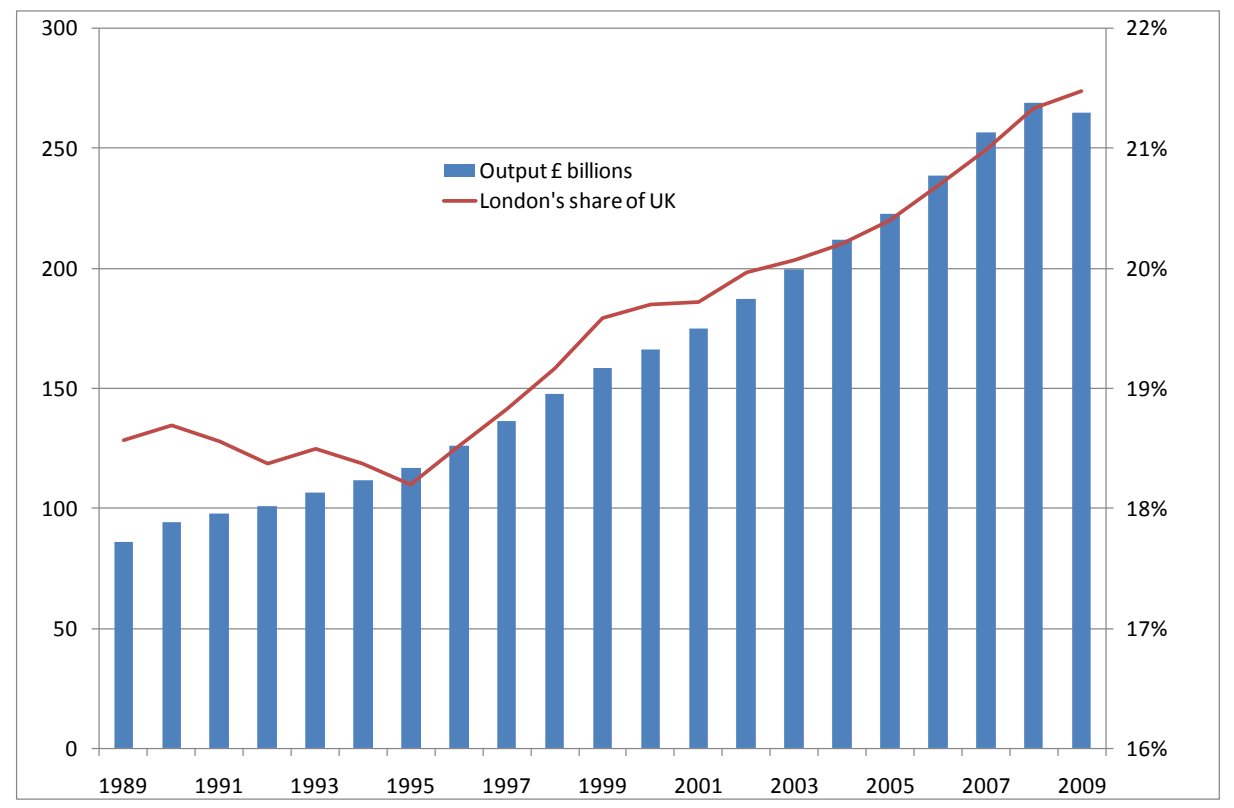

Source: Gross Value Added (GVA), December 2010, ONS 
The city also serves as the headquarters for more FTSE500 companies than New York, Paris or Hong Kong and is the most common destination for foreign direct investment in Europe. Business, financial and other services account for approximately $40 \%$ of London's total employment and reflect the changes to the structure of the economy over the last forty years. ${ }^{1}$

Figure 3.2 looks in more detail at the current industrial structure of London's economy in relation to the UK economy and shows that economic activity in London is concentrated in financial services, businesses services and - to a lesser extent - other services and transport and communications. GLA Economics estimates that London's total exports of goods and services totalled GBP 66.4bn in 2008 with London accounting for one third of all UK exports of services.

Figure 3.2. London's broad sectors: Index of Specialisation (relative to GB) and share of London's total output

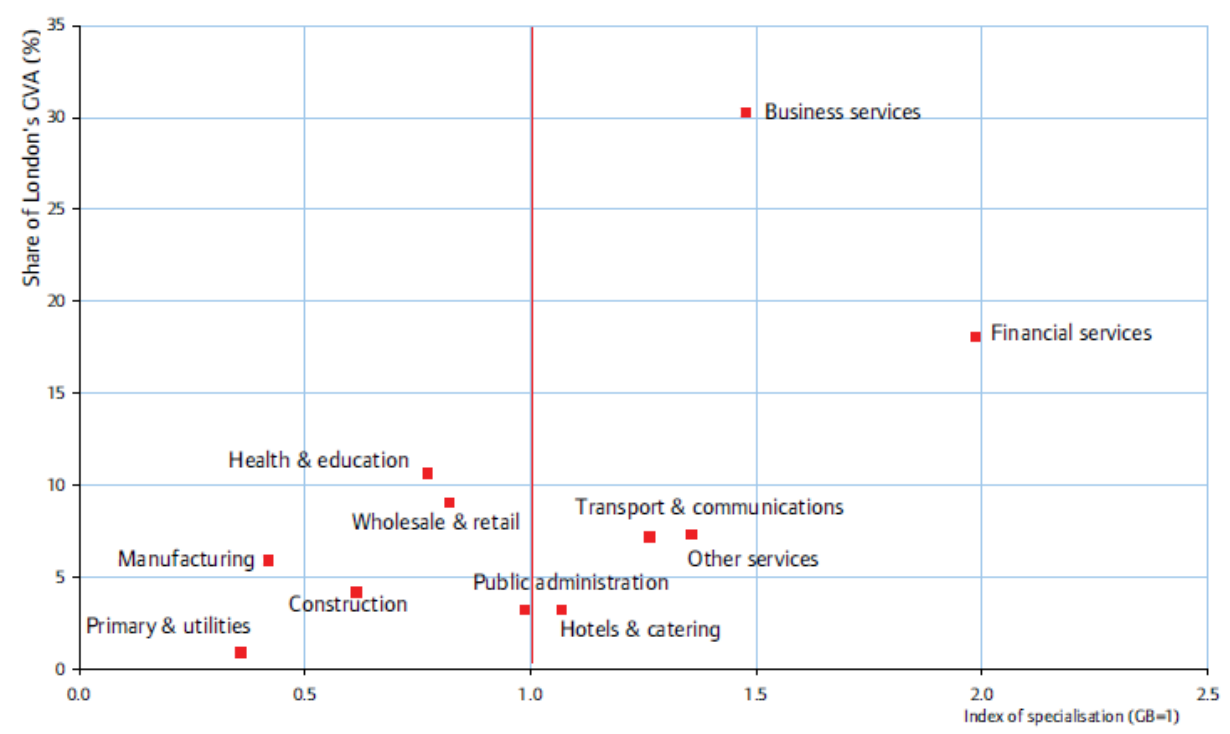

Source: Annual Business Inquiry - ONS Crown Copyright; UK Regional Accounts - ONS Crown Copyright

London's population has increased significantly over the last quarter of a century and in 2009 accounted for $12.5 \%$ of the UK population with approximately 7.8 million people ${ }^{2}$. The recent population growth in London is in stark contrast to demographic trends in the most of the UK with London growing grown much quicker than any other UK region. ${ }^{3}$ London's population is also much younger than the rest of the UK's (see Figure 3.3) and more diverse. In 2007 around a third of Londoners were from BAME groups ${ }^{4}$ and over the past 20 years the share of London's foreign-born worker population has doubled to $33 \% .^{5}$ 
Figure 3.3. Population by age cohort, London and the UK

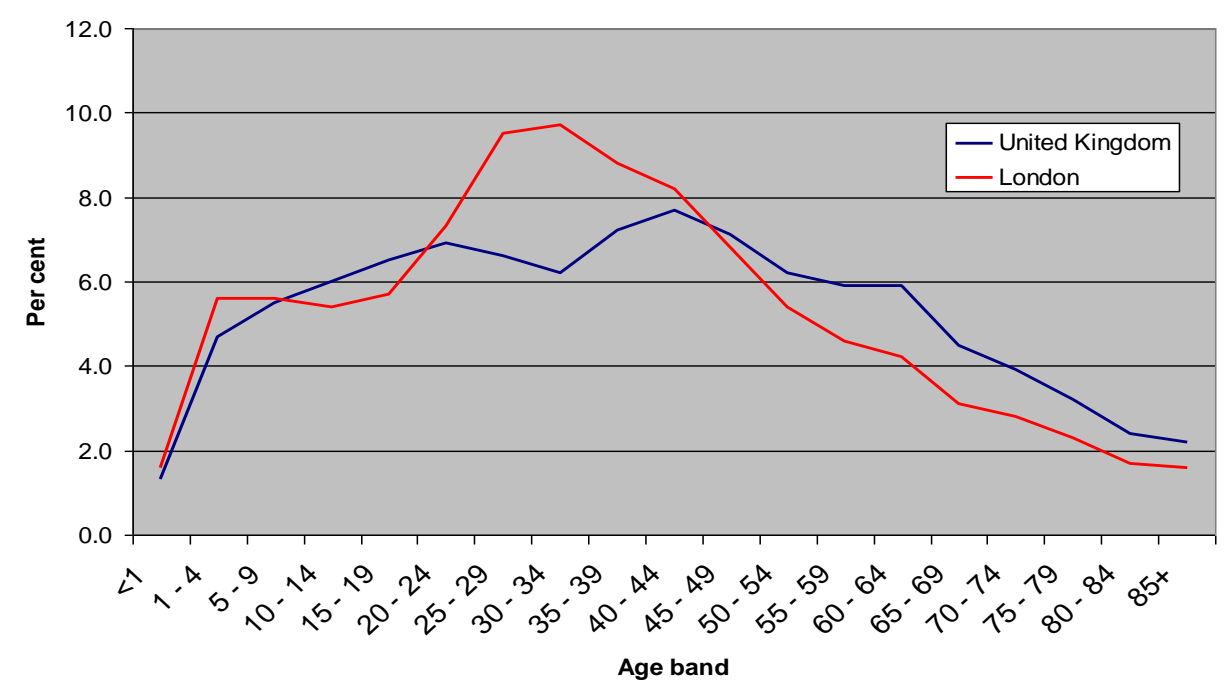

Source: ONS Office for National Statistics, Estimated resident population by ethnic group and sex, mid-2007 (experimental statistics)

\section{London's labour market}

There are 5.2 million people of working age in London, with 3.5 million of these in work. ${ }^{6}$ London's employment rate has consistently lagged the national average by between two and five percentage points for over a decade (see Figure 3.4). More recently the employment rate gap between London and the rest of the UK has closed to 2.8 percentage points, but largely because London's' employment rate has not dropped as sharply as the rest of the UK's during the recent recession.

Figure 3.4. Employment rates and employment gaps by group, London and Rest of the UK, 2010

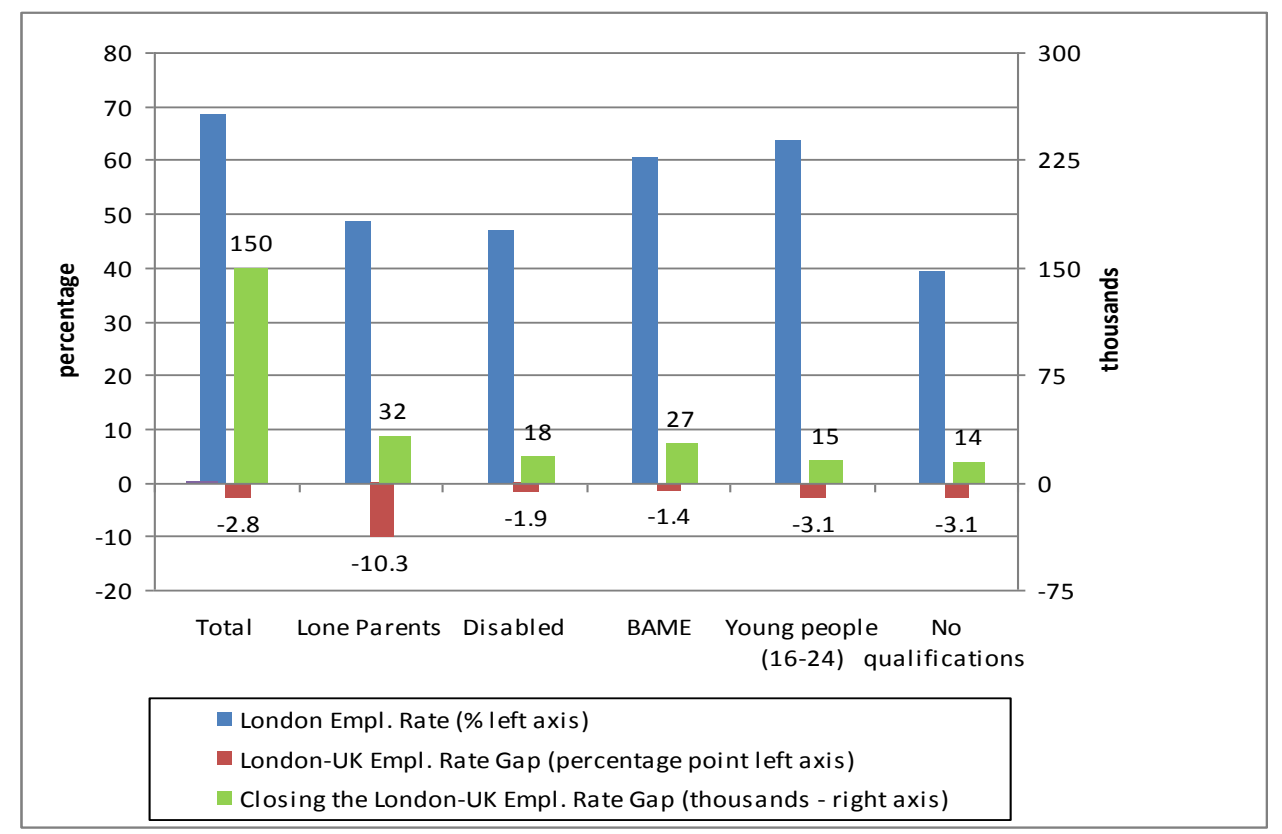

Source: LFS July-Sept 2010, Lone parent data are LFS Household dataset April-June 2010. Data is for working age population. Data for young people and people with no qualifications excludes students 
In addition London also has significant structural challenges in relation to worklessness. Currently around one-in-three Londoners are out of work classified as either unemployed or economically inactive. In 2010 London's unemployment rate was $9 \%$ with claimant count unemployment at $4 \%$.

The jobs being created by London's economy are increasingly highly skilled. Today the largest occupations, and the ones that have grown most over the last 30 years, are professional and managerial occupations. There have also been significant rises in the number of people employed in sales and customer service occupations, more than doubling since the early 1970s. At the same time, the number of Londoners employed in administrative and elementary occupations has halved.

The occupations that have grown have tended to be ones that require a higher and different set of skills to the ones that have shrunk. Within occupations too, required skills levels have risen significantly the same job today often requires vastly different skill sets, such as IT skills, than it did a generation ago.

\section{Skills in London}

London has a more polarised skills profile than the rest of the UK (see Figure 3.5). More than four in ten Londoners have high skills, compared to one in three nationally. One in four Londoners has low or no qualifications. This is in line with the national average.

Figure 3.5. Working age population by highest qualification, 2009

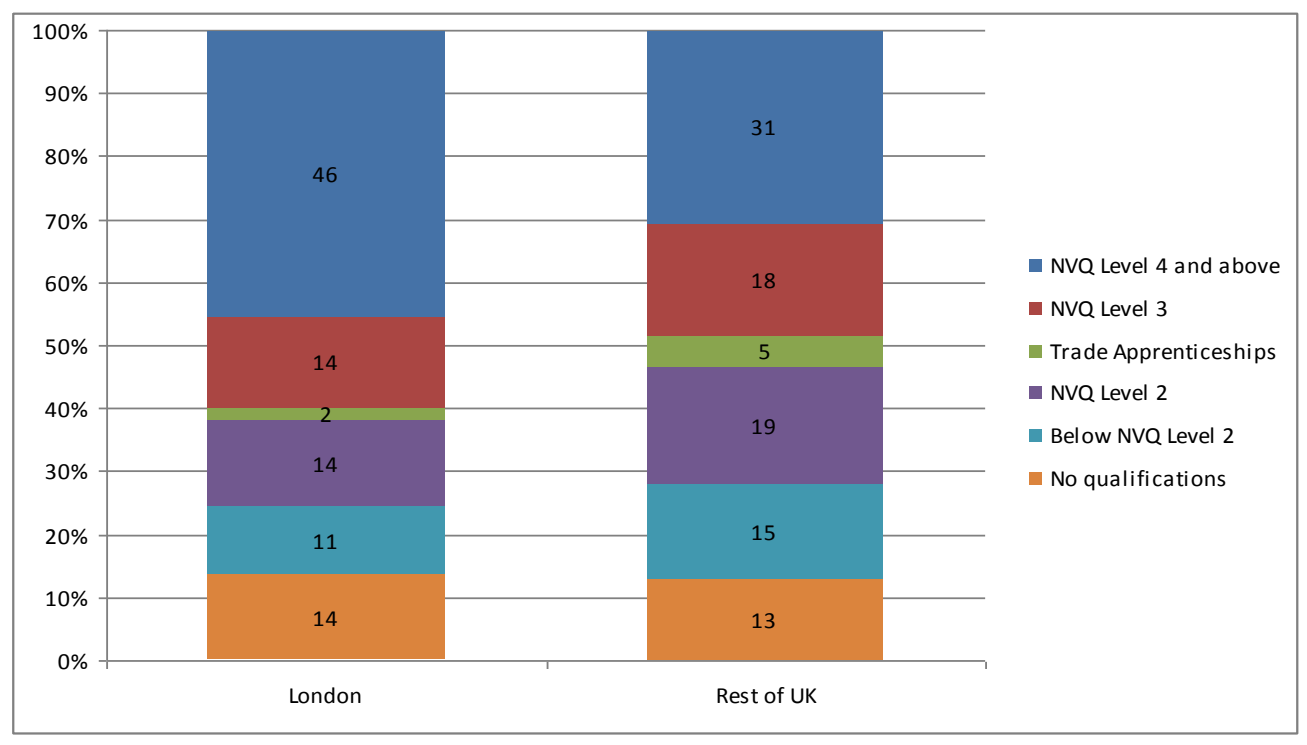

Source: APS/LFS, ONS (April-June 2009)

\section{London's low-carbon economy}

Overall, London's low-carbon economy is estimated to be worth approximately GBP 22billion in the past year which represents around 4\% of London's economy. Much of this growth is being driven by the Carbon Finance which accounts for around a quarter of the total value in the low-carbon economy at GBP 5.5bn per annum, and exhibits the highest annual growth rate of any sub-sector. ${ }^{8}$ London is also quickly establishing itself as a key global hub in relation to Carbon Finance accounting for around $18 \%$ of the global market and $97 \%$ of the UK market. ${ }^{9}$ 
More recently the London Development agency commissioned a study on London's low-carbon job prospects where the definition for the low-carbon economy excluded carbon finance as well as smaller sectors such as pollution control activities, contaminated land, noise and vibration control and environmental monitoring activities. This narrower definition values London's low-carbon at approximately GBP $13.4 \mathrm{bn}$ in $2008 / 09$, the equivalent of $16 \%$ of the total UK low-carbon market value as defined by BIS and Innovas.

\section{Company and employment numbers}

There are approximately 5500 companies engaging in primary activity across the twelve sub sectors in London's low-carbon economy. Wind energy, alternative fuels and geothermal sub sectors all have in excess of 1000 companies in London reflecting the size of turnover in each of these sectors which is in excess of GBP $2 \mathrm{bn}$ per year.

The cumulative turnover achieved by firms operating within the sector based in London is around GBP 13.4bn. The four dominant areas are geothermal, alternative fuels, wind and building technologieseach sub-sector achieving a sales turnover of around GBP $2 \mathrm{bn}$. Photovoltaic, waste management, biomass and recovery and recycling are also important sectors - with turnover ranging from GBP $1.2 \mathrm{bn}$ to GBP 0.85 bn. Energy management, additional energy sources, hydro, renewable consulting and wave and tidal energy are small sectors, with energy management the largest of these achieving turnover of up to GBP 320million.

The low-carbon labour market in London is already relatively significant for an emerging sector. It is estimated that London employed approximately 100000 people in 2008/09. In employment terms the largest sub-sectors are alternative fuels, geothermal, building technologies and wind energy accounting for $65 \%$ of total employment within the low-carbon sector, see Figure 3.6.

Figure 3.6. Employment numbers by sub sector, London 2008/09

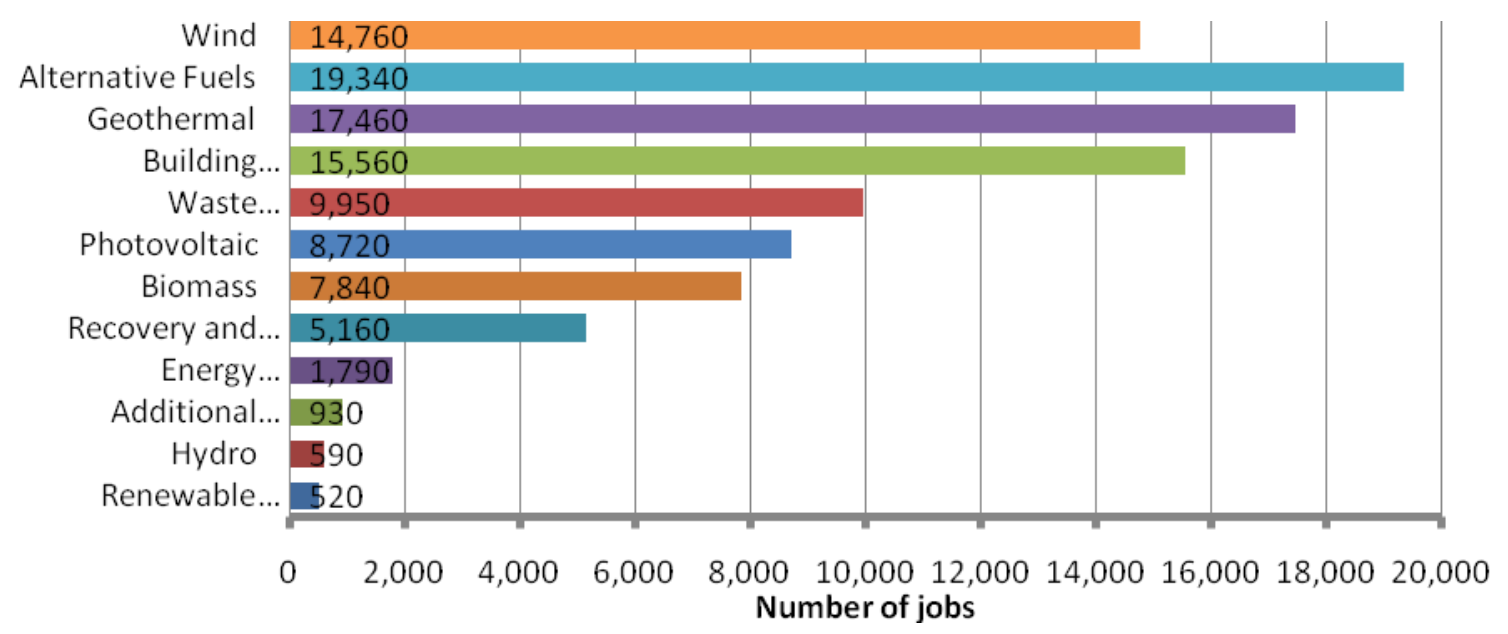

Source: Innovas taken from London Development Agency, (2010). 'Green Expectations: London's Low-Carbon Job Prospects', Labour Market Research Series 3

The alternative fuels sub-sector includes gas and therefore is considerably broader than a narrow definition confined to wood, biomass or hydrogen sub-sectors alone. Similarly, in geothermal there is considerable employment within the piping, valves and drilling sectors that are not solely supported by geothermal activity. 
Building technologies, which is estimated to employ over 15600 people in London, is likely to be directly influenced by the current Mayoral low-carbon interventions of RE:NEW and RE:FIT, together with elements of energy management.

There is an expectation that the low-carbon sector will continue to show above average trend growth, particularly within the renewable energy sub-sectors (geothermal, wind, solar, biomass and wave and tidal). Growth rates in more developed sub-sectors, such as waste management and recovery and recycling industries are forecast to be more moderate, but remain strong at above $2 \%$ per annum (see Figure 3.7).

Figure 3.7. Forecast growth by sub sector $2009-2013^{10}$

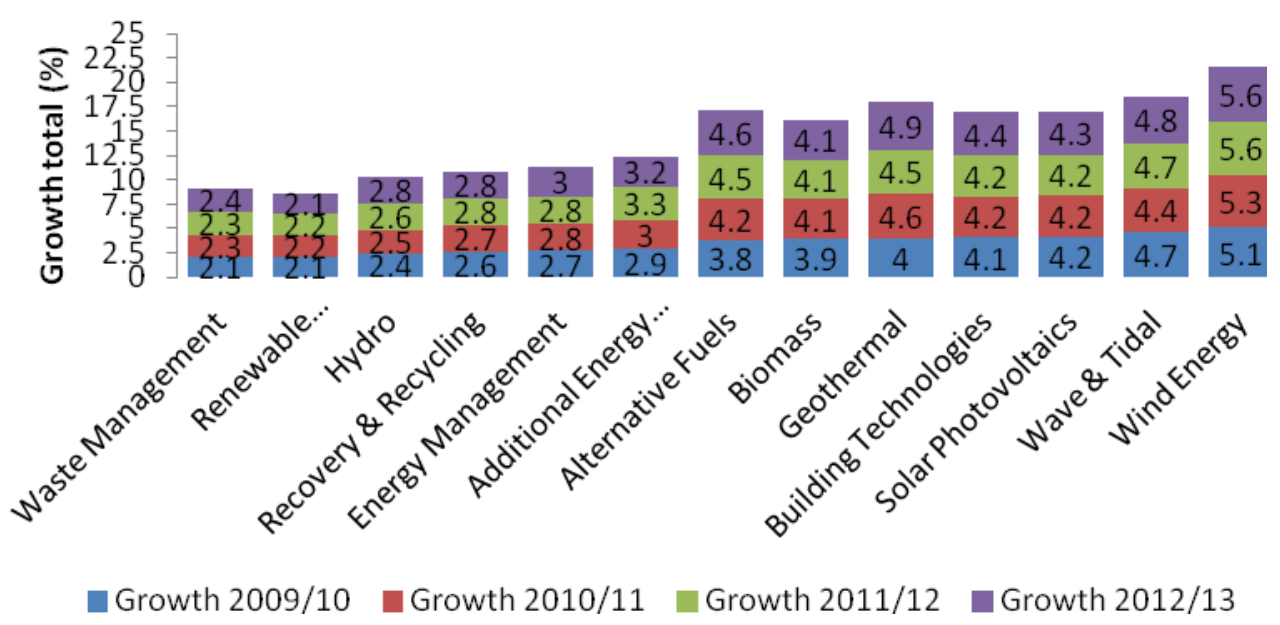

Source: Innovas taken from London Development Agency, (2010). 'Green Expectations: London's Low-Carbon Job Prospects', Labour Market Research Series 3

Survey evidence of London's low-carbon businesses corroborates these findings. Over the next year, and bearing in mind the survey took place during a recession, six in ten firms expected growth and just over one in ten expected this growth to be substantial. Over the next 3-5 years eight in ten firms were confident that the market would grow with $30 \%$ expected to see the market increase substantially and $51 \%$ expecting to see more moderate growth. ${ }^{11}$

Importantly, when we are looking at the employment growth potential for the low-carbon economy it is essential to remember than often new job totals are not net new jobs, but gross new jobs. When estimating net job growth it is important that calculations are able to differentiate between positions created by substitution or alteration, and those which are actually additional when reviewing employment figures for the low-carbon economy. Applying this logic and growth forecast to current employment numbers in London provides the following net employment changes by 2012-2013 (see Figure 3.8). 
Figure 3.8. Forecast net increase in employment 2008-09 to 20012-13

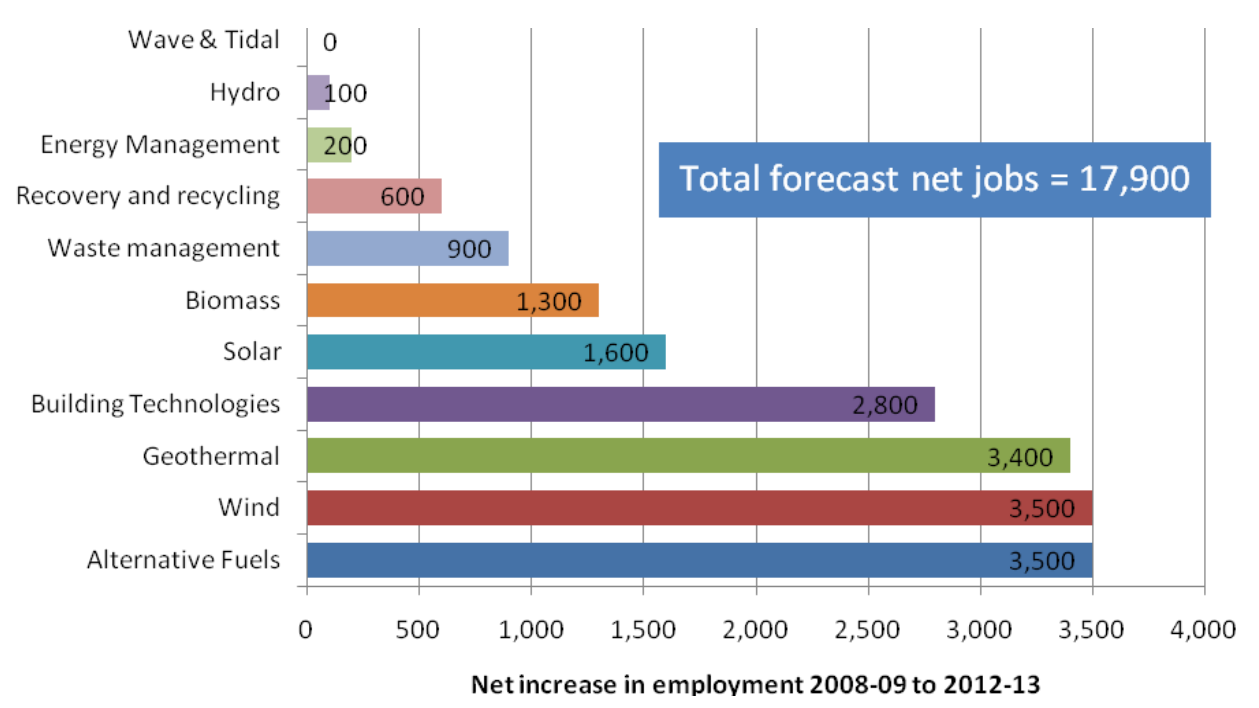

Source: Innovas and DTZ taken from London Development Agency, (2010). 'Green Expectations: London's Low-Carbon Job Prospects', Labour Market Research Series 3

As shown in Figure 3.8, the rates of growth assume that a further 18000 jobs will exist in the lowcarbon sector by 2012-13. Across the sub-sectors, alternative fuels, geothermal, wind and building technologies will experience the greatest number of job increases, with employment in each sub-sector growing by a total of between 2800 and 3500 by 2013. These findings are in line with survey evidence of London's low-carbon businesses undertaken by DTZ in 2010. Of the 200 firms interviewed, over a third said that they expected employment growth in their companies in the next 12 months and almost two-thirds expected employment growth over the next three to five years. ${ }^{12}$

\section{Low-Carbon Skills}

As the low-carbon sector continues to innovate and expand, the skills the sector requires will continue to change. The current skills requirements vary by activity and qualification required. Whilst the sector is characterised by higher level skills, there are substantial opportunities to create jobs that require lower level skills too. As with any emerging sector, skill shortages can be a threat to expansion.

LDA analysis suggests that London's low-carbon workforce is around 100000 strong, with around half of these jobs being in organisations defined as core low-carbon businesses. Figure 3.9 estimates the skills profile of the sector and sub sector in London. This suggests that the low-carbon sector is highly skilled with almost 6 in 10 employees having a degree or above. Intermediate skills and trades are also important with around $29 \%$ of the current workforce having either an NVQ Level $2 / 3$ or a trade apprenticeship. Low-skills also feature with around $15 \%$ of employees having below level 2. Interestingly, $4 \%$ of the workforce has no formal qualifications. 
Figure 3.9. Skills profile of the low-carbon sector

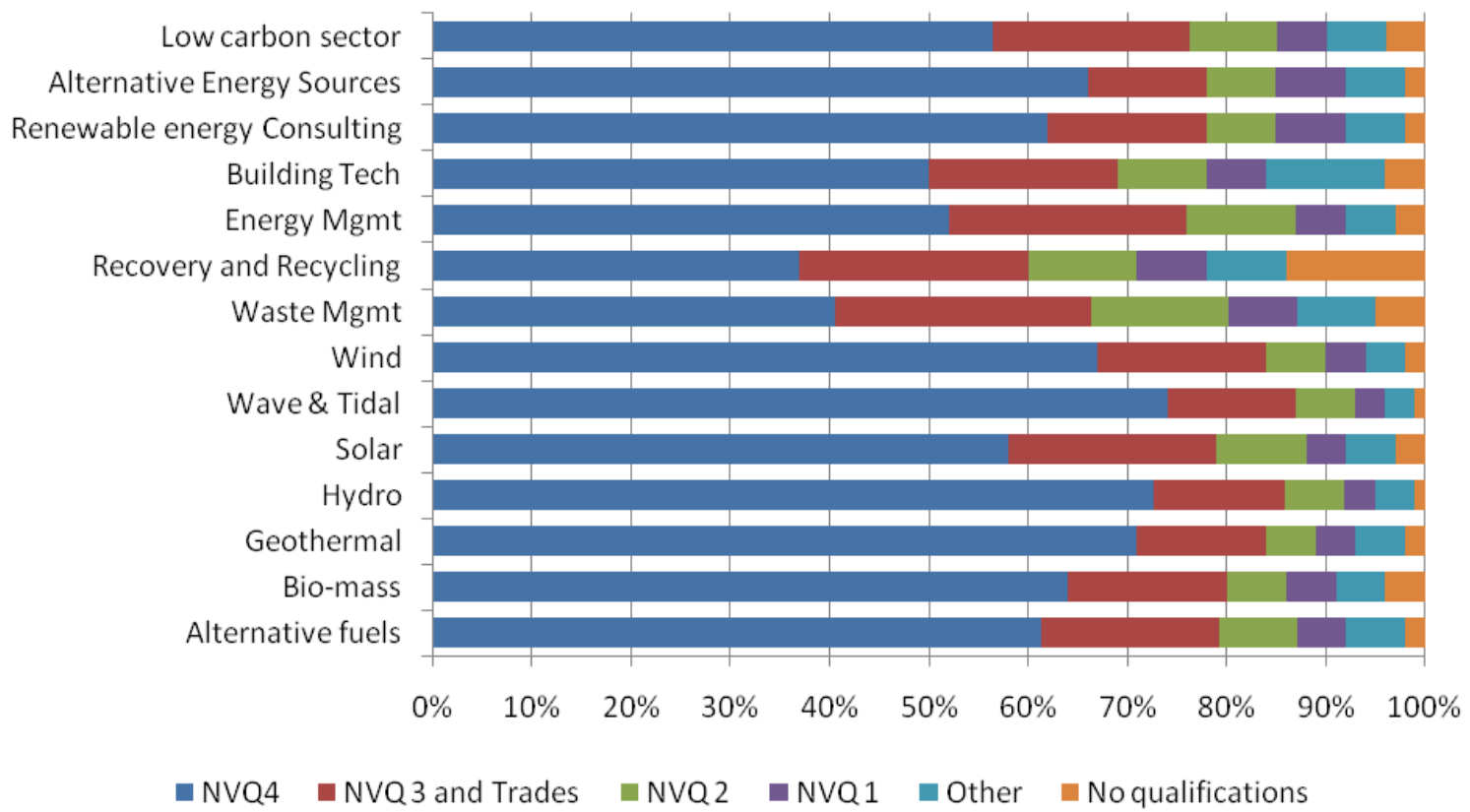

Source: APS, DTZ Bussiness Survey and own calcultaions

The broad sectoral level masks some more interesting findings in the sub sectors. For instance, $70 \%$ of the wave \& tidal, geothermal and hydro sub sector workforce is high skilled. In contrast the recovery and recycling sub sector has only $37 \%$. More interestingly, the recovery and recycling sub sector also has the highest number of low-skilled employees with almost 1 in 3 jobs requiring skills below Level 2. Whilst this particular sub-sector is an outlier, the evidence does suggest that there are opportunities for low-skilled Londoners to enter or progress in the low-carbon sector in London with around 1 in 3 jobs requiring a level 2 qualification or below.

Within the wider and less easily defined supply chain activity, which accounts for an important $48 \%$ of employment in the sector, it is very difficult to accurately attribute estimates of skills levels. Therefore, in recognition of the breadth of requirement, it is assumed that the supply chain reflect the skills demand of the economy as a whole. As such, higher level skills (NVQ 4+) are less dominant and lower level skills are more prominent. The importance of the low-carbon economy as a driver for wider employment across these skills levels should not be underestimated. Enhancing awareness of the principles of 'low-carbon' is and will become increasingly important across the wider supply chain.

\section{Future demand for skills - sub sector forecasts}

If we apply our skills findings to net employment growth, assuming that sector qualification needs will remain broadly unchanged, the additional employment would require the following qualification levels to meet the needs of specialist firms (core firms) within London, see Figure 3.10. These findings are corroborated by survey results where over half of firms interviewed expected to see an increase in demand for higher level skills including degrees and technical expertise. However, one in five firms expected to see an increase in demand for lower skilled staff. ${ }^{13}$ 
Figure 3.10. Future employment opportunities by qualification level in core companies

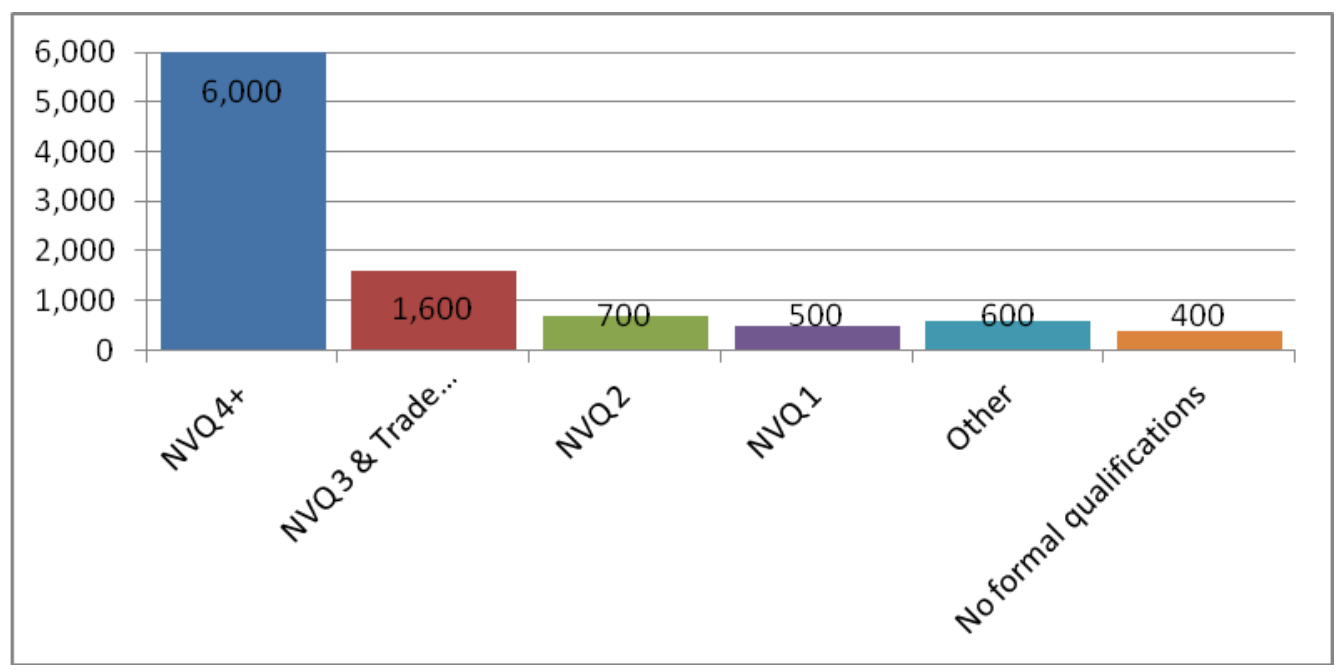

Source: Innovas and DTZ taken from London Development Agency, (2010). 'Green Expectations: London's Low-Carbon Job Prospects', Labour Market Research Series 3

Based on the labour market dynamics, it can be assumed that there are significant opportunities for low-skilled Londoners in the low-carbon labour market. Over the next three years alone we estimate that 2200 jobs could be available in core low-carbon firms either as progression opportunities, low-skilled Londoners re-skilling and moving into jobs requiring Level 2 skills, or back to work options for those with no qualifications and who find themselves out of work. These opportunities are in addition to the general supply chain demand, which is likely to reflect general national trends.

The analysis is based on assumptions of sector turnover in 2008/09 and is not able to disaggregate regional specific initiatives. Therefore, importantly this analysis does not take into account the specific employment needs associated with the Mayoral plans or recent changes in Government, and is therefore a conservative estimate. If we take into account the forecast impact of the mayoral ambitions (securing an additional GBP 17bn) then we would expect the medium-term employment numbers to increase significantly.

\section{Low-Carbon Economy: Initiatives and Programmes}

According to the 2006 London Energy and Greenhouse Gas Inventory, London's $\mathrm{CO}_{2}$ emissions in 2006 were 47.5 million tonnes $\left(\mathrm{MtCO}_{2}\right)$. This represents $8.6 \%$ of the $\mathrm{UK}^{\prime}$ 's total $\mathrm{CO}_{2}$ emissions. London continues to have the lowest per capita emissions of any region in the country, standing at 6.2 tonnes of $\mathrm{CO}_{2}$ per person per year, well below the UK average of 8.7 tonnes.

Workplaces constitute the largest source of $\mathrm{CO}_{2}$ emissions in London, accounting for $20.5 \mathrm{MtCO}_{2}$ (43\% of total emissions) in 2006. Homes account for $17.1 \mathrm{MtCO}_{2}(36 \%)$ and the transport sector 9.9 $\mathrm{MtCO}_{2}(21 \%)$.

If no further actions were taken to reduce London's $\mathrm{CO}_{2}$ emissions beyond those already taking place - a 'business as usual' scenario - it is predicted that $\mathrm{CO}_{2}$ emissions in the capital would fall to $41.7 \mathrm{MtCO}_{2}$ by 2025 . This is a $7.5 \%$ reduction on 1990 levels. 


\section{The Mayor's strategy to mitigate climate change}

The Mayor has committed to reducing London's $\mathrm{CO}_{2}$ emissions by $60 \%$ on 1990 levels by 2025 . To help achieve this goal, he is proposing interim $\mathrm{CO}_{2}$ reduction targets of $22 \%$ by 2015 and $38 \%$ by 2020 . London's 2025 target is on a steeper trajectory than that of the Central Government, which aims to reduce the UK's $\mathrm{CO}_{2}$ emissions by $80 \%$ on 1990 levels by 2050 .

The Mayor has developed a range of programmes that will contribute to his ambitious climate change targets whilst stimulating demand for the low-carbon economy in London. These include programmes related to decentralised energy, energy efficiency in homes and commercial buildings, and low-carbon transport.

\section{Decentralised Energy: Current Situation and Future Targets}

In 2006, $\mathrm{CO}_{2}$ emissions from London's electricity supply were $23.5 \mathrm{Mt}$; total emissions from energy supply including heating were $38.6 \mathrm{Mt}$. The business as usual scenario has this falling to $34.9 \mathrm{Mt}$ in 2025 (due in part to a reduced $\mathrm{CO}_{2}$ content of national electricity supplies and improvements to buildings). The Mayor's decentralised energy programme is expected to reduce London's $\mathrm{CO}_{2}$ emissions from energy supply by $2.5 \mathrm{MtCO}_{2}$ per year. Combined with government action a total savings of $8.6 \mathrm{MtCO}_{2}$ would be achieved. The Committee of Climate change has recommended that the Government adopt more ambitious targets than it currently has, which could reduce London's energy supply emissions still further.

Taken together, the Mayor's aim is "[t]o meet the energy demands of London's homes, businesses and infrastructure through the provision of an efficient, affordable and secure supply of low and zero carbon energy including 25\% from decentralised energy by 2025". The Mayor will contribute towards this aim by delivering decentralised energy through new development and through supporting boroughs and developers with the tools needed to identify and deliver decentralised energy projects.

Table 3.1. timeline for Mayoral, EU and government action on decentralised energy

\begin{tabular}{lcccc}
\hline & $\mathbf{2 0 1 2}$ & $\mathbf{2 0 1 5}$ & $\mathbf{2 0 2 0}$ & $\mathbf{2 0 2 5}$ \\
\hline $\begin{array}{l}\text { London's energy from } \\
\text { decentralised energy }\end{array}$ & $5 \%$ & $10 \%$ & $20 \%$ & $25 \%$ \\
\hline
\end{tabular}

\section{Homes: Current Situation and Future Targets}

In 2006, emissions from London's homes were $17.1 \mathrm{MtCO}_{2}$ per year, which in a business as usual situation would be expected to reduce to $14.9 \mathrm{MtCO}_{2}$ by 2025 . This is due to a number of programmes the Mayor has already committed to, and the decarbonisation of London's electricity supply that would happen under current government policies. The Mayor's programmes, combined with government and EU action, will aim to reduce London's $\mathrm{CO}_{2}$ emissions from homes by $7.66 \mathrm{Mt} \mathrm{CO}_{2}$ by 2025 . This relies on delivering a new model for financing hard to treat homes. If government adopts more ambitious $\mathrm{CO}_{2}$ emission reductions scenarios, according to the recommendations of the Committee on Climate Change, it is expected London's $\mathrm{CO}_{2}$ emissions from homes will reduce by $0.95 \mathrm{MtCO}_{2}$ per year in 2025 .

\section{Workplaces: Current Situation and Future Targets}

In 2006 emissions from London's workplaces were $20.5 \mathrm{MtCO}_{2}$ which in a business as usual situation would be expected to reduce to $18.8 \mathrm{MtCO}_{2}$ by 2025 . This is largely due to the increasing growth of the service sector and the projected decline in manufacturing. Government and EU action, combined with the Mayor's programmes and catalysing of the wider market, are expected to reduce London's $\mathrm{CO}_{2}$ emissions from workplaces by $9.6 \mathrm{MtCO}_{2}$ by 2025. If government adopts more ambitious $\mathrm{CO}_{2}$ emissions reduction 
scenarios, according to the recommendations of the Committee on Climate Change, it could reduce London's $\mathrm{CO}_{2}$ emissions from workplaces by an additional $1.85 \mathrm{MtCO}_{2}$ by 2025 .

London aims to make its workplaces some of the most energy efficient of any major city in the world. The Mayor is working with key partners to achieve this aim, supporting organisations to reduce $\mathrm{CO}_{2}$ emissions from their existing buildings by retrofitting them with energy efficiency measures, building the knowledge and capacity of workplaces to use energy more efficiently, and sharing best practice.

\section{Transport: Current Situation and Future Targets}

In 2006 emissions from London's transport sector were $9.9 \mathrm{MtCO}_{2}$, which in a business as usual situation would be expected to reduce to $7.95 \mathrm{MtCO}_{2}$ in 2025. This is due to the ongoing long-term trend of vehicle fuel efficiency improvements, a number of programmes the Mayor has already committed to, and the decarbonisation of London's electricity supply that would happen under current government policies. The Mayor's programmes, combined with government action, are expected to reduce London's $\mathrm{CO}_{2}$ emissions from transport by $1.55 \mathrm{MtCO}_{2}$ by 2025. If government adopts more ambitious $\mathrm{CO}_{2}$ emissions reduction scenarios, according to the recommendations of the Committee on Climate Change, it could reduce London's $\mathrm{CO}_{2}$ emissions from transport by a further $0.78 \mathrm{MtCO}_{2}$.

The Mayor aims to ensure that by 2025 London's transport system will excel amongst global cities, with low-carbon infrastructure and access to ever more low-carbon transport options. Reductions in $\mathrm{CO}_{2}$ emissions will be achieved through a shift to more efficient modes and operation of transport, and through the use of low-carbon vehicles, technologies and fuels.

\section{Key climate change programmes}

\section{Decentralised Energy: Key Programmes}

Co-development of exemplar decentralised energy projects: A prime example of such a project is the London Thames Gateway Heat Network which, when completed, will be the largest new decentralised energy development in Europe. The LTGHN will supply affordable low-carbon heat from sources including Barking Power Station and the Tate \& Lyle sugar refinery. Heat from developments will be captured and the hot water distributed via pipes to properties where the heat will be used for domestic hot water and central heating, replacing conventional boilers.

The Decentralised Energy Masterplanning Programme: offers a comprehensive package of support to boroughs, helping them identify and develop decentralised energy projects.

London Heat Map: a web-based, interactive GIS tool that aids the identification of decentralised energy opportunities to boroughs, generation companies and developers.

London Waste and Recycling Board: providing GBP 84 million of funding to deliver new, clean waste infrastructure for London to reduce the carbon footprint of London's waste.

\section{Homes: Key Programmes}

RE:NEW Home Energy Efficiency for Tomorrow Programme (formerly HEEP): this retrofitting scheme is aimed at reducing $\mathrm{CO}_{2}$ emissions from London's domestic sector, which represents the largest single source of $\mathrm{CO}_{2}$ emissions in London. RE:NEW seeks to create a proven and effective delivery model which includes free-of-charge, easy-to-do and innovative measures. Ultimately it aims to offer more expensive measures such as loft and cavity wall insulation at no upfront cost as well. In addition to 
reducing $\mathrm{CO}_{2}$ emissions and achieving cost savings for households, the RE:NEW programme is expected to stimulate significant growth and jobs in the low-carbon sector.

RE:CONNECT (formerly Low-Carbon Zones): the Mayor will work with London boroughs and local communities to cut $\mathrm{CO}_{2}$ emissions by $20.12 \%$ by 2012 from 10 Low-Carbon Zones. The zones will cover over 13000 residential properties, 1000 shops and businesses, and public buildings such as hospitals and community centres. The Zones will act as exemplar models for a whole community approach to reducing $\mathrm{CO}_{2}$ emissions that can be rolled out within and beyond London.

The Mayor's Housing Strategy and Beyond Decent Homes: the Mayor will work with the Homes and Communities Agency, London boroughs and other partners to explore options for the delivery of an enhanced Decent Homes standard, and support improvement of social rented homes so that they are more than 'Decent', with environmental standards a priority for any enhancement to the Decent Homes standard. The Mayor will also maximise funding for homes retrofit from central and regional housing funding pots and ensure that it complements the overall approach adopted by RE:NEW.

\section{Workplaces: Key Programmes}

RE:FIT programme (formerly BEEP): RE:FIT provides an innovative commercial model for public bodies to finance energy efficiency improvements to their buildings and reduce $\mathrm{CO}_{2}$ emissions. The model guarantees a future income stream to fund investment in improvements, and the economies of scale achieved through retrofitting a group of buildings at once allows for more long-term infrastructure investment over cheaper, quicker measures. A pilot of 42 public buildings has so far yielded energy savings of $28 \%$ over an average seven year simple payback period. It is anticipated that if successfully rolled-out across the public sector, the model could be modified to function within the private sector as well.

The Better Buildings Partnership (BBP): the BBP provides support for commercial landlords' collaborations with occupiers and managing agents to make London's existing commercial building stock more energy efficient. The BBP brings together 14 of the largest and most influential commercial landlords in London. For the first time, these companies are developing sustainability solutions not just for their own portfolios, but with the intention of rolling them out to the entire market. By 2025, the aim is for the BBP to have catalysed activity that will be reducing $\mathrm{CO}_{2}$ emissions by 30000 tonnes per year.

Carbon Trust London Challenge: this new partnership between the Mayor, the Carbon Trust and the LDA will be launched in autumn 2010. It will incorporate the existing Green500 scheme and serve the needs of its current members while providing Carbon Trust's expert guidance to even more organisations across the Capital. Members will receive ongoing support to help reduce their organisation's energy use, cut costs and reduce carbon emissions through a tailored programme of seminars, workshops and events. Over the next three years, the Carbon Trust London Challenge aims to help 1500 organisations save up to 1 million tonnes of $\mathrm{CO}_{2}$ and save GBP 100 million in energy costs over the lifetime of their projects.

Transport: Key Programmes

Creating a cycling revolution: this will include delivering a central London cycle hire scheme, Cycle Superhighways and an additional 66000 secure bike parking spaces.

Making walking count: this will include improving the urban realm, on-street way-finding, and route planning facilities for pedestrians through the Legible London scheme.

Encouraging the uptake of less polluting vehicles: this will include reaching the milestone of 100000 electric vehicles on London's roads as soon as possible, ensuring that all new buses introduced to 
the London bus fleet are hybrid vehicles from 2012, and encouraging the implementation of pricing differentials based on vehicle emissions for resident parking permits and parking charges.

\section{Green Enterprise District}

The Mayor believes that embracing the low-carbon economy and making London one of the world's leading Low-Carbon Capitals will not only help achieve his ambitious $\mathrm{CO}_{2}$ emissions reduction target for 2025, but will also provide opportunities for businesses, inward investors and Londoners to participate in the global low-carbon economy.

The Mayor and LDA are also working with partners to promote the creation of London's first Green Enterprise District. This will be an international exemplar of a planned approach to creating a low-carbon environment in which to live, work and play. The Green Enterprise District will be:

- A place that will showcase the principles and practice of sustainable development in the most rapidly changing area of one of the world's leading cities.

- London's first area with a focus on fostering low-carbon enterprise and attracting inward investment to support it.

- A place for innovative projects that demonstrate how cities can transition to a low-carbon future, as well as reducing other environmental impacts.

- A location of choice for businesses involved in developing and supplying low-carbon technologies.

- A place that actively supports low-carbon activity through the provision of relevant utilities, transport, business, property, financial and fiscal infrastructures.

- A place that helps to inform businesses and people about the importance and relevance of a lowcarbon economy.

\section{National Measures for the Low-Carbon Economy}

The government has launched a number of programmes in recent years which are aligned with London's dual goals of reducing $\mathrm{CO}_{2}$ emissions while stimulating the low-carbon economy. These include:

Community Energy Saving Programme (CESP): CESP is aimed at helping households in areas of low income. It is funded by an obligation on energy suppliers and generators. CESP is promoting a 'whole house' approach to energy efficiency. The programme is delivered through community-based partnerships between local authorities, energy companies and community groups. Seven of London's Low-Carbon Zones have applied for CESP.

Carbon Emissions Reduction Target (CERT) for energy utilities: CERT is an obligation on domestic energy suppliers with over 50000 customers to make savings in the amount of $\mathrm{CO}_{2}$ emitted by householders. The government recently announced the extension of CERT until December 2012. It has committed to focusing CERT on the UK's most vulnerable citizens, ensuring that $15 \%$ of homes helped will be the lowest income households more at risk of fuel poverty. The government will also increase the quantity and speed of insulation installation; the recent changes to the programme mean that approximately 3.5 million more homes across the UK should benefit from insulation. 
Boiler Scrappage Scheme: this Scheme was announced in January 2010, and will give GBP 400 to 125000 homes throughout the UK to replace their G-rated boilers, the least efficient still in use today, with modern A-rated ones. There are currently 3.5 million homes in the UK with G-rated boilers; it is expected around $4 \%$ will be upgraded through this scheme.

Green Deal: By properly insulating homes, people can save money on fuel bills, protect the warmth of their home and cut carbon emissions. It is estimated that, on average, the most energy inefficient homes in the UK could save around GBP 550 per year by installing insulation measures. The government recently announced in the Queen's Speech that it is to introduce legislation which will enable households to finance more expensive measures like solid wall insulation with no upfront costs. Through the Green Deal, energy efficiency work could be repaid through a charge on a home's energy meter offset by the savings made on fuel bills, meaning many householders will benefit from day one. This Green Deal is expected to be available in late 2012.

Green Investment Bank: The Green Investment Bank Commission, an independent advisory group convened by the Chancellor of the Exchequer, recently released a report which calls for the urgent establishment of a new public financial institution to generate the investment required for the UK to accelerate its transition to a low-carbon economy. It suggests several roles for the Green Investment Bank including unlocking project finance, creating green bonds for institutional investors, and selling green individual savings accounts. The Government has welcomed the publication of the report and has stated that detailed proposals on the creation of a UK Green Investment Bank will be brought forward following the upcoming Spending Review.

The Mayor will actively lobby government in a number of areas for better alignment across, and improvements to, existing legislation to support the growth of the Low-Carbon Capital. Specific recommendations include:

- Introducing additional financing mechanisms to drive energy efficiency retrofit measures for buildings;

- Creating rewards for encouraging behaviour change among householders and businesses;

- Creating further incentives for businesses and investors to invest in the low-carbon activity; and

- Ensuring sufficient new low-carbon energy supply is available to support London as the LowCarbon Capital. 


\section{ENDNOTES}

${ }^{1}$ GLA Economics, (2010), “'Economic Evidence Base’, GLA

${ }^{2}$ Source: ONS

${ }^{3}$ GLA Economics, (2010), 'Economic Evidence Base', GLA

${ }^{4}$ Office for National Statistics, Estimated resident population by ethnic group and sex, mid-2007 (experimental statistics)

${ }^{5}$ City of London, (2011), 'London's Competitive Place in the UK and Global Economies', Oxford Economics and City of London Corporation, London

${ }^{6}$ LFS/APS April -June 2009

${ }^{7}$ ILO unemployment rate using LFS, ONS Jul-Sept 2010 and claimant count unemployment using claimant count data Nomis September 2010

${ }^{8}$ Department for Business, Innovation and Skills, (2009), 'Low Carbon Environmental Goods and Services: an industry analysis' Innovas

${ }^{9}$ Ibid

${ }^{10}$ Innovas derive these forecasts from a range of external sources such as investment houses, specialist organisations and trade associations. The forecasts below can therefore be considered a 'consensus view' or average market expectations. The accuracy of the forecasts is reviewed by Innovas, who compare them with actual rates of change that are observed, removing those sources that have been shown to be unreliable over time. The forecasts take into account known UK-wide government initiatives and incentives, and are influenced by the direction of government policy

${ }^{11}$ London Development Agency, (2010), 'Skills for a Low Carbon London', DTZ and Innovas

${ }^{12}$ Ibid. Chapter 4

${ }^{13}$ Ibid. Chapter 4 



\title{
CHAPTER 4.
}

\section{THE LONDON LABOUR MARKET IN THE GREEN ECONOMY}

\author{
by Andy Westwood
}

\begin{abstract}
This chapter concentrates on London's labour market - including an analysis of its working population, mechanisms for welfare to work and skills training, initiatives to support green workforce development and policies aimed at transforming and capturing the benefits of a shift to a greener economy. The chapter starts by providing an overview of the governance of the employment and skills system(s) and their interconnection, followed by description and analysis of the key issues, policies and activities observed during the OECD visit to London in September 2010.
\end{abstract}

\section{Introduction}

As the UK's capital city, seat of government and home to most of its leading businesses and sectors, the public commitment by London to lead the country's transition to a low-carbon economy is a significant political and practical ambition. However, London itself has fewer direct powers over its governmental or its broader economic footprint than similar cities elsewhere in the world, and although the Mayor of London can show such leadership, in practice much of what happens in the city depends on the policies, actions and commitment of others.

The Mayor of London - an office only established in 2000 - has limited powers over law making, revenue raising and public policy in the city, sharing decision making with many other different layers of local and national government. Upstream, the Mayor must work with Parliament in Westminster where the UK's national government, ministers and civil servants reside. Just as important in an assessment of powers, are day to day relations with London's thirty three local councils - each with their own direct powers over planning, public service delivery and resources. Recent legislation suggests that the powers of the London Mayor may be set to increase, especially in the areas of housing, regeneration, economic development, and the 2010 Olympic legacy ${ }^{1}$.

A conservative definition of London's economy suggests that it is responsible for some $20 \%$ of the UK's GVA (GBP 255 billion) in 2008 - growing from 18.5\% in $1981^{2}$. More than half of the UK's top FTSE 100 companies have their headquarters in London - and over one hundred of Europe's top 500 companies are also headquartered in the city. Some $75 \%$ of the world's 'Fortune 500's index of leading businesses have major offices in London.

London's economy and labour market is much bigger than its administrative boundaries and much greater than that delivered by residents of the city. It is a leading international business location with many foreign nationals visiting and working in the capital and waves of immigration from across the world continue to define life and work in the capital. London's economy sprawls ever more widely across the country. Some observers and academics now routinely talk of the Greater South East with locations as far afield as the Midlands (Birmingham, Coventry and Leicester), East Anglia (Cambridge and Norwich) and 
the Home Counties (Kent, Essex, Hertfordshire, Buckinghamshire, and Oxfordshire) as all being major contributors to its economy ${ }^{3}$. Rising house and land prices in the UK and in the South East have pushed firms and individuals ever further from the centre of London and the labour market is characterised by significant commuting and clustering patterns.

\section{Analysis of London}

'Tackling climate change now is critical for the welfare of our planet. It will also be key to solving another vital issue: the need to renew the health of our economy. We are committed to placing London at the forefront of the national and global transition to a more sustainable future to help us secure this recovery. The capital's existing track record as a global economic centre proves that London has the assets and expertise to be a leading provider of finance, business services, and innovation within the emerging low-carbon economy. To demonstrate leadership and ensure London's sustainable future, the Mayor of London, Boris Johnson is committed to challenging carbon reduction targets. We estimate that it will cost around GBP 40 billion investment and create a workforce of 225000 people to achieve these ambitious goals. ${ }^{4}$

Worklessness is a major problem in London. The capital city has persistently endured the poorest employment rate in the whole of the UK for over nearly two decades. This often comes as a major shock to visiting academics, given the vibrancy and success of its broader economy, but it adds the clear policy ambition of creating jobs and businesses from the low-carbon economy to improve the employment rate. So the shift to a low-carbon economy is about much more than just lowering emissions and reducing reliance on fossil fuels, it is an economic shift that has the potential to drive a sustained growth in employment and productivity in London.

Since the 1970s, London's economy has seen major and fundamental changes in its industrial and occupational structure. Over the same period, the service sector's share of the economy has increased, with manufacturing and other industries declining significantly. The share of service sector jobs in London increased from $42 \%$ in 1981 to $60 \%$ in 2001 , and around $90 \%$ in 2008 . In contrast, the manufacturing and construction industries have seen the biggest decline in jobs share, from $24 \%$ of London jobs in 1981 to $7.2 \%$ in $2008^{5}$.

Over the ten years prior to the global recession in 2008, London experienced strong employment growth, in common with the rest of the UK. The number of jobs in London rose from 3.9 million in 1992 to 4.6 million in 2006, with an average increase of 50000 per year. Jobs in London rose as a share of jobs in Great Britain from around 14.5\% in 1996 to a high of between 15.5 and 16\% throughout the 2000s. But despite this growth, the overall employment rate for London residents declined over the same period (see Figure 4.1), showing that many new jobs were taken by those coming from outside the city - either commuters or migrants to the UK whilst Londoners became more dislocated from the labour market.

As Figure 4.1 shows, the initial increases in London's employment rate - in common with the UK as a whole - after 1994 have now begun to tail off. Despite strong employment growth, the London employment rate has persistently lagged behind the national rate over the last decade and a half. In the three months to September 2010, London's employment rate stood at 68.7\%, 2.1 percentage points below the UK rate $(70.7 \%)^{6}$. Reinforced by the impact of the global recession; and at less than $70 \%$, London's employment rate remains the lowest of any UK country or region, with worklessness particularly concentrated in inner and East London and rates of child poverty higher than elsewhere in the UK and in many parts of Europe. 
Figure 4.1. Employment rates in London and the rest of the UK, 1992-2006

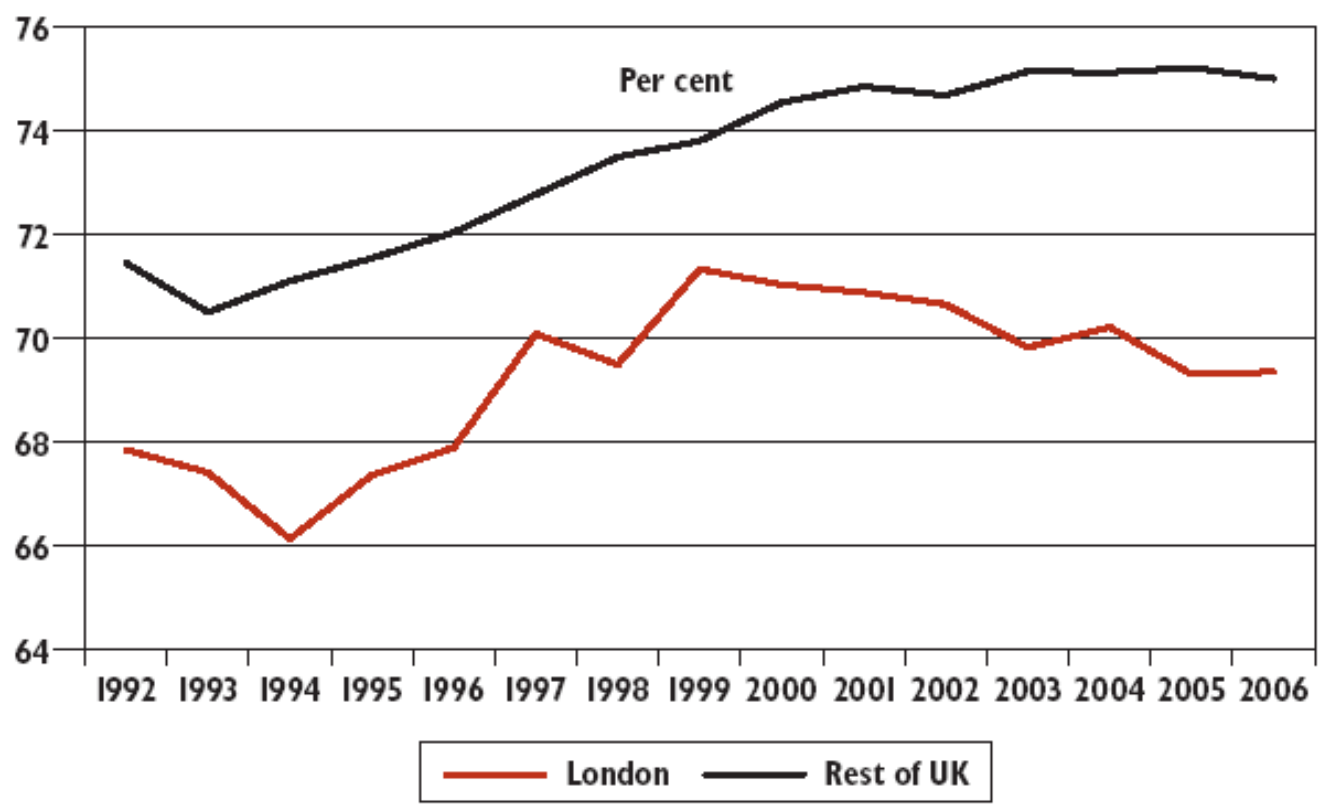

Source: Labour Force Survey, Spring Quarters ${ }^{7}$

As with residents of other cities in the UK and Europe, many Londoners have characteristics that tend to put them at risk of unemployment and worklessness. Inner and East London are the areas of the city with higher proportions of recent and second or third generation immigrant families - especially Pakistani and Bangladeshi communities - and also higher proportions of lone parents as well as the least skilled in the working age population. Londoners are also more likely to experience multiple barriers to gaining and sustaining employment than other UK residents.

Geographically these are also the parts of London that have experienced most industrial change in the last three or four decades with the decline of the docks and industry and manufacturing in these areas. This is a significant factor in explaining London's relatively low employment rate, with greater proportions of excluded groups such as lone parents, ethnic minorities and the unskilled amongst London's resident population. There are also high concentrations of social housing, particularly in Inner London that draws even greater proportions of benefit dependants into these areas.

Government - both in London and the UK - has placed much effort and investment in regenerating these areas of the capital. The two most significant projects have been the Thames Gateway regeneration programme - often described as the largest regeneration opportunity in Europe ${ }^{8}-$ and staging the London Olympics in 2012. The Olympic site is in Stratford, East London, whilst the Thames Gateway zone encompasses this and stretches out on both sides of the Thames estuary eastwards into Essex and Kent.

The London 2012 Summer Olympics have been conceived to be "the greenest games ever" - see Box 4.1. With such an important event in the pipeline, which implies large investments in infrastructure and human capital development, London has a golden opportunity to shine at international scale and unleash the potential of the low-carbon economy. The emphasis put in the Olympic Games in terms of legacy and sustainable economic development is a model that could serve for the rest of the world if successfully achieved. 


\section{Box 4.1. London 2012 Summer Olympics: The Greenest Games Ever?}

"Ensuring a sustainable approach to building the Games will help ensure London 2012 is remembered not only as two weeks of fantastic sporting action, but also as the greenest games to date"

David Higgins, former Chief Executive, Olympic Delivery Authority (2007)

Almost three years after this mission statement, the Department of Communities and Local Government, UK commissioned the OECD Local Economic and Employment Development (LEED) Programme to "highlight the strengths and weakness evident through current arrangements" to deliver a successful London 2012 Olympic local development legacy. The final report, "Local Development Benefits from Staging Global Events: Achieving the Local Development Legacy from 2012" was published by the OECD in October 2010.

Implicit with the goals of the Review was an examination of the arrangements to 1) deliver a 'green Games,' and 2) build a sustainable local development legacy for East London.

In relation to the delivery of the Games, the Review commended the work of the Olympic Delivery Authority and specifically its efforts to:

- $\quad$ Remediate the land and clean up of River Lee in East London to address over a century of industrial blight and pollution;

- $\quad$ Achieve the highest standards of sustainable construction during the build out for the Games; and

- Remove environmental blight, including many pylon power lines from East London, which were perceived to be major detractor on quality of life and development potential of the area.

The Review also highlighted the potential for the Olympics to catalyse the long-term regeneration of East London and add a new clean, green and creative chapter to the story of London's physical and economic development. The report suggested that the major public transport investments and enhanced international exposure associated with the Olympics represented a significant legacy opportunity for the area. Not only could they facilitate the delivery of key development projects such as Greenwich Peninsular, the Sustainable Industries Park and the Green Enterprise District, they could also encourage economic diversification and the growth of new clean tech industries throughout East London.

The report concluded that as a traditionally polluted and disadvantaged area, the visible and dynamic regeneration of East London could be "critical to London becoming a greener and more inclusive city." With over a year of preparations left, the foundations seem to be in place for a successful Olympics but continued hard work remains before London 2012 is remembered as the 'Greenest Games' ever.

London is the central focus for migration both within and from outside the UK. Its strong job growth in recent decades particularly at higher level skills end, coupled with relatively high levels of service sector jobs and work in the informal economy makes the 'pull' of labour to London strong. Over the last decade London's working age population showed rapid growth of 68000 per year - entirely due to the growth in the foreign born population. By 2008 this group comprised 40\% of London's working age population ${ }^{9}$.

Additional factors reinforce this. Geographically, London is the closest conurbation to mainland Europe and the main airport and rail hub. London's high ethnic minority population with some three hundred languages spoken in the capital makes it an extremely diverse city with well established ethnic groups from all over the world. Many migrants of low and high skills have networks in London. London is also good at 'processing' newcomers to the UK.

For the majority of non English speaking immigrants there are free English Language classes and additional support in many areas. In labour market terms many migrants quickly find work and it is 
estimated that some 200000 migrants each year, both legal and illegal, are absorbed into the labour market $^{10}$.

London is one of the only cities in the world forecasted to grow in population during the next two decades, with growth driven mainly by migration. There are 34 communities of foreign nationals in London with more than 10000 members each. These include many Europeans, including 125000 French people and an estimated 50000 Swedes $^{11}$. Migrants are drawn to London to fill both low and high skilled jobs and although the new coalition government elected in May $2010^{12}$ is committed to restricting immigration, especially amongst lower skilled workers, the effects on London's labour market are yet to take effect.

This polarisation in London's labour market and its economic performance is also reflected in (and connected to) its skills profile. As Figure 4.2 demonstrates, London has the highest proportion of residents qualified to degree level or above in the UK, but also one of the highest proportion of people without a Level 2 qualification - the equivalent of five good GCSEs ${ }^{13}$. This particular group have seen their employment rate in the UK drop to below 50\% over the decade to 2010 and poor skills levels remain a major barrier to improving economic and social conditions in London.

Figure 4.2. Skills Profiles across the UK

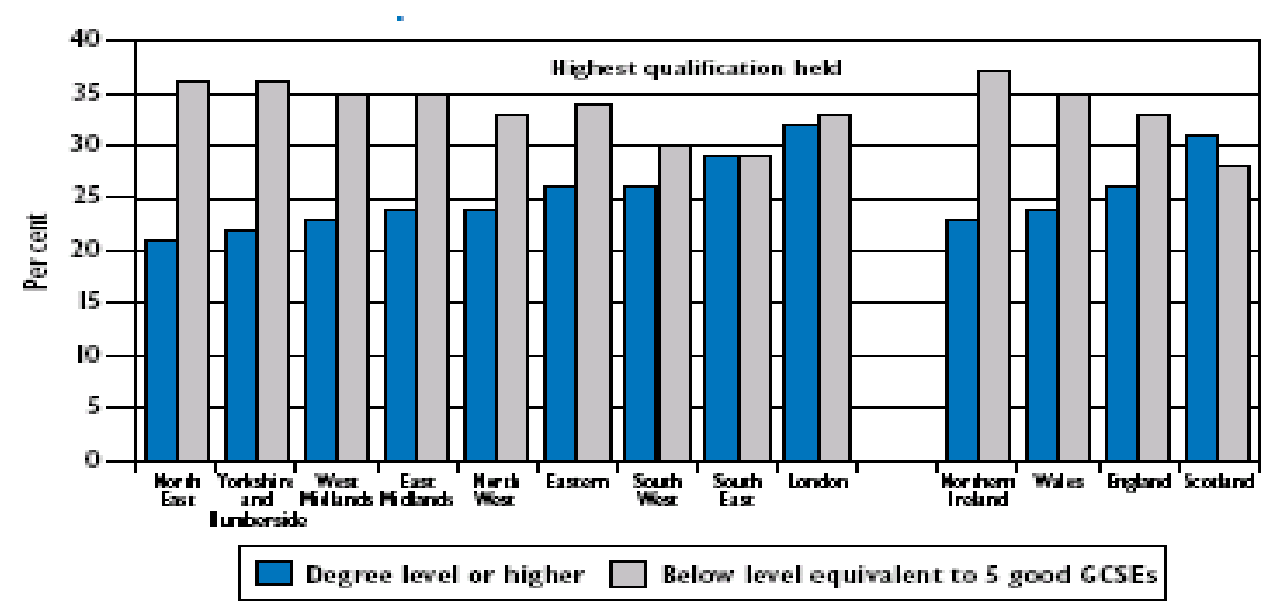

Source: Leitch Review of Skills Final Report, HM Treasury 2006

According to the Leitch Review published in 2006, nearly one in five adults has poor literacy and nearly one in two London adult residents have problems with numeracy. This is a widespread problem in the UK but more concentrated in London. However, when combined with other factors - many workless residents are likely to suffer from other forms of labour market disadvantage as well for instance they could be lone parents, suffering from illness or incapacity or may have a criminal record at the same time. The higher concentration of low-skilled and disadvantaged groups, swelled by low-skilled migrants and their families means that the level of competition for lower skilled jobs is intense. According to a UK Treasury Study on worklessness in London, there is a greater level of labour market congestion for the lowest skilled than in any other part of the UK (see Figure 4.3). 
Figure 4.3. Ratio of low-skilled residents to low-skilled jobs

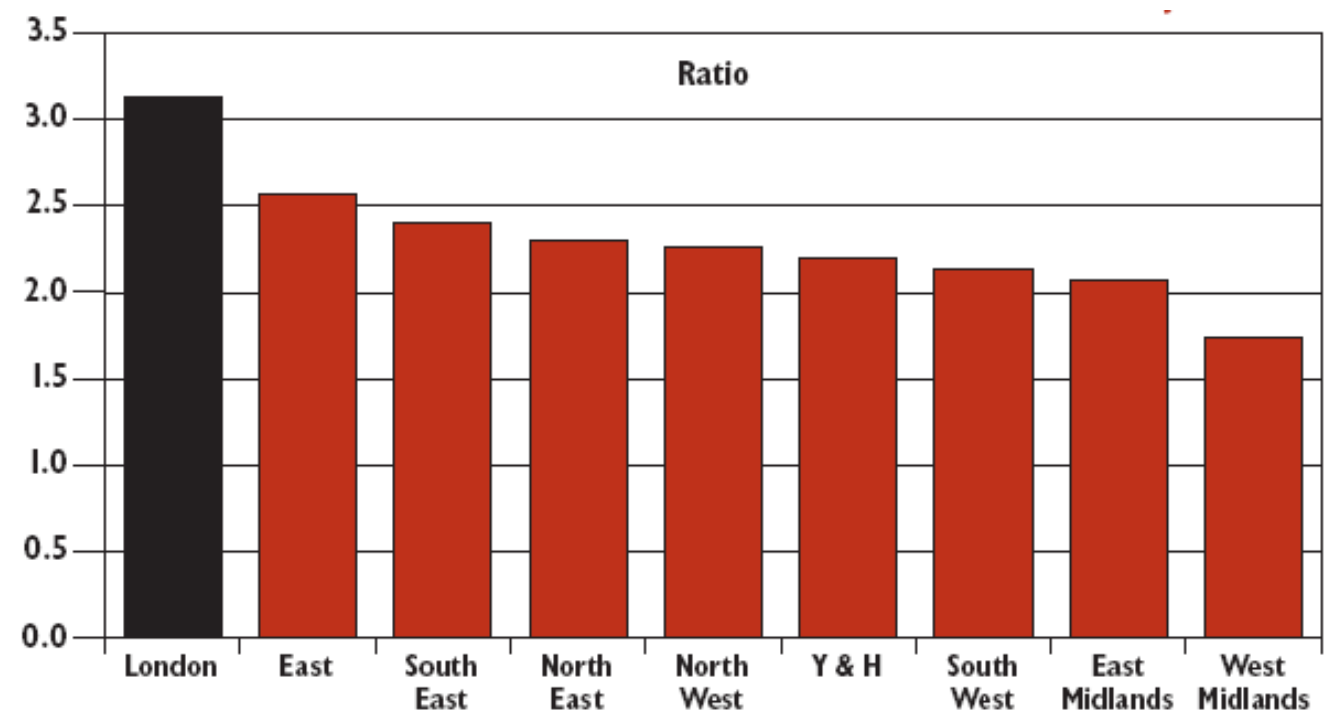

Source: Labour Force Survey, Quoted in HMT ‘Employment Opportunity for All; Tackling Worklessness in London’ HM Treasury 2007

\section{Employment and skills systems in London}

There has been no shortage of initiatives and policy reforms aimed at tackling employment and skills problems in London and the UK during the last two decades. After 1997, the Labour Government almost completely reinvented the structural landscape governing and delivering the employment and skills systems. The new coalition government of Conservatives and Liberal Democrats elected in May 2010 are busily doing the same with a newly launched 'Work Programme' and a radical ambition of reshaping the complex benefit system into a single 'Universal Credit'. Under both Governments, reforms have concentrated on the creation of new government structures and agencies such as Jobcentre Plus and a series of active labour market policies ranging from Labour's New Deals and City Strategies to the Coalition's Work Programme.

Added to this has been a limited process of local, regional and national devolution, with newly created Governments in Scotland, Wales and Northern Ireland, together with some regional and local devolution in England. The most high profile example of the latter has been the creation of the office of the London Mayor $^{14}$ and the Greater London Assembly in the late 1990s. This restored London Government after its abolition by the then Prime Minister Margaret Thatcher in the 1980s.

However, devolution to the London Mayor has thus far been limited and sporadic. Initially granted powers over economic development and transport - with direct responsibility for the London Development Agency and also for London Transport - powers over areas such as employment and skills have always been marginal.

Following the 2005 General Election, additional powers were granted to London's Mayor, including the formation of a London Skills and Employment Board, Chaired by the Mayor and made up largely of employers in the capital. It was expected to work jointly with the national authorities such as the Learning and Skills Council (succeeded by a Skills Funding Agency for adult training in 2008) to establish a strategy for adult skills in London ${ }^{15}$. 
As Figure 4.4 shows, the London Skills and Employment Board (LSEB) had only partial control over education and training in the capital and over the national agencies funding and controlling skills policy. The London Skills and Employment Board and the Mayor were granted little responsibility for employment services either, despite the fact that these services were also developing along a more flexible, employer-led approach. Welfare to work and benefits policy remained a centrally controlled and planned policy area.

Figure 4.4. The Employment and Adult Skills System in England (and London) at the time of the granting of powers to London Mayor

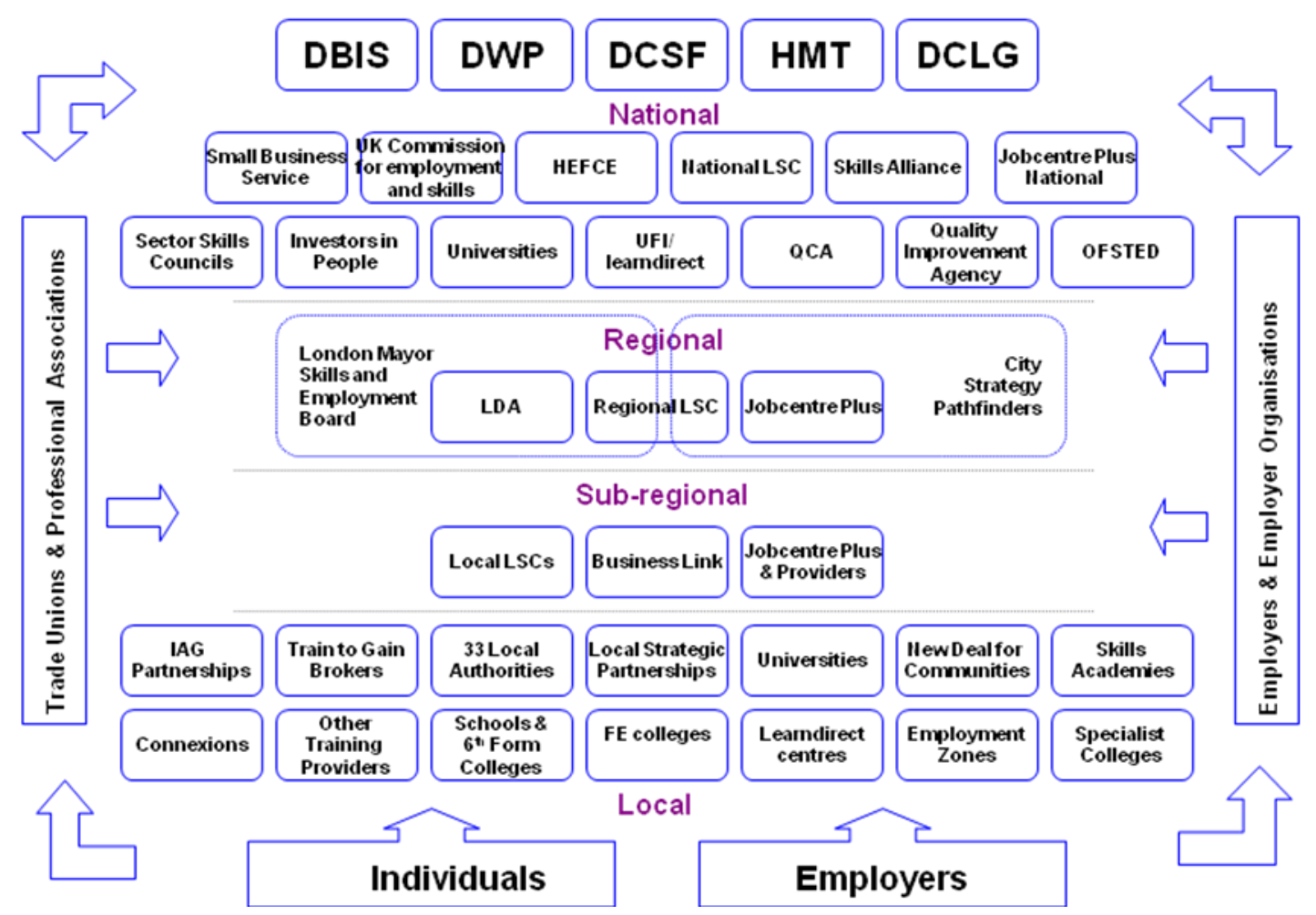

Source: Provided by LDA, adapted from adapted from Leitch Review of Skills 2006

\section{Further changes to the Political Landscape in London and the UK}

The new Coalition Government elected and subsequently formed following the General Election in May 2010 has been rapidly redrawing the policy landscape in London and the UK. In institutional terms the Department for Schools and Families has been rebranded as the Department for Education, Business Links and Train to Gain have been abolished. Further reforms initially developed by the previous Labour administration have continued. These include the breaking up of the Learning and Skills Council into a Skills Funding Agency for learning post 19, a Young People's Learning Agency for learning between 16 and 19 and a new National Apprenticeships Service. Local LSCs have been abolished and several local initiatives such as Employment Zones, New Deal for Communities, City Strategy Pathfinders and Local Strategic Partnerships have all ended.

Central to the new Government's objectives has been the reduction of the Government deficit with a commitment to removing it by the end of the parliamentary term in 2015. This has comprised an Emergency Budget in June 2010 and a Spending Review in October confirming that public spending would be cut by some GBP 80 billion over the five year period. Combined with ambitious plans to reform 
welfare and also both the further and higher education systems, this has meant a major redrawing of policy frameworks and responsibilities in London.

Most notable are the abolition of Regional Development Agencies (including the London Development Agency) and the withdrawal of statutory functions from the London Skills and Employment Board. Although many functions may continue to exist - some of the staff and responsibilities of the LDA will fold into the Mayor's office and to the Greater London Authority and the LSEB may continue as an advisory rather than a strategic body - the changes are significant in this context.

Firstly, although these changes are evolving alongside or after many of the Mayor's commitments and ambitions for employment and skills stemming from the shift towards a low-carbon economy, the changes will affect the powers and resources available to the Mayor. Secondly, the overall level of power at any level of government and the economy will limit the ability of the Mayor to actively intervene to help shape the paradigm shift and to capture the benefits from it.

Despite its name, the London Skills and Employment Board has never had significant control over any policy or resources in welfare to work. Jobcentre Plus and welfare to work has remained a centrally controlled power in both policy and delivery terms. Despite the large number of locally orientated policies and locally managed programmes, the main policy framework has been centralised and uniform alongside the single national frameworks for benefit claiming. The LDA and individual local councils have benefitted from resources in the past - typically through the Working Neighbourhoods Fund (WNF) or through European funds - though these are all disappearing amidst current restructuring and cost saving measures.

At a national level, the new Coalition Government are continuing with the spirit of reforms proposed by Lord Freud under the Labour Government, by regionalising all welfare to work delivery into a largely private sector controlled prime contractor model. This will be the organisational mechanism that delivers the new Work Programme and although the GLA and Mayor will be able to scrutinise and complement it with their own programmes they will not be able to change or adapt the overall shape. Policy delivery and programme/provider commissioning for the vast majority of welfare to work will therefore remain the responsibility of the Department for Work and Pensions, in collaboration with the regional contractors that it appoints.

The purpose of this chapter is not to consider all of the labour market interventions previously or currently delivered by the London Development Agency and the GLA, nor is it to consider the comprehensive skills strategy set out by the London Skills and Employment Board. However, in the context of the Mayor's intention to maximise the labour market benefits of the city's shift to low-carbon targets, it is important to understand exactly what limited powers are available. The next section considers some of the specific initiatives that sit within this approach.

\section{Actions in London to capture the benefits of its low-carbon ambitions}

Economic and labour market opportunities will exist in sectors right across London, the UK and the global economy as business shifts relatively rapidly to a new low-carbon paradigm. For businesses, the transition to low-carbon offers both commercial opportunities and the chance to save money and release productive resources through greater energy efficiency. At the heart of the Department for Energy and Climate Change (DECC) agenda for capturing the benefits of industrial change are four key areas:

- Energy efficiency to save businesses, consumers and the public services money

- Putting in place the energy infrastructure for the UK's low-carbon future - in renewables, nuclear, Carbon Capture and Storage and a 'smart' grid 
- Making the UK a global leader in the development and production of low-carbon vehicles

- Ensuring skills, infrastructure, procurement, research and development, demonstration and deployment policies make the UK the best place to locate and develop a low-carbon business and make sure international business recognises that.

The global shift to a low-carbon economy is also seen as part of a renewed economic growth that will lift the UK out of the economic downturn by capturing the benefits of new technologies, innovation, businesses and jobs ${ }^{16}$. In 2009 the Department for Energy and Climate Change (DECC) published its strategy outlining how the UK could make the transition to a low-carbon economy by 2020. The UK's plan included:

- Delivering carbon emission cuts of $18 \%$ on 2008 levels by 2020

- Sourcing of $40 \%$ of the UK's electricity from low-carbon sources by 2020

- Channelling of GBP 3.2 billion to help households to become more energy efficient (via the Carbon Emissions Reduction Target)

- Helping the UK to become a centre of green industry through supporting the development and use of clean technologies

The transition plan was a clear signal to the UK market of the value that the previous administration placed on this shift to a low-carbon economy. In London and throughout the UK, the broad ambition is that by combining scientific and technical expertise and technical skills together with financial and policy support, a new world leading 'green sector' will emerge. Furthermore by setting ambitious and rapid carbon reduction targets in London and for the UK as a whole, both the national government and the Mayor of London hope that they will accelerate such growth and consolidate their position at the forefront of global economic opportunities.

"Volatile oil prices and an economic downturn are coming together to make action on climate change a potential boom industry. I want to unleash the potential to create a thriving ecoeconomy in London providing new 'green collar' jobs, skills and businesses." Mayor Boris Johnson ${ }^{17}$

London and the South East are the centres for innovation with London-based companies responsible for more than half of the total UK R\&D spend of GBP $21 \mathrm{bn}$. Four of the world's top ten universities are located in the Greater South East, of which two are in London (University College London and Imperial College). Oxford and Cambridge are both less than an hour away and the links with London are strong and longstanding. No other city in the world has more than one top ten leading university in its region.

In 2008, the UK hosted 34 private venture capital backed clean technology companies with a cumulative total of GBP $186 \mathrm{~m}$ invested in them; of these over $90 \%$ were located in London. Germany followed with 25 companies with GBP $123 \mathrm{~m}$ invested and France had 12 companies with GBP $30 \mathrm{~m}$ invested. 


\section{Box 4.2. The Mayor's Carbon Reduction Targets and Ambitions}

- Target a $60 \%$ reduction in London's $\mathrm{CO}_{2}$ (on 1990 levels) by 2025 (equivalent to emissions of just 18 million tonnes by 2025), half through initiatives introduced and encouraged by the Mayor; and half as a result of regulatory changes by national government;

- Ensure that $25 \%$ of London's energy is delivered through decentralised energy by 2025 through deploying a decentralised energy programme;

- Dramatically improve the energy efficiency of London's homes and buildings;

- $\quad$ Reduce emissions from London's transport;

- $\quad$ Reduce emissions from our waste and use it to provide energy;

- Drive up energy and supply efficiency in public and private sector infrastructure;

- $\quad$ Capture the economic benefits of a moving to a low-carbon London.

Source : 'The Low-Carbon Capital', LDA 2010

To that end, the Mayor and the London Development Agency have publicly identified eight core areas where they can accelerate London's transition and capture the benefits along the way ${ }^{18}$. These projects are consciously aligned to the Mayor's wider ambitions for London and the powers and role that he occupies:

1. Securing London's low-carbon prosperity

2. London showing the way

3. London setting the standard

4. Making London's size count

5. Export London's low-carbon solutions

6. Attract the 'green pound' to London

7. London as a low-carbon innovator

8. London government setting a good example

The overall approach is one of both leadership and practicality. Conscious of the limited local powers available to the Mayor, London still sets store by his significant public and political profile and therefore the Mayor's ability to 'show the way', 'set the standard' and set a good example'. The approach also aims to make practical use of the powers that the Mayor does possess - using procurement, policy and regulation to maximise its position. Finally, London is keen to play to its not inconsiderable strengths specifically its scientific and research capabilities, and its status as a global centre for finance and venture capital. 
London is already relatively energy efficient with a carbon footprint at nearly half the UK average. London is responsible for only $8 \%$ of all UK emissions, equivalent to an estimated 44 million tonnes of $\mathrm{CO}_{2}$ in 2006. As a result of economic and population growth - already described in this paper - this is forecast to reach an estimated 51 million tonnes per annum by 2025. Per capita, Londoners also have a smaller carbon footprint than the UK average largely because of the high availability and usage of public transport and the density of housing and other developments. And yet the city still consumes roughly GBP 12 billion of energy and produces 22 million tonnes of waste every year. As the Mayor and the LDA observe, this in itself represents an opportunity to use this scale to deliver or enhance new solutions to energy and waste that could maximise economic returns in the shape of jobs and businesses in the capital.

'In sheer scale, these are both tremendous opportunities for new, low-carbon technologies. If you consider this scale along with London's world-leading research institutions and financial and business services sector, the capital is tremendously well-positioned to take a lead in catalysing the green economy. We are looking to combine our funding for these programmes in a London Green Fund, which creates the opportunity to kick-start markets and attract private investment in the energy savings these programmes will deliver. Importantly, these programmes will not only save energy but will create economic value and jobs - conservatively, 10-15000 jobs and GBP 700 million GVA from the activity associated with the new energy economy.' Mayor Boris Johnson $^{19}$

The Mayor has set up a Low-Carbon Taskforce to make sure London succeeds in attracting this green investment and creates new jobs, establishing a public-private 'London Green Fund' and a new Green Enterprise District (incorporating the 2012 Olympic park) ${ }^{20}$. London has also created a prospectus for investment in London's emerging green economy, identifying opportunities for London and where London's key business sectors are - in financial and business services, through London's universities and other academic institutions and the city's ability to offer venture capital and other clean technology funding. In the prospectus, the Mayor and the LDA estimate that London could gain up to GBP 4 billion of investment growth and 10-15000 green jobs through to $2025^{21}$.

The LDA and GLA group is also leading the way in 'green' procurement, ensuring that it is lowcarbon, resource efficient and environmentally friendly. Based on their reported purchases, the Mayor's Green Procurement Code signatories have made the following environmental savings already: over 72000 tonnes of material diverted from landfill; over 22000 tonnes of $\mathrm{CO}_{2}$ emissions avoided; over 65 billion litres of water saved. Increasingly the procurement process is also focusing on the skills and jobs that can be provided for Londoners. The Thames Water super sewer scheduled to start work next year is expected to generate 4000 skilled engineering jobs.

The procurement of projects such as the 'super sewer' or similar work for Transport for London forms the basis of a holistic approach to maximising economic benefits in London through a variety of levers, activities and resources. As already explained, the powers of London Government are limited but even with much greater levels of responsibility and resource it is evident that the Mayor could not and should not try to achieve all of his ambitions by himself. However, London must still act imaginatively and concertedly if it is successfully align the powers that it does possess and also if it is to maximise its ability to influence and shape broader public, private and market behaviours. This will require an approach that is 'more than the sum of its parts' by aligning the powers that do exist - across planning and other regulation, procurement, funding and policy/service delivery - in order to maximise the outcomes in terms of business and job growth ${ }^{22}$.

Figure 4.5 demonstrates how London - in the form of the GLA group - understands and deploys some of this approach. 


\section{Figure 4.5. Spectrum of interventions open to the Mayor and the GLA Group}

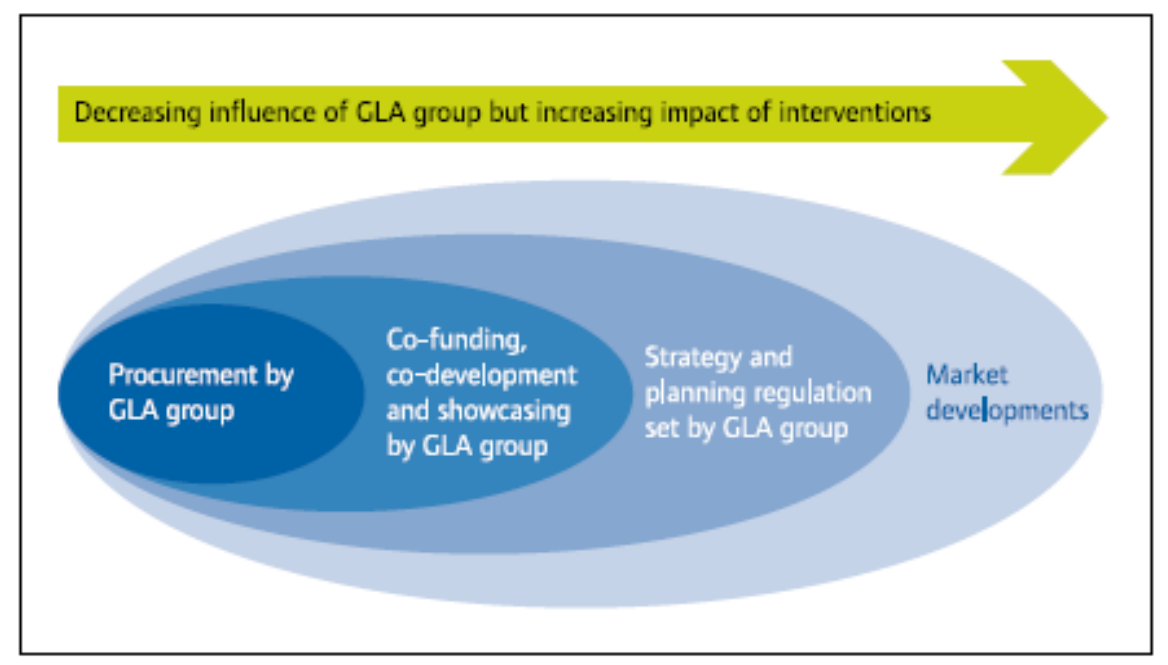

Source: Diagram taken from presentation 'LDA Climate Change Programme', May 2010

The interconnection of levers across policy, regulation, investment and the broader effects on public and private investment and behaviour can be seen in the example of transport policy in London. Box 4.3 shows how a concerted push across a range of areas can spur innovation and local benefits in the form of new jobs and business opportunities. Together the example of cycling demonstrates how a combination of regulation, investment and policy can drive behaviour change, economic growth and innovation.

\section{Box 4.3. Cycling revolution and low-carbon transport solutions in London}

Increasing cycle usage has been a major policy objective of both London Mayors - Ken Livingstone and Boris Johnson. Usage has been growing rapidly over the last decade, catalysed by a range of factors from the improvement of cycling infrastructure, tax incentives for bicycle ownership and for financial and health reasons.

Cycling should be the most efficient and exhilarating way of getting around town. Though cycling has increased in popularity in London it still only represents two \% of journeys - compared to $20 \%$ for Copenhagen and $30 \%$ for Amsterdam. To reach a level of even $5 \%$ of journeys by bike needs a step change - and that can only be accomplished with a broad, coordinated series of improvements. Some initiatives in this service are:

- Cycle hire scheme. Nicknamed 'Boris bikes' this new scheme has been introduced in 2010, starting with 6000 bikes in central London. It is similar to the 'Velib' scheme operating in Paris which has expanded rapidly.

- London is also building 12 new Cycle Superhighways by the end of 2012 - with dedicated routes that give cyclists the confidence they need and safe, direct routes into and out of central London.

- London is also committed to providing up to 66000 more cycle parking spaces, within London to accommodate increasing numbers of cyclists.

One major spike in cycle usage came when the congestion charge was introduced by Mayor Ken Livingstone for cars and other vehicles travelling into central London during peak hours on weekdays. This has given a major boost to a range of innovative businesses such as those dedicated to producing, buying and selling electric vehicles and also to other low-carbon transport solutions and practices. One such London firm benefitting directly has been the folding bicycle manufacturer Brompton, based in West London. Its lightweight, folding bicycles have become very popular with commuters and residents alike and the company is now developing a significant export market as well as rapidly growing sales in London and the South East. 
The Mayor and the LDA/GLA also plan to convert $25 \%$ of all non-emergency response vehicles in the GLA fleet - equivalent to 1000 cars and vans - to electric by 2015 and to installing 25000 Electrical vehicle charging points. Transport for London is also committed to a large scale roll-out of hybrid buses, with 56 currently on the road and a further 300 planned by 2012. TfL are also trialling at least five hydrogen buses for a period of three years from 2010. This is part of ongoing efforts to help accelerate the commercialisation of hydrogen vehicles.

Each of these initiatives - whether for electric vehicles, the manufacturing of 'Boris' or Brompton bikes, gives a major boost to business. With specific targeting, the presence of such regulation-driven markets will also provide major opportunities for business growth and innovation in London.

\section{Skills for a low-carbon economy in London}

As this report shows, one of London's priorities is the integration of low-skilled and workless London residents into businesses and occupations in the emerging low-carbon sector. Key to that will be the training and welfare to work services in place to support the development of a new green workforce.

'Greening the Curriculum' involves the improved supply of human capital with relevant low-carbon skills into London's workforce concentrating on both existing occupations and sectors that are adapting to new technologies and practices, as well as new jobs requiring a more fundamental approach. In both examples this requires significant co-ordination and effort from a range of stakeholders - especially from FE and HE providers, trade unions, awarding, funding and accreditation bodies. The supply of new and adapted skills will be essential to London's economic and labour market ambitions and will require a step change in both delivery and culture. For many years, London has relied on migrant workers to bring specific and general skills to its labour market but to use the green economy as a way of training more lowskilled and/or workless Londoners will require a much more focused and organised approach.

The scale of opportunity does appear significant though. The Low-Carbon Environmental Goods and Services Sector (LCEGS) was worth GBP 106 billion in 2007/8 and is estimated to grow to GBP 156 billion by 2014/15. As presented in Chapter 3, London's broad low-carbon economy is estimated to have generated a sales turnover of approximately GBP 22 billion in the past year which represents around $4 \%$ of London's economy. Much of this growth is being driven by the Carbon Finance.

To bring the large number of stakeholders and organisations together the Mayor and the LDA have created a Low-Carbon Skills Forum where all the actors - including colleges and universities - can come together to discuss and agree interventions and align activities. The Forum contains representatives from Sector Skills Councils (SSCs) such as Summit Skills, the GLA, London councils, the Skills Funding Agency (SFA), FE and HE institutions and also employer and workforce bodies such as the Federation for Small Businesses and the TUC and Unionlearn. There is much overlapping of responsibilities, a large number of 'quangos' outside of the Mayor's direct control - see skills landscape diagram in Figure 4.4 though London must work with these national and local bodies and bring them together into this practical, action-orientated forum.

The problems of co-ordination at the local level are significant. During one meeting of the LowCarbon Skills Forum, observed during the OECD visit, a representative from a Sector Skills Council described the forum as bringing together 'lots of different bodies doing lots of different things'. Another participant from a London university described the different actors and interest groups as often working in 'self imposed silos' to the mutual disadvantage of the sector as a whole.

There are widespread concerns that because of this complexity and competing structures and frameworks, the training infrastructure will not be able to deliver the skills required by the shift to low- 
carbon and as a result a disjuncture between short and long-term demands in the labour market is likely to emerge. A number of engineering and construction training centres are apparently in jeopardy in Londonmany departments closed during the last recession in early 1990s because of poor short-term demand and expensive facilities to maintain. There are concerns that the current round of cuts in FE and HE likely to exacerbate the problems and further restrict London's ability to train in these areas.

There are also concerns about the reliance in both further and higher education on student, rather than labour market, demand. Many Low-Carbon Skills Forum members agreed that with poor information and advice, many young people were not choosing courses in green occupations, because there was insufficient information on the jobs and opportunities that they might bring. Course closures in FE and HE are therefore likely even though they are specialising in key areas of the low-carbon economy. The CEREB centre at London South Bank University currently has only two students on a sustainable buildings course. This is all part of a dangerous skills mismatch in London and the South East, and threatens the ability of the low-carbon sector to become established in the city.

\section{Box 4.4. CEREB}

The Centre for Efficient and Renewable Energy in Buildings (CEREB) is a state-of-the-art facility located at the roof level of the London South Bank University in the heart of London. CEREB has been developed in partnership between London South Bank, City and Kingston Universities with funding from the Higher Education Funding Council for England (HEFCE), from the London Development Agency (LDA) and M\&E Sustainability. It provides both research and teaching facilities related to eco-building techniques and energy efficiency in construction.

CEREB hosts a number of renewable and intelligent energy solutions. This makes it an invaluable resource for understanding how to design, operate and manage technologies for future low-carbon buildings - both new build and retrofit. CEREB also runs Knowledge Transfer Partnerships in the industry.

Source: $\underline{w w w . c e r e b . o r g . u k}$

Businesses also complain that the supply side is too slow to respond and 'dislocated' by national government policy from responding directly - SSCs developing occupational profiles for new qualifications and apprenticeships can take up to two years and even then the Skills Funding Agency have to sign off formally for funding before colleges are able to recruit and deliver courses. Higher Education is delivered on an entirely different basis but businesses are as likely to claim similar problems about speed and flexibility of course design and accreditation in universities.

Colleges in particular, are aware of this slowness to respond and are equally frustrated. One Further Education College pointed to the fact that despite there being no bricks on the Olympic site the thirty four colleges within London were still training lots of bricklayers. This shows, starkly, that much technician training may be increasingly out of date.

Taken together, it is a concern that London's economic and labour market ambitions may be jeopardised by the disconnect between London's ambitions and the processes through which new courses are designed and accredited in both further and higher education. The supply side, especially individual colleges and universities, must be supported to be more flexible and responsive to policy change and to business and individual demand. Removing the London Skills and Employment Board's strategic responsibility to set priorities for London will exacerbate this disconnect and as we have seen a system that is more reliant on the decisions of individual students (in both FE and HE) may further jeopardise the flow of new skills into London's green economy. 


\section{Box 4.5. Business Case Studies}

\section{Greener Home Insulations}

Based in Greenwich and operating in South East London and also further afield in Surrey, Kent and East Sussex. Originally the business started up in the 1980s offering home insulation but now is diversifying and extending to new forms of green retrofitting such as PV Solar installations. This is made possible by DECC's introduction of 'Feed-in Tariffs' with guaranteed rates for 25 years and also through CERT and CESP funding.

Housing contributes $38 \%$ of the total $\mathrm{CO} 2$ emitted from London each year - over half of it from heating so existing homes must be made more energy efficient, homes today will still be two thirds of the homes available in 2025 as new homes account for just $1-2 \%$ of London's building stock in any year. Therefore, the $60 \%$ carbon reduction target cannot be met without a major programme of retrofitting this stock. Achieving this will depend on private sector businesses such as Greener Home Insulations, providing retrofitting services:

Greener Home Insulations employ fifteen people - all earning circa GBP 20k basic salary but with overtime and bonuses up to GBP 30-40k per year. They still find it very hard to recruit staff in London even though they look for attitude and commitment rather than formal qualifications. They recently recruited six staff from Greenwich and New Eltham Jobcentre Plus but very quickly ended up with only two as the others dropped away quickly. They are particularly interested in recruiting people with interest or experience in electrical, or roofing skills, but are prepared to pay for statutory training such as the Electrician's license to practice qualification (known as the 17th edition part B).

\section{Quiet Revolution}

Quiet Revolution are the largest UK (and EU) manufacturer of small wind turbine systems - owned with stakes from venture capitalists and with stakes owned by a German Utilities company. The LDA supported some initial activity with GBP 100000 grant to build prototype turbines. Installing the commercial turbine systems come with approximately GBP 100000 costs but the promise of a ten year payback - again because of 'Feed in Tariff' legislation.

Quiet Revolution offer design, build, operate and service functions - and currently make one turbine a week but expanding to 2 or 3 per week in next two years.

They recruit engineers (postgraduates and others from automotive and marine engineering backgrounds due to drive shaft technologies) and designers and are based in Clerkenwell, with a manufacturing plant in South Wales where costs are cheaper and there is a plentiful supply of skills at technician level including engineering, IT, diagnostics and electrical installation.

\section{Green 500 Scheme}

The Green500 is a membership scheme for London's biggest organisations with the greatest carbon saving potential. 185 members have signed up so far including Transport for London, Marks \& Spencer and Chelsea Football Club.

Twenty-two member companies have signed off detailed carbon reduction action plans committing to making improvements and saving CO2. Addison Lee, one of London's leading minicab and courier companies, is cutting pickup distances by half, saving 16000 miles per day. Another member, Pret a Manger - sandwich makers and retailers are increasing the percentage of their packaging that can be recycled (already at 96\%; they are aiming for $100 \%$ ); saving over eight tonnes of packaging material a year; and swapping from plastic salad bowls to sustainable cardboard packaging, saving seven tonnes of plastic a year.

The business case studies in Box 5 do show that some things in London are working well. Fundamentally, the case studies demonstrate that the community and private sector are engaging in diverse initiatives that could be further developed and so the Mayor does not have to do or fund everything. Working with the grain of regulation and by demonstrating leadership, the Mayor and the LDA are able to tap into significant private investment in the low-carbon economy. Whether through small start-up grants or through working with the direction of national policy incentives, the LDA has helped to catalyse growth 
in green businesses. Incentives and national regulation have driven private investment and growth - where businesses are prepared to spend their own money to train, upgrade and expand their activities.

The greater the link between these firms and the training system, the better the likely outcome. If the levers over procurement can be maximised alongside, then the chances of creating or growing more green businesses will increase - both through retrofitting and through the spin out companies likely to work closely with universities and centres for new technology.

As it has been argued, one of the priorities for London is facilitating the transformation of the labour market to a low-carbon economy. The challenge relies in finding the right balance between training needs and training provision, and also between skills demand and skills supply. For instance, there are currently no classification schemes for green jobs in operation. And an audit of existing skills available for the lowcarbon economy has not taken place. There is a risk that skills (low, medium, high) in London are wasted only because there is not real consideration of their potential in the low-carbon economy.

\section{Opportunities and Challenges for London}

\section{Strengths}

\section{Clear focus}

London has a clear focus on the long-term economic labour market and broader economic opportunities offered by the shift to a low-carbon economy. This is evident from the policy framework developed by the Mayor, the GLA and the LDA in order to grow the green economy and the subsequent opportunities for new or existing businesses and for new jobs in the capital.

\section{Long term actions}

Long term targets and policies are in place that mutually support and reinforce overall objectives for meeting environmental standards and carbon reduction targets as well as the generation of new opportunities in the green economy (these appear well-aligned and shared across the political spectrum in London and with local and national governments).

\section{Solid research and education base}

Strong institutional expertise in green industries and technologies exists in or close to London especially in education and research (4 of top 10 universities in the world based in London and the broader South East of England). This represents a significant asset in the science, research and technological capabilities available to London's green economy.

\section{Strong leadership}

Strong leadership with specified and clear green ambitions - this intent appears to be shared at local and national levels. Experience of green regulation and policy making at local level exists in London and its councils. The London authorities understand how they can use their policy, funding and regulatory powers and resources to practically drive green objectives. There is a good appreciation of the multitude of sectors and occupations affected by transition as well as those likely to be created by the low-carbon focus. There is a practical focus on both low and high skilled sectors and occupations 


\section{Targeted objectives}

Ambitions to improve employment rates and skills levels of London residents through the shift to low-carbon and the resulting business and job creation opportunities are laudable. This links directly to some of the labour market failures inherent within London's labour market and the clear desire for improvement in the resident population's employment rates and skill levels.

\section{Weaknesses}

\section{Limited powers}

London is part of complex skills and employment system(s) - with limited (and declining) local power for the Mayor and the GLA group. This makes direct intervention and investment practically difficult. The lack of national joining up between skills and employment policy is a particular problem especially given the green economy's requirement for new skills and occupations developing together. The shifting national and local policy landscape with reduced powers and resources for Mayor - especially over skills and employment is a weakness and now a real problem when trying to achieve the specific labour market ambitions in the green economy.

\section{Slow responsiveness}

Market-based skills and training systems focused on current and past needs - not easy to capture future trends or future demand. The lag between future market assessments and economic data (perhaps market rhetoric) and market activity is often disconnected. The slow development of new frameworks and qualifications for the low-carbon curriculum may lead to sub optimal outcomes for green industries as a whole and also for the ambition of the Mayor to get more London residents into new green jobs. Long cycles/processes of qualification and course development in further and higher education - inhibitive qualifications and funding models in apprenticeships, FE and HE. Institutions and processes on the supply side of the skills system can also be slow to respond/change; colleges, universities, funding and awarding bodies).

\section{Lack of entrepreneurial capacity}

In London there is a clear lack of entrepreneurial capacity. There is little business creation in the lowcarbon economy. Business support agencies have not shown any adjustment to the emerging needs of businesses in the low-carbon economy. Moreover, there are weak links between job placement and vacancy matching and broader business support/ development.

\section{Planning not focused}

There are risks of economic, sectoral and labour market 'planning' processes (bureaucratic, 'picking winners') where expectations are imposed on institutions and firms (equally there are risks that there won't be enough focus on planning and market intervention!)

\section{Opportunities}

\section{Capitalise on assets in place}

Key sectors and expertise are already in place - from established sectors to centres of research expertise and businesses expanding to offer more jobs in the green economy. Major institutional assets and sectors are also in place such as a well funded university base and financing capabilities for new businesses and technology investment. More could be done to capitalise on these strengths. 


\section{Better use of levers}

Experience of new regulation/ policies at local level already - spurring local innovation systems and green jobs. Identification (and enactment) of levers at national and local levels - procurement, regulation, policy - is influencing growth of green economy and driving behaviour change. This is evidenced by the local impacts of national initiatives such as feed-in tariffs as well as locally designed activities such as the Mayor's Green Procurement Code. Even better use and alignment of existing local levers could be targeted.

\section{Further drive green innovation}

There are also opportunities to exploit public demand and behaviour change to develop 'lead users' and 'lead markets' in key low-carbon sectors. London has a reputation for innovative products and emerging green markets (from Greener Homes to Brompton bicycles). Even more could be made of the presence of lead users and markets to drive more green innovation - not least using London's procurement of vehicles and the like as demonstrators.

\section{London 2012 Olympics site}

In many ways it seems that the London 2012 Olympics have provided a pivotal moment for London in particular and the UK in general. Old orthodoxies of best value and free markets in labour had set the framework for the Olympic process - but, driven by the London authorities, this approach has begun to change. At one stage there were less than 50 apprentices on site, despite an overall public investment of over GBP 9 billion. The stories of migrant rather than resident London workers have been also common place. Finally the latest techniques deployed in the building of the various sites, dramatically have showed up the disconnection with what is still taught in many of London's schools, colleges and universities. There is an opportunity for London to make the most out of the Olympics site to strengthen the workforce base for the low-carbon economy and set the criteria of a low-carbon site.

\section{Skills audit in London}

Currently, there is an opportunity that is being missed in relation to skills identification. Indeed, the current system does not have a classification for those skills that can be utilised in the low-carbon economy or in related sectors which exist in London in other sectors (i.e. transferrable skills). The information is received mainly by Job Centre Plus, but it is not well filtered or processed.

\section{Threats}

\section{Identify London's unique advantage}

'Winner takes all' technologies and lead market/users - some cities, regions and countries are already developing key sectoral and technical advantages and may have established comparative advantage in several areas of low-carbon economy. Everybody is targeting the same industries - widespread identification of green technologies and businesses as driver for future economic growth in localities throughout the world. How does London know that it has unique advantages?

\section{Not enough information available}

Venture capital markets and financial institutions may not be backing new innovation in firm support or lending due to 'myopia' or because lending is restricted by post recession banking targets. This may be an information failure too as such firms might not see the short or long-term benefits of such investment, because they are lacking knowledge of regulatory and policy changes. 


\section{'Nimbyism'}

'Not In My Back Yard' may get in the way of planning and other regulatory incentives that benefit low-carbon business growth (e.g. planning decisions against wind turbines or objections to large scale plants offering renewable energy and/or waste facilities). Planning availability may be restricted to parts of the South East (and London) that are too far away from centres of knowledge, finance or population to fill job vacancies created.

\section{Recommendations for London}

"The debate about industrial policy always raises the spectre of 'picking winners'. But in a globalised economy it's time to move this debate on a bit - be clear about what this means. Because in some ways we have to be picking winners. We have to make choices about allocating the training budget, or funding certain kinds of science or research, or promoting science, technology, maths or engineering degrees for higher education. We have to make some strategic choices. We can't avoid that. But the 'winners' in this sense are the skills we judge we will need for the future, and the sectors they support. Because while we can't divine the future, we can recognise in a broad sense what Britain is good at and likely to become good at, and the areas where the changing nature of the global economy make it futile for us to try to compete - our comparative advantage in economic jargon. We can and must allocate scarce public resources on the basis of this evidence."

Vince Cable MP, Secretary of State for Business, Innovation and Skills ${ }^{23}$

Through its prioritisation of low-carbon growth and its desire to maximise the outcomes for its labour market and business growth, London is defining a framework that actively supports the development of low-carbon industries. It has long been argued that 'picking winners' is a bad thing to do, but attitudes are changing and many cities and governments are engaged in precisely that process. London has identified the low-carbon or green sector as a future economic strength and is trying to do all that it can to ensure that London leads the way in this new economy. As important is the objective of sharing the benefits of that growth with London's resident workforce and businesses. The following short conclusions and recommendations are designed to maximise the amounts of jobs and business opportunities created by London and for London.

\section{Make use of the existent powers to build a green economy}

London authorities can always acquire more powers over a range of statutory duties and services. In some areas such as skills and employment services this is actively desirable. However, this should not deflect from the fact that London and any other level of government can always do more with what powers and resources that it currently has. English cities are way behind the global norm when it comes to local or city powers. The OECD average for locally raised taxation (as a proportion of overall tax payments) stands at 55\%. In England the proportion is only $17 \%$ and most of that is directed from the centre. Nonetheless, London and any other Government can still better use what resources and powers that it or they do have.

\section{Work through partnerships}

London should consider making use of its relationships with universities and other actors to build a stronger partnership around the Low-Carbon London initiative. London may also consider further involving the private sector in its activities, building on the presence of large companies in the city and a strong supply chain. London should bring the private sector to the low-carbon debates in order to strengthen their involvement and gain their support. 


\section{Encourage democratic participation}

Regulatory and planning power is vital to understanding the way that London can lead and shape markets and behaviour. However, London also requires more powers over the supply side generating human capital and needs to explore mechanisms with which this can happen. This power can be gained through democratic participation. Some collaborative platforms are already in place and could be strengthened. Connections among these platforms and between these platforms and other actors should be built to reach a larger audience. For instance, the London Skills and Employment Board, chaired by the Mayor and made up largely of employers in the capital should be retained. The LSEB should be as lobbied for in the past and should also incorporate greater traction over employment services and higher education in the capital. Without this the ambitions of London to capture the benefits in its resident workforce will be more difficult to achieve. Another good example is the London's Low-Carbon Skills Forum. This is also an important forum for the sharing of economic data across partners and for the co-ordination of a flexible, green curriculum. This type of collaborations should be strengthened and pursued, but connections between these should be sought to avoid overlaps and build synergies.

\section{Promote private investment and behaviour change}

It is clear that London simply does not have enough direct control over policy levers to ultimately achieve either its environmental ambitions or its labour market targets (or perhaps its broader low-carbon aspirations over longer term). This is a clear conclusion but far from a criticism because London - in the form of the LDA, the GLA and the Mayor - are all well aware of these limitations. London recognises that it cannot and should not do everything in the shift towards a low-carbon future and that there is a clear role for private investment and public and private behaviour change. As it has been mentioned before, London should bring the private sector to the low-carbon debates in order to strengthen their involvement and gain their support. Behaviour change in the public and private sector should be a strategy in itself. Building a culture of environmental consciousness will take time but should be sought drawing on the leadership of the city, its Mayor and the plans in place.

\section{Maximise outcomes}

Policy and other powers need to be more than the 'sum of its parts'. London needs to be sure that it is maximising outcomes from the investment, regulation and policy levers that it does have at its disposal just getting the absolute best out of what government does.

\section{Enhance your leadership}

\section{Communicate effectively}

The importance of leadership cannot be underestimated - and London should deploy to its best effect. This power comes through setting an example, by the profile of the Mayor's targets, objectives and priorities and by the way the Mayor (and his agencies) is able to make persuasive arguments - to national and local politicians, to business and to the broader public.

\section{Pursue demonstrative leadership}

London clearly understands and articulates the softer powers of the Mayor through the public and political profile of the office. So this is very much about active and demonstrative leadership - pushing politicians and political processes, challenging public and private behaviour, creating opportunities and providing a clear focus. Partly because of the limitations to power in other areas, this is well recognised and exploited to great effect in London. 
Use the London 2012 Olympics as a platform to pursue a green growth strategy

The Olympics provides an unparalleled opportunity to show leadership and to drive behaviour change and practice through procurement of the games and London's broader infrastructure. Where possible, new targets and aspirations have been introduced into the preparation, building and planning for the Games in 2012 - with some notable successes. More can still be done. Will this be the 'greenest games ever'? Will it benefit Londoners and London businesses as much as it could? A global city such as London will have a series of high profile projects and opportunities to make the case for changes in the way we live and work but none will be bigger than the 2012 Olympic Games.

\section{Focus on both 'evolution' and 'revolution' jobs and businesses}

\section{Deploy support for adaptation and flexibility}

Growth in new 'green collar' businesses and jobs are likely to come through both evolution and revolution: not all jobs and businesses will be created from 'scratch' through completely new technologies and new sectors. Occupations will be high and lower skilled and everything in between. London should deploy support for adaptation and flexibility of workers into the labour market. It is more about attitudes than formal qualifications. In a sense this can also be characterised in human capital terminology as both 'development' and 'deployment' skills - providing new product training such as deploying, testing and refining new technologies (e.g. photovoltaic cells, electric batteries and small and large wind turbines). Equally it may be plumbers, electricians or motor vehicle mechanics adapting and learning about new pieces of equipment - new domestic boilers, hybrid or electric car engines. Both are essential components and phases of innovation cycle and activity.

\section{Promote science, research and technology transfer}

London should support science, research and technology transfer that will fuel a low-carbon paradigm shift. Many jobs and businesses will emerge through greater specialisation and the application of new technologies in existing sectors such as construction, building services, engineering, motor vehicle, energy companies and so on. But jobs and businesses will also grow through entirely new businesses, occupations and sectors - such as carbon capture, other renewable energy sources ${ }^{24}$ and in waste and recycling sectors. Businesses and jobs in a new 'green' economy will be many and varied. Further support to businesses in the low-carbon economy should be provided, and notably more collaboration between HE/FE, businesses and London authorities should be sought to maximise the potential of the actors in place and enhance green innovation.

\section{Support innovative firms and market development}

Labour market change can be successfully driven through regulation, procurement and other policy interventions. London should actively explore the connections between job and business growth whilst maximising the levers for change within its control. Planning and procurement are major levers but so too are small resources of capital to support innovative firms in product and market development. Local versions of national bodies and initiatives such as the Technology Strategy Board and SBRI ${ }^{25}$ (Small Business Research Initiative) are good examples of how small sums and innovative procurement can drive local innovation.

'Demand is sometimes aggregated or mediated through Government, as with defence or (in the UK) healthcare. In these cases the procurement decisions of Government can have important intended or unintended consequences for innovation. ... We must get better at stimulating businesses through this route so that other small firms can be helped on the road to similar success... Spending about GBP 220 billion pounds annually, it's vital that the public sector uses 
that purchasing power effectively. There is a lot more that we can do here both to back SMEs and to back innovation. A purchasing contract can be as effective a way to get money to an innovative small business as a grant or a capital investment. ${ }^{26}$ David Willetts MP, Minister for Universities and Science

David Willetts points to the process through which governments can mediate demand. The congestion charging and cycling example described in Box 3 shows how regulation and procurement can also drive innovation and business growth as well as changed transport behaviours. The success of Brompton or the potential to procure 'Boris' bikes and associated technology for the scheme from within London show how these levers could be applied. Procurement and contracting (together with regulatory powers and broader industrial policy) are very important - but only partially controlled by LDA or Mayor. More can always be done.

\section{Innovation in public service delivery}

\section{Make better use of social enterprises}

NGOs and other social enterprises in London are very active and proved to be achieving change amongst residents and excluded groups facilitating the implementation of welfare-to-work programmes and changing behaviours. It would be important for London to support these structures in order to reach the most excluded groups and facilitate the delivery of public services to a wider audience. The example of the Wise Group in Glasgow could be of inspiration (see annex A).

\section{Support market-oriented funding systems}

While London will have to take its share of national spending reductions it is regrettable that powers such as that enjoyed through the London Skills and Employment Board are changing and/or disappearing. Shifts to more market orientated (and less bureaucratic) funding systems in both further and higher education and less direct London/Mayoral control mean that the likelihood of market failure or at least suboptimal outcomes are increased. A concerted policy approach to support and stimulate the green economy such as that implemented by the Mayor requires more and not less planning and intervention - especially where the market has failed to react in the past or present.

\section{Undertake a skills audit for London}

\section{Identify transferrable skills}

The green curriculum also requires similar attention to identify and deliver core, transferable skills for low-carbon industries. Clearly there are some key skills that are relevant across sub sectors such as engineering, motor vehicle, construction and building management that can be identified and bedded into new activities. As previously described, these transferable skills apply in both 'revolution' and 'evolution' sectors and occupations. Job Centre Plus receives a number of applicants with very diverse set of skills which are no longer required in traditional sectors but that may be useful in emerging green sectors. These skills should be analysed in a way that allows for an easy identification of connections between "green" sectors that are recruiting and jobseekers with potentially useful skills. An example in of how this is being done in Alsace is provided in the annex with the learning models.

\section{Faster and more flexible response from FE and HE institutions}

Qualifications and specialisation in further and higher education may be increasingly out of step with the requirements of low-carbon or green occupations and firms. Time lags in occupations and sectors driven by rapidly moving technologies are problematic. There are clear problems with the speed and 
flexibility of developing and accrediting new apprenticeships and technical qualifications. Whilst there is evidence of local colleges adapting or enhancing qualifications at a local level while the national systems and processes catch up, this is also an unnecessary barrier to change. London should lobby to retain its ability to set an overall strategy for the skills and employment systems and ensure that an aligned and rapid switch to a 'greener' curriculum takes place.

\section{ENDNOTES}

${ }^{1}$ See the DCLG Localism Bill introduced in December 201 www.communities.gov.uk/news/corporate/1785509

${ }^{2}$ www.lse.ac.uk/collections/LSELondon/pdf/BC_RS_LPUKfullreportforweb.09.pdf

${ }^{3}$ Amin, A., D. Massey, and N. Thrift (2003), "Decentring the Nation: A Radical Approach to Regional Inequality", Catalyst Paper 8, Catalyst, London.

${ }^{4}$ Mayor of London in foreword to 'Leading to a Greener London - An Environment programme for the Capital' July 2009

${ }^{5}$ See GLA Economics Evidence Base www.london.gov.uk/sites/default/files/evidence-base-2010-final-low.pdf

${ }^{6}$ http://lseo.org.uk/sites/default/files/downloads/LS2010FINALWEB.pdf

${ }^{7}$ Quoted in HMT ‘Employment Opportunity For All; Tackling Worklessness in London’ HM Treasury 2007

8 "Creating Sustainable Communities - Delivering the Thames Gateway" ODPM March 2005

${ }^{9}$ See www.london.gov.uk/sites/default/files/evidence-base-2010-final-low.pdf

${ }^{10}$ London Project report, PM Strategy Unit, Cabinet Office 2006

${ }^{11}$ Idem

${ }^{12}$ The General Election saw the election of a coalition with the Conservative party as the leading partner. This followed the election of the first Conservative Mayor of London, Boris Johnson, in 2008.

${ }^{13}$ Five good GCSEs (i.e. passes at grade A to C) are the qualifications that school leavers are expected to achieve at aged 16. Currently some 56\% (check) achieve this level at age 16.

${ }^{14}$ Several other local authorities and cities have also elected mayors in place, but the UK Government's enthusiasm for the mayoral model has varied over time. The coalition government elected in 2010 are committed to introducing city mayors in England's twelve largest cities.

${ }^{15}$ NB During the consultation process the Mayor Ken Livingstone pushed for full powers over employment and skills and also for 16-19 education, but the powers of the LSEB were restricted to skills for adults over 19 (but not including Higher Education). 
${ }^{16}$ Research and new technologies in carbon capture, bio-fuels (biomass, bio liquid)combined heat and power, hydro generation systems, wind energy, solar photovoltaics (PV) and recycling integrated technology applications are commonly expected to create businesses and jobs in the renewable sector.

${ }^{17}$ In foreword to "Leading to a Greener London - An Environment programme for the Capital” July 2009

18 "Leading to a Greener London - An Environment programme for the Capital" July 2009

${ }^{19}$ In foreword to "Leading to a Greener London - An Environment programme for the Capital” July 2009

${ }^{20}$ LDA engaging in cluster support - Green Enterprise District in East London: Institute for Sustainability, Siemens new technology demonstrators - Beckton, Havering Dock area and Rainham Marshes (including wildlife /conservation alongside waste/ recycling activities

${ }^{21}$ A specific example is waste. The GLA group will put forward GBP 4 million in initial seed capital to start up this fund. London Waste and Recycling Board (LWaRB), has an GBP 84 million fund which turn waste from a cost into an opportunity. This will be supplemented by a further GBP 18 million match funding from JESSICA and leveraged by around five times by private investment.

${ }^{22}$ For more information see 'Innovation Nation', Department for Innovation, Universities and Skills, 2008

${ }^{23}$ Vince Cable 3rd June 2010 Cass Business School

${ }^{24}$ Research and new technologies in carbon capture, bio-fuels (biomass, bio liquid)combined heat and power, hydro generation systems, wind energy, solar photovoltaics (PV) and recycling integrated technology applications are commonly expected to create businesses and jobs in the renewable sector.

${ }^{25}$ The Technology Strategy Board is a government agency that promotes technology collaboration between private and public organisations by making funding available for demonstrators, collaborations and networks, SBRI is a US designed initiative which sets aside small percentages of procurement contracts for small firms engaged in leading edge Research and development activity

${ }^{26}$ Science, Innovation and the Economy David Willetts Minister of State for Universities and Science (attending Cabinet) 9 Jul 2010, Royal Institution, London 


\title{
CHAPTER 5.
}

\section{GREENING THE WORKPLACE}

\author{
by Bettina Schaefer
}

\begin{abstract}
This chapter presents analysis of existing programmes to stimulate demand for greener goods or services in London, including actions to green public service sector elements of the economy using green, sustainable or responsible public procurement, and public programmes in the building sector to encourage the low-carbon economy in supply chains. The chapter analyses the role of the public sector, opportunities for the private sector and the importance of facilitating behavioural change for consumers.
\end{abstract}

\section{Policy Issues}

As the study visit focused mainly on low-carbon economy activities, other important policy issues such as sustainable consumption and green public procurement were not covered in depth. The policy issues described in the following paragraphs should provide the necessary background for the SWOT analysis and the recommendations of this chapter for London.

\section{Sustainable Consumption Policies}

The OECD, UNEP and the Commission for Sustainable Development have led the policy definition on "Sustainable Consumption and Production" since the early nineties", including recommendations to OECD member countries to reduce the environmental impacts of their own operations and decisionmaking processes". For the UN Commission on Sustainable Development "changing consumption and production patterns" has been an "overriding issue" and a "cross-cutting theme" since $1999^{3}$. As a result of the World Summit for Sustainable Development in 2002, signatory governments started the Marrakech Process, a global process to support the elaboration of a 10-Year Framework of Programmes on Sustainable Consumption and Production, focusing on specific themes, including building and construction, tourism, public procurement, sustainable products, lifestyles, and education and cooperation with Africa ${ }^{4}$. Priority policies for the framework plan are those that integrate a mix of tools (economic incentives, regulation and communication tools, such as labelling) and should build on partnerships between governmental bodies, international organisations and private companies ${ }^{\mathbf{5}}$.

At the EU level, the Sustainable Consumption and Production, and Sustainable Industrial Policy (SCP/SIP) Action Plan " is a dynamic framework to improve the energy and environmental performance of products and foster their uptake by consumers. (...) The challenge is to create a virtuous circle: improving the overall environmental performance of products throughout their life-cycle, promoting and stimulating the demand of better products and production technologies and helping consumers to make better choices through a more coherent and simplified labelling."

This new policy approach combines various potential policy tools, which include, on the demand side, minimum requirements for products under the Ecodesign Directive, consumer information based on the Energy Labelling Directive and the Ecolabel Regulation, the promotion of Green Public Procurement and 
work with retailers and consumers. On the supply side, the tools focus on boosting resource efficiency, supporting eco-innovation and enhancing the environmental potential of industry.

\section{Green Public Procurement}

As part of the SCP/SIP Action Plan, the European Commission published the communication "Public Procurement for a better environment ${ }^{7}$ " in order to provide guidance on how to reduce the environmental impact caused by public sector consumption and to use GPP to stimulate innovation in environmental technologies, products and services. Based on the scope for environmental improvement, level of public expenditure and potential impact on the supply side, common GPP criteria have been developed for ten priority product groups, including: construction, food and catering services, transport, electricity, office IT equipment, textiles, paper, furniture, and cleaning products and services. The communication states that "by the year $2010,50 \%$ of all tendering procedures in priority product groups should be green".

In the 2003 communication "Integrated Product Policy: Building on Environmental Life-Cycle Thinking", the EU encouraged its member states to develop publicly available National Action Plans (NAP) for greening their public procurement. In summer 2010, 21 Member States adopted a GPP NAP, and 6 Member States are in the process of preparation or adoption. The UK is considered as one of the frontrunners on GPP at EU level. It is important to say that, for the Commission, GPP is a cross-cutting approach which combines a range of policy instruments such as regulations, training and awarenessraising, work with suppliers, etc. The Commission uses the following categories: adoption of a formal Action Plan; existence of guidelines; establishment of GPP targets and criteria; market analysis, communication and training; monitoring and legal provisions.

\section{Energy and Innovation Policies}

A wide range of European policies in the field of energy and innovation also recognise the role of Public Procurement. The most important of these are the reworked Energy Performance of Buildings Directive, which aims towards almost zero carbon buildings (specifically public sector buildings), and the Europe 2020 Strategy: A European strategy for smart, sustainable and inclusive growth ${ }^{9}$. The initiative "Innovation Union" focuses on challenges such as climate change, energy and resource efficiency, health and demographic change. The Commission proposes improvement for business innovation, making "full use of demand side policies, e.g. through public procurement and smart regulation" and "encouraging wider use of green public procurement."

\section{Analysis of London}

This section analyses the role of the public sector in stimulating green demand. It summarises the main policies regarding sustainable, responsible or green procurement at national or London level. As these items were not addressed in detail during the study visit, the analysis is mostly based on literature review and on further information received by the interviewees after the study visit. In order to analyse the actions that the public sector is undertaking to stimulate the demand for greener products and services in London, it is necessary to understand in depth ongoing procurement policies both at national and London level.

\section{Green Procurement: the national context}

In June 2006 the Sustainable Procurement Task Force (SPTF), commissioned by DEFRA and HM Treasury, published a report ${ }^{10}$ which outlines the commitment to deliver $\mathrm{CO}_{2}$ reductions and resource efficiency across the government estate and supply chain. One of the core elements of the GPP NAP is the "Flexible Framework", a maturity matrix for sustainable procurement with 5 levels of ambition (Level 1 Foundation; Level 2 Embed; Level 3 Practice; Level 4 Enhance; Level 5 Lead) ${ }^{11}$. The target for 
Government Departments is to achieve level 3 by 2012 and level 5 by 2015 . The Flexible Framework is organised around 5 mayoral items: People; Policy, Strategy and Communication; Procurement Process; Engaging Suppliers; and Measurement and Results.

As the Mayor of London's Green Procurement Code (MLGPC) correlates closely to the Flexible Framework, its contents would require deeper analysis. In comparison with the GPP strategies of other countries, it is important to stress that the UK strategy is not based on qualitative and quantitative goals in priority product groups of public spending, and that the definition of specific environmental criteria is less specific than in other countries. The minimum criteria, known as "Buy Sustainable Quick Wins" refer exclusively to common energy consuming products - IT equipment, light bulbs, white goods, heating and air conditioning, paper and others, including detergents, paints and varnishes - with the aim of buying the best product possible. Compared to the EU's GPP criteria, the UK criteria refer exclusively to the environmental quality of products purchased; environmental requirements on bidders are not defined. For instance, selection criteria concerning the technical capacity of bidders to perform a certain contract, including minimum environmental skills and knowledge; or the inclusion of elements of Environmental Management Schemes such as good practices in waste collection or energy consumption as part of contract clauses are not specified. This means that, although a set of criteria exists, the message sent to the market in terms of stimulating clear environmental improvements is not as strong as it could be, and, above all, the Quick Wins do not include supplier related requirements. During 2010 the Quick Wins were revised, updated, expanded (embedding the EU criteria and product groups) and re-launched as "Government Buying Standards", but they still focus mainly on product criteria.

Although it is a mandatory administrative requirement in the UK that all central government departments and their executive agencies incorporate environmental criteria into their procurement procedures across a series of priority product groups, as set out in Government Buying Standard ${ }^{12}$, this is not a binding legal requirement. Evidence gathered during the study visit showed that only some Departments (e.g. Department of Health, Department of Transport) are actively implementing sustainable procurement across the five items covered by the Flexible Framework. However, there is potential for a much deeper intervention. This vision is also confirmed by the National Audit Office ${ }^{13}$.

Probably the most challenging goal of the sustainable operations targets for the Government office estate (SOGE), is to go carbon neutral by 2012 and to reduce carbon emissions by $30 \%$ by 2020 . Working with the supply chain is critical to achieving this goal, and it also implicates the development of a high level of skills in maintenance and facility management.

\section{Responsible procurement at the GLA group}

"By using GLA group's purchasing power of more than GBP 3 billion for goods and services each year wisely, we can deliver real benefits to all Londoners, our businesses and our city. This is the core of my approach to responsible procurement and also a part of my Economic Recovery Action Plan. Together they provide the action to help London businesses - particularly small businesses - and promote the skills and employment development we need, now and in the future." Boris Johnson, Mayor of London

Internally, the GLA Group [Greater London Authority (GLA), Transport for London (TfL), the London Development Agency (LDA), the London Fire and Emergency Planning Authority (LFEPA) and the Metropolitan Police Authority (MPA) / Service (MPS)] has had a Responsible Procurement Policy in place since $2006^{14}$ 
The policy focuses on seven issues, which are:

1. Encouraging a diverse base of suppliers

2. Promoting fair employment practices

3. Promoting workforce welfare

4. Addressing strategic labour needs and enabling training

5. Community benefits

6. Ethical sourcing practices

7. Promoting greater environmental sustainability.

Approximately $10 \%$ of the total spend in 2007-08 was with London-based SME's ${ }^{15}$. Worth mentioning is the "CompeteFor" project, a web service which brings together suppliers and the public sector, widening the opportunities to bid for GLA group and Olympic contracts.

\section{Box 5.1. CompeteFor}

CompeteFor is an online contract advertising system developed by the LDA. The system was created to build a business network and brokerage service to allow businesses to benefit from investment in the London 2012 Olympic Games. Since 2009 the system has been available to London's public authorities. Other private and public sector organisations can also use the service. "GLA group buyers have posted 357 contract opportunities, with a total contract value of GBP $29 \mathrm{~m}$ on the system since January 2009. In addition, following the inclusion of flow down provisions into major GLA group contracts, almost 1200 supply chain opportunities have been posted on the system ". More than 60000 businesses are registered on CompeteFor.

The CompeteFor buyer template, a pre-qualification questionnaire, includes qualification questions regarding the environmental policies and management schemes in place in the company. Their environmental performance and credentials can then be further tested at the Invitation to Tender stage of the procurement process - which is managed through a separate system - the E-Tendering system. Responsible procurement requirements are then carried through to the grant award and contracting phase of any procurement activity - requiring successful bidders to then deliver on their promises regarding environmental, and workforce equity objectives.

Source: www.competefor.com

Regarding the promotion of low-carbon, resource efficient goods and services, the Responsible Procurement Programme mentions specifically the formerly Buildings Energy Efficiency Programme (BEEP) renamed RE:FIT, the promotion of electric vehicles, the Freight Operator Recognition Scheme (FORS) and waste reduction in public buildings. Opportunities to use procurement to promote economic, environmental and social benefit are seen particularly in major projects like the 2012 Olympics and in work with boroughs.

The goal of the Responsible Procurement Programme is to establish London as leader on responsible procurement - nationally and overseas. Collaboration with London boroughs and central government is ongoing. All parts of the GLA group achieved the Mayor of London's Green procurement code gold standard in 2009 (based on the Flexible Framework). There are two good practice examples within the MPS. Firstly, the Facilities Management Service Contract (2007), which included as an innovative element 
the incorporation of the internal waste collection into the cleaning contract and secondly, the provision of training to MPS staff, including waste reduction and waste recycling targets for 2010. The London Fire Brigade (LFB) is another outstanding department in integrating environmental sustainability in contracts ${ }^{16}$.

The LDA and the GLA are encouraging London-based organisations to improve their environmental standards by adhering to the Mayor's Green Procurement Code, the Green 500 initiative and the RE:FIT Programme.

Similar to the implementation of national policies on GPP, no clear environmental requirements regarding priority products and service groups are identified in the GLA Sustainable Procurement Policy; the focus for energy and resource efficient procurement is on major contracts and energy efficiency in buildings. On the other hand, engagement with suppliers seems to be excellent. Particular areas for improvement are greater standardisation across the different buying organisations of the GLA group and better coordination between public sector departments.

\section{GPP at external level: the Mayor of London's Green Procurement Code}

The members of the Mayor of London's Green Procurement Code (MLGPC) are both public and private organisations. The GLA group and all 33 London boroughs are active members. The MLGPC is run by London Remade and focuses on "reducing their environmental impact through responsible purchasing", providing free advice and support to its members. As opposed to GLA's internal Responsible Purchasing Programme, the focus is on embedding green purchasing into the organisations, especially in the fields of office products, products with recycled content (e.g. steel, concrete and other building products), sustainable timber, energy, water and transport. Key Performance Indicators (KPI) are used to monitor progress; they are also calculated specifically for the London Boroughs. Green purchases cover 31 product categories reported on by the participants.

Measurable benefits are reported, for example the reduction of $\mathrm{CO}_{2}$ emissions from fleets, lighting, paper, buildings, water savings, waste reduction and the increase of recycling rates or financial benefits (e.g. reduction of spending on lighting and heating, reduction of cleaning or disposal costs, etc.). Some savings are in the form of reductions in embodied carbon: the $\mathrm{CO}_{2}$ emissions generated in the production process of the product. In 2009, 56220 tonnes of $\mathrm{CO}_{2}$ emissions were avoided, and 118641 tonnes of waste diverted from landfill as a result of the green purchases made by signatories ${ }^{17}$.

In 2009, data on 1686 green purchases in 30 different product categories were reported with GBP 436 million of spending. It is estimated that the purchases made by signatories supported 831 jobs $^{18}$. The total procurement budget reported by the signatories was over GBP 15 billion; purchases that addressed an environmental issue ("green spend") corresponded to not more than $3 \%$ of the total procurement budget reported. For the LDA, this percentage should increase significantly for 2010 if the two major framework agreements (RE:FIT and RE:NEW) are considered as "green contracts" in the field of construction.

In 2009, 16 organisations achieved the gold level of the Green Procurement Code (including the 5 members of the GLA and 2 London boroughs), 28 signatories achieved silver and 24 bronze. The gold level of the Green Procurement Code is comparable with achieving level 3 of the Flexible Framework.

\section{London's Low-Carbon related programmes in the building sector}

"Delivering London's Energy Future" lists the following key programmes designed to capture all areas of a Londoner's life, from work to home to travel:

- RE:FIT Public Buildings Energy Efficiency Programme; 
- RE:NEW Home Retrofit for London's existing housing stock;

- Decentralised Energy Projects (based on biomass and combined heat and power);

- $\quad$ Green Enterprise District;

- London Waste \& Recycling Board (waste reduction, re-use and recycling);

- Low-Carbon Zones for local communities and buildings.

The first two are specific framework agreements run by LDA, linked to GPP and employment. Indeed, making the existing building stock more efficient is not only a challenge for London, but also a huge opportunity for stimulating job creation through public procurement while contributing to the lowcarbon economy. The LDA is investing GBP 9.5m in the RE:FIT Programme, a Framework agreement based on the Energy Performance Contracting approach for public buildings with guaranteed energy and financial savings. RE:FIT has been piloted by TfL, Metropolitan Police and London Fire Brigade in 42 buildings with a saving of GBP 1 million on fuel bills and achieving a $27 \% \mathrm{CO}_{2}$ reduction with a payback period of seven years. The public sector targets within the framework agreement are 400 buildings (40\% of the public sector) and an expected $\mathrm{CO}_{2}$ reduction of $2500000 \mathrm{t} \mathrm{CO}_{2}$. More than 100 public organisations are in the RE:FIT pipeline, most of them Boroughs, Universities and NHS.

A crucial problem identified in interviews with building sector experts during the London study visit is the lack of tradition and culture in Energy Service Contracting. The ESCO's on the market are mostly French or from other countries outside the UK. Combined with the fact that London has a below average market share across Building Technologies (see DTZ Skills for a Low-Carbon London), the creation of local knowledge on energy management in the building sector is one of the main challenges for London, but also an opportunity.

RE:NEW, the former Homes Energy Efficiency Programme (HEEP), is a home's retrofitting scheme for the residential sector, run in partnership between LDA, GLA, London Councils, the Energy Saving Trust and the 33 London Boroughs. As described in Chapter 3, the programme provides a range of cost effective easy measures and energy saving advice in order to offer something to every home. RE:NEW is linked with existing funding schemes like CERT. Pilot projects have been conducted in more than 8000 homes and the framework agreement includes a panel of 12 suppliers who will work on approximately 200000 homes until 2012.

As the LDA states, the main threat is funding for home owners: the LDA has provided GBP 9m seed funding to develop the delivery model and begin roll-out of the programme; additional funding (from suppliers, central government and boroughs) is levered in through the delivery of the scheme. The London Green Fund will provide the opportunity for social housing organisations to borrow funds for home retrofit. Ultimately, different financing solutions need to be found such as the "Green Deal" pay-as-yousave model. "For these models to work, it is critical that the financial benefits of reducing carbon are communicated to the market" (DTZ Skills for a Low-Carbon London). It is also essential to stimulate the use of these programmes by making the funding easily available to home owners.

\section{Encouraging the greening of the service sector}

The Green 500 programme, carried out by the LDA, is working with the 500 biggest organisations based in London. Their high potential for carbon savings will help to deliver the target to cut London's carbon dioxide emissions by $60 \%$ by 2025 , "create green collar jobs and stimulate a low-carbon economy". Green 500 aims to help organisations meet the criteria of the Carbon Reduction Commitment (CRC) scheme. The initiative is based on Carbon Mentoring, networking and the Green 500 Badges rewards, using 7 categories (energy management, carbon savings, carbon footprint action plan, transport, water and waste, etc.) with a weighted scoring. Until now the participating organisations have saved around 570000 
tonnes of carbon and over GBP 70 million off their energy bills. The scheme will be expanded to smaller businesses. The expanded scheme is expected to involve 1500 London organisations and to save up to 1 million tonnes of $\mathrm{CO}_{2}$ and GBP 100 million in energy costs over the next 3 years.

The Better Buildings Partnership is linked to the Green 500. Within the Partnership, leading commercial building owners work together with occupiers to develop energy efficiency programmes for London's existing commercial buildings. For the moment, both initiatives are targeting the largest organisations with the biggest impacts, leaving out SMEs or smaller third sector organisations.

The third support programme for London-based organisations is the aforementioned Mayor's Green Procurement Code, which focuses on all organisations, including SMEs and third sector organisations.

\section{Chamber of Commerce and Industry and Trade Unions}

The education of employers and employees in the day to day greening of the workplace was not really mentioned during the study visit, although complementary documentation about initiatives carried out by the London Chamber of Commerce and Industry (LCCI) and the trade unions (TUC) were provided after the visit. The LCCI is carrying out environmental improvements in their own premises (selective collection of waste, green purchasing of office consumables, energy saving measures) and is also working with the GLA in greening LCCI member organisations. TUC is carrying out the Green Workplace Project, which includes newsletters and guidelines for a sustainable workplace, focused on implementing specific actions in everyday work to achieve carbon reductions and environmental benefits. A number of significant projects to green workplaces have been delivered nationally and in London ${ }^{19}$, although it seems that the above mentioned initiatives are, for the moment, having a minor impact.

\section{Greening the cultural and hotel industry}

The GLA is also working with the cultural and creative industry (theatres, music industry, hotels, etc). Specific guidelines for carbon reduction have been developed: Green Music Guide, Green Screen, Green Theatre, Green Orchestra, Green Visual Arts, Moving Arts (managing the impact of touring), etc. The initiative is lead by "Julie's Bicycle", a coalition of music, theatre and scientific experts "committed to delivering a concerted response to climate change".

\section{Box 5.2. Industry Green}

Julie's Bicycle is promoting the "Industry Green" mark, a voluntary certification scheme, designed to reflect the activities of creative industries. Standards for environmentally-responsible business are available for festivals and outdoor events, venues, offices and CD packaging. The Julie's Bicycle Industry Green programme is a systematic approach to managing the environmental impacts of specific activities, and includes four steps: engage; measure; reduce and improve; track and report progress.

Source : www.juliesbicycle.com/about-jb/industry-green

Although no information was available in the context of the study visit and the literature review regarding the carbon reduction and awareness raising impact of the initiative, it is very promising and has to be considered a best practice case at the international level; a high impact on society can be expected if the potential of transmitting the message to the audience is explored.

On the other hand, although it was mentioned during the study visit that London is also working with the hotel sector, no further information or evidence has been provided. It would be important to further 
explore the potential of working with the tourism sector, as there is a high number of low qualification jobs with significant "greening potential" (energy and water savings, waste collection).

\section{Opportunities and Challenges for London}

\section{Strengths}

\section{Good GPP policies in design of public buildings}

As stated at the Low-Carbon Skills Forum and also at the meeting with Higher Education representatives, the criteria for the design of public buildings are very well developed. This applies particularly to the construction work carried out for the Olympics ${ }^{20}$. The meeting with Bovis Lend Lease confirmed high environmental standards with continuously upgraded targets, such as a Code for Sustainable Homes Level 4. Bovis Lend Lease also demonstrates an excellent level of auditing and implementation of environmental standards in the supply chain during construction works, including, among others, Project FSC certification and a Black and Grey List of prohibited and referable materials. For projects managed by Bovis Lend Lease under construction management forms of contract, the trade contractors are requested to provide information on timber use, water consumption, fuel consumption, and waste arising. This includes the raw data, together with back-up information such as delivery notes and waste transfer documents to substantiate the raw data. Bovis Lend Lease ensures the data are entered into a system called "Minimise", based on their "Smartwaste Plan" website, which they have developed together with the company Building Research Establishment. This allows Bovis Lend Lease to report on a range of environmental/sustainability key performance indicators.

\section{Leadership in the "Low-Carbon Economy"}

The UK and London as the "Low-Carbon Capital" are without any doubt global leaders in developing projects, methodologies, standards and certification schemes for the Low-Carbon Economy. The Carbon Trust as well as UK-based NGOs (or UK sections of international NGOs) are important players internationally. The above mentioned work of Bovis Lend Lease in the development of the Olympic Village is very ambitious, including the calculation of the construction work's Carbon Footprint. From an international point of view, there are few examples of urban development projects with a similar level of environmental and energy efficiency auditing, both in the project and the construction phase. The Vauban District in Freiburg, Germany's "green capital" - promoted by the civil society and leading German research experts - is one of them. London's Low-Carbon Projects are on a broad scale - decentralised energy projects, energy efficient housing as well as transport. The only thing that might be missing in London is a portfolio of projects related to agriculture and/or global and local food provision ${ }^{21}$.

\section{Weaknesses}

\section{Lack of priority setting in GPP}

In London, there is a large number of ongoing projects and programmes showing similar objectives, but with a different focus. In the field of public procurement the GLA's internal Responsible Procurement Programme has a different focus to the external Mayor of London's Green Procurement Code (MLGPC). Depending on what policies are aiming towards, "responsible procurement" or "sustainable procurement" are used as synonyms of supplier engagement, employment practices, local community benefits, energy efficiency or, to a lesser extent, as resource efficiency.

As a consequence of the arbitrary definition of "green", "responsible" or "sustainable" procurement in parallel projects, no clear GPP strategy nor GPP criteria for strategic contracts have been defined, and London's public procurement activities are not as visible as they could be. The public sector could be 
"leading by example", however that is not currently the case, even though there are a few exceptions (best practice cases in the GLA group and London boroughs). Procurement should be part of the strategy from the beginning in order to drive the market and to signalise future requirements driving performance improvements in the private sector.

\section{Low awareness level of low-carbon and greening opportunities}

In order to get the market ready, educating and raising the awareness of employers, employees and end-users is crucial. London's Low-Carbon programmes recognise the threat, but for the moment the actions taken are not enough. "A challenge for both government and policy developers is to ensure that the initiatives which are being encouraged are effective in delivering the carbon reductions, whilst being understood by consumers and households. If consumers and households are to invest the remaining GBP 17-GBP 40bn in the initiatives, the projects being delivered with the government's GBP 100m investment must show some demonstrable benefits and results that are effectively communicated to the consumer."(DTZ Skills for a Low-Carbon London)

\section{Lack of skills in maintenance and energy management of buildings}

Although the design standards for buildings are well defined, the Low-Carbon Skills Forum maintained that they "do not have the skilled persons to run the building". For example, a "Sustainable Facility Management Course" offered by LSBU had only 2 enrolled students. LSBU also stated that as there is no tradition of Energy Service Contracting in the UK, skills and knowledge for the good maintenance of existing buildings, especially commercial buildings, are lacking. As the CEREB representatives expressed: "buildings generally under-perform by the factor of 2 due to a lack of skills in installation and maintenance of the systems". The lack of skills or awareness is also applicable to the endusers. Indeed, the fact that consumers do not have the ability to use smart building technology has also been identified as a barrier to good energy performance.

\section{Lack of institutional capacity and awareness of GPP across London's institutions}

It is clear that the Mayor of London's own organisations are leading by example in green procurement and are setting a high standard for other organisations to follow. ${ }^{22}$ The members of the Greater London Authority (GLA) Group merit a special mention in this section. The five organisations - Greater London Authority, London Development Agency, London Fire Brigade, Metropolitan Police, and Transport for London - scored consistently highly in all sections in part one of the MLGPC progress review survey with an average total score of $96 \%$. Although the survey states the GLA group and London boroughs' excellence in procurement, the study visit revealed a significant lack of knowledge and/or recognition of the importance of these activities by the respondents. Nearly all information about GPP and greening the service sector included in this report comes from literature review and internet research.

During the study visit, most of the interviewees from GLA Group and other public agencies considered not to have the institutional capacity to provide high quality advice to businesses or to change the culture of sustainability within their work places. This might be related to the specific responsibilities of the individuals that were interviewed, but it gives a clear indication of the relatively weak implementation of GPP both in London's Public Institutions and in Government Departments. GPP has to be carried out as a coordinated strategy of the main actors in order to give clear messages to the supply side. A weak implementation of GPP in Government Departments therefore has impacts on London's GPP policies. Also during the study visit, it was clear that a change of mindset and a long-term commitment are still lacking for the implementation of GPP to be successful. As the Report on Low-Carbon Construction states for the building sector, there is a "lack of drivers for a change in customer demand, without which 
the supply side lacks the confidence to invest in new products and services for which there may be no market at a profitable price."

\section{No behavioural change for end-user}

Indeed, behavioural changes are processes which take time ${ }^{23}$. It is surprising that both the National Government and London's initiatives for the public sector and for business are all based on models with upgrading levels of maturity. (For example, the 5 levels of the Flexible Framework, the levels of the Code for Sustainable Homes, the 5 levels of the Mayor's Green Procurement Code, etc.). However, in contrast to this stepwise approach, individual consumers are supposed to make the jump from 0 to 5 in a very short time frame. London's challenge is the end-user; how to up-skill them and take them to the next level in order to change consumer's behaviours.

\section{Opportunities}

\section{Good growth prospects for the low-carbon sector}

There are 5500 companies working in the low-carbon sector. This is a good starting point and presents an opportunity for the further development of the low-carbon economy. There are low-carbon jobs that do not involve radical changes in qualifications or skills. Only some new learning or apprenticeship models are needed because the main skills already exist.

\section{Building on existing good practice cases}

Communication on existing good practice could be improved in future, although experience has been gained over the last few years, and good practice cases in the field of GPP have been documented (GLA group and London boroughs). This is a very good starting point in terms of leading by example and an opportunity for the further development of a consistent strategy.

\section{Greening the workplace means economic benefits}

Evidence has been gathered in London, in the UK and at the international level on the economic benefits of greening the workplace and the development of the Low-Carbon Economy. Financial savings from the retrofitting of buildings, as piloted in GLA buildings, have been made; indirect economic benefits, such as job creation in the supply chain, have been reported by the MLGCP; and international studies (see UNEP Green Jobs facts and figures) are supporting national and London specific results. The large number of reports on KPIs, studies and audits carried out (e.g. Olympics) are a solid base for establishing methodologically robust reference cases. More visibility could be given to enhance their impact.

\section{Threats}

\section{Scattered understanding of Low-Carbon London}

A barrier to progress is the plethora of policies, reports and initiatives undertaken by a variety of Government Departments, by NGOs or other special interest groups, which are incapable of being adopted by businesses, and which need to focus on the more immediate interests of their clients and shareholders ${ }^{24}$. This analysis not only applies to the national Government, but also to London. The impression during the study visit was that priorities need to be defined to communicate a clear message to the stakeholders concerned and to the civil society. Information on the opportunities and possibilities within the low-carbon economy should be clearly presented, market-oriented and condensed to facilitate its uptake. 
Too narrow a definition of the low-carbon sector

During the study visit and in the diagnostic report for London (see Chapter 3), the definition used for defining jobs and skills was exclusively related to "Low-Carbon", including the fields of Energy Efficiency, Energy Supply, Renewable Energy and Waste, and Waste to Energy. As explained in the report "Skills for a Low-Carbon London ${ }^{25}$, this definition is widely used by BIS and Central Government, but limits the full potential to move London to a low-carbon economy.

\section{Identify future procurement and private sector opportunities}

The Local government's strategy for sustainable procurement (IDeA and LGA 2007) states that "only rarely is the public sector making the most of opportunities to signal its future requirements to the market and so drive performance improvements in products and services".

The major threats for the Low-Carbon Capital have already been highlighted by London: to identify priority areas and strategic goals for public sector low-carbon procurement; to identify and support lead boroughs and steering groups to champion/research new low-carbon category business cases and tests; to consider establishing a panel of private sector and leading London research institutions to work with the public sector in order to develop and bring to the market low-carbon solutions; and to establish a way of recognising best practice and innovation in municipal procurement of low-carbon technologies ${ }^{26}$. The identification of future "low-carbon" procurements implies the early identification of procurement opportunities based on a prospective analysis of future public spending, leading to the emergence of new markets or the expansion of existing ones.

\section{No technical criteria or minimum standards for GPP/Low-Carbon Skills}

No clear environmental standards for GPP product groups have been developed. GLA should be engaged in the process of updating UK National Action Plan criteria on GPP together with the Government and other stakeholders (for detailed recommendations, see Local government's strategy for sustainable procurement (IDeA and LGA 2007)). A switch from criteria for products to criteria for service (and works) contracts is of major importance to influence and stimulate the green labour market and to integrate Low-Carbon Skills into Public Procurement.

\section{Innovation in procurement}

The Low-Carbon Industrial Strategy commits "to aid a transition to low-carbon across the economy. This includes measures to encourage organisations to improve resource efficiency and energy savings, skills development and changes in government procurement". The London Fire Brigade was one of the first public organisations to implement Forward Commitment Procurement. Innovation in public procurement, especially in the building sector, should be explored in the future.

\section{Dynamism of the Low-Carbon sector}

Continuous research and development requires continuous adjustments to the skills needed by the sector. It is difficult to match up the professionals with the required skills to the emerging low-carbon activities at the right time and in the right place. This requires leadership and flexibility to adapt rapidly to the new low-carbon paradigm well ahead of society and client demand. Clearly, students need to be prepared for future as well as existing technologies. The low-carbon challenge for HE is, therefore, to prepare students for jobs that do not yet exist, using technologies that have not yet been invented, to solve problems we do not yet know are problems. ${ }^{27}$ Finding the balance between skills availability and job openings is not easy. There is a risk of having too many "green" skilled workers and not enough jobs 
available if the industry does not take off, while the opposite could also happen if the labour market does not respond to the demands of the industry as it grows.

\section{Recommendations for London}

\section{Gradual up-skilling of the population and the end-user}

Raise awareness among the population and the end-user

Public awareness at individual consumer level seems to be one of the core issues for the future. Stakeholders participating in the business roundtable during the study visit agreed that a number of people would use the green grants for retrofitting their homes if they knew about them.

For instance, in the field of mobility, London's new public bicycle scheme might be a step in the right direction, but what is missing are initiatives challenging consumer choice and behavioural changes over a longer period. Evidence gathered during the study visit showed that strategies at individual consumer level are based on economic rationale. This means, in practice, that behavioural changes motivated by individuals' consciousness of environmental or climate change issues are not considered as drivers.

\section{Facilitate access to information on RE:NEW}

The RE:NEW programme is combining "easy measures" with the identification of further measures (like loft and cavity wall insulation). RE:NEW needs a combination of both behavioural change and private investment. Public sector expectations of the individual consumer's response to the RE:NEW programme are relatively high. A long-term strategy to raise the awareness of individual consumers should be developed. One element of a successful approach might be a contract of awareness called 50/50 (used especially in schools, www.euronet50-50.eu). However this should also be complemented by other policy instruments, like information about consumer choice for greener products, labelling, and awards, or economic tools like property tax reductions for energy efficiency measures in housing to support the RE:NEW programme (see Paris learning model). This, together with a strong communication strategy, would enhance the outcome of the RE:NEW Programme and would facilitate to reach the target expected to be attained

\section{Improve visibility and communication to the end-user}

Step by step up-skilling of the population means implementing a combination of economic, communicative and other voluntary measures, and developing strategies similar to Green500 or the Mayor of London's Green Procurement Code, adapted to individual consumers. London should better brand its plan and communicate more clearly its ambitions to other public and private actors, as well as to its population in general. This will help to strengthen global perceptions of London as a green city and as a home to green industries, technology and 'know how' (see Sakai model in Annex A). Better visibility and communication of London's existing initiatives and projects to end-users might also be considered as a helpful element in an overarching strategy. Indeed, there is very little information available to the enduser. This could be better presented in an online portal which would concentrate the relevant information for end-user, together with a selection of key support schemes to move towards a low-carbon economy. See Paris learning model. 


\section{Revise definitions and criteria}

\section{Identify GPP criteria}

At the national level, GPP criteria are under revision (in fact, most of the criteria are exclusively product specifications). The development of UK-wide criteria for service contracts, based on elements of good environmental management practices in the field of energy, water, waste and resource efficiency could help to implement green workplace practices both in local public authorities and in the private sector. London could lead the debate in the definition of GPP criteria if the MLGPC moves in this direction. At the same time, behavioural changes can be reinforced and further extended to private consumers and businesses if they take part in the debates to set the criteria.

As previously mentioned, works and service contracts are the most labour-intensive public contracts, involving a high percentage of the low-skilled workforce. The criteria for service contracts (regarding specific training of employees, good environmental practices in energy and water savings, and resource efficiency) could be easily implemented in both public and private sector contracts. A sector to take a particular consideration would be the hotel sector, in which low-skilled workers in particular would be "greened" and "upgraded" (for example in cleaning services, laundry services, waste collection, gardening, etc.).

\section{Re-define low-carbon sector}

For effectively greening the workplace, the current definition of the low-carbon sector has to be expanded to include resource efficiency, recycling, remanufacturing, minimisation of waste and pollution, and organic farming ${ }^{28,29}$. All uses of natural resources, such as materials or water, have embedded carbon emissions. The GPP takes this into consideration, and also includes other environmental impacts (see the MLGPC indicators). A broader definition could be based on "Low-Carbon and Resource Efficient Economy"30.

\section{Greening training}

\section{Build "green" capacities across the public sector}

The public sector should lead by example, which would be equivalent to reaching minimum level 4 (People) of the Flexible Framework. This means including sustainable procurement in skills and selection criteria, and as part of employee induction programmes. As far as the public sector is concerned, GPP should also be embedded into the National School of Government curriculum. Furthermore, the London authorities could make better use of CEREB to maximise its potential. Indeed, the GLA should provide all their planners, energy managers, etc, with practical training at CEREB. More challenging is the teaching of "soft skills", which have been mentioned as particularly crucial for energy advisors in the RE:NEW Programme. Public officials should receive sustainability and/or green procurement related training regardless of her/his position. This would contribute to changing behaviours from within the public sector.

\section{Train the consumer}

In the development of training modules, both professional skills for specific green jobs and generic sustainability skills for everyday work and living practices should be considered. A "green" component or sustainable training should be included in every discipline to raise awareness and prepare the consumer for the green market; this applies to all levels of $\mathrm{HE}$ and FE training courses across disciplines. A barrier to embedding sustainable or green issues is that no more than $10 \%$ of content can be easily changed (in terms of administrative procedures), but $10 \%$ should be enough for integrating a "green" component in basic training. However, London should work towards making the vocational education and training system 
more flexible in order to accelerate its adjustment (see Sydney model). Training and information on the possibilities for greening the workplace should be further developed in both the public and private sectors.

\section{Support London's business sector}

\section{Create new businesses in the low-carbon sector}

It is important for London to develop plans to support the creation of new businesses in the lowcarbon sector, as well as the growth of micro-enterprises. This is essential to create jobs and support the expansion of emerging sectors in the low-carbon economy. Entrepreneurship promotion and business development services should be oriented towards new market niches within the low-carbon agenda. An opportunity that should be seized concerns the building technology sector. One of the LDA's major investment programmes for public buildings, RE:FIT, is based on a framework agreement with energy service suppliers. A local market of knowledge in Energy Efficient Building Management (Facility Management) could be developed together with research institutions like CEREB, the university colleges and the building professional sector.

\section{Facilitate access to information to businesses}

It would be useful to communicate more effectively the market opportunities available for businesses in the low-carbon economy. Many studies and reports prepared for London authorities make a clear bet on the low-carbon plans, but not much of that information is easy to access and "digest" by businesses, especially SMEs. The clarification of measuring criteria (e.g. how should a "green" business look), the presentation of the support schemes for potential entrepreneurs and businesses (e.g. incentives, grants), the market opportunities (e.g. domestic and internationally) as well as the facilitation of access to financial institutions to support eco-innovations (e.g. venture capitalists) could be extremely useful for businesses to develop in London. More "easy to digest" information should be made available. It would be helpful to create a one-stop-shop online platform where businesses can find information on the market opportunities, the support schemes, measuring criteria, etc. for the low-carbon economy.

\section{Target businesses in the building sector}

A large proportion of London's major projects and policies relating to the "Low-Carbon Capital" are linked to the building sector. As mentioned before, the building sector is underrepresented in London's economy, for example there is no tradition of Energy Service Contracting in the UK economy. Developing market capacity to design, build and maintain energy and resource efficient buildings is crucial to the broad implementation of ESCOs, the retrofitting of residential buildings and for innovation in Low-Carbon Building technologies. A broad range of professions and skill levels will be necessary to deliver "zero carbon buildings" in the future; not just "green collar jobs"- architects, designers, engineers - but also lowskilled workers employed in construction and service contracts. On the business side developers, suppliers and building owners are involved in the installation and management of energy efficient buildings.

The level of experience is already quite high - take CEREB or the Olympic works, for example. Methodologies regarding Carbon Footprinting or key performance indicators for sustainable buildings have been tested. For the implementation of the Low-Carbon Capital the potential to develop the whole value chain, from design to maintenance and end-use of buildings, should be taken into account as an integrated strategy.

\section{Position London as a low-carbon building area}

London has been designated Low-Carbon Building Area by the UK Government. This suggests that the building sector has been identified as a competitive advantage of the city. London has many assts in 
the eco-building sectors (including CEREB, highly-performing companies like Bovis Lend Lease, well trained advisors, etc) and is putting a lot of efforts in improving the energy efficiency of its housing stock through various programmes and support schemes. London could be a laboratory for further R\&D in the area of eco-building as well as a model of effective retrofitting if all efforts converge. The 2012 Olympic Games also provide a unique opportunity to show the way towards major infrastructure investments in the low-carbon economy. The label "Low-Carbon Building Area" could be better utilised and exploited to position London as the reference in eco-building worldwide.

Support government actions through social enterprises and SMEs

The contribution of the third sector and civil society to ensuring the involvement of lower-skilled workers in low-carbon activities is essential, and therefore should also be part of a strategy in itself. During the study visit most of the projects mentioned were big projects; indeed stakeholder involvement is also focused on London's major enterprises, like the Green 500 campaign. Smaller projects addressing London's 11000 micro-enterprises, the third sector or civil society in general have not been demonstrated. This reflects the minor role that is given to them in the low-carbon agenda. Smaller initiatives should be better organised and supported to facilitate the transition to a low-carbon economy. Promoting smaller projects, closer to everyday life in London, maybe at borough level or even on a smaller scale, could only be beneficial. The approach of Vienna's or Hannover's Local Agenda 21 projects might be helpful for developing this kind of micro project (Vienna being more focused on neighbourhood initiatives and Hannover following a thematic approach). See the learning model section for more details. 


\section{ENDNOTES}

${ }^{1}$ UNEP (2001) Consumption Opportunities. Strategies for Change, Geneva, UNEP.

${ }^{2}$ OECD (1997), Sustainable consumption and production. Paris: OECD.

${ }^{3}$ UN Secretary-General (1999), Comprehensive Review of Changing Consumption and Production Patterns, Report of the Secretary-General, CSD, Seventh Session, New York: UN.

${ }^{4}$ See: www.unep.fr/scp/marrakech/taskforces/

${ }^{5}$ UNEP (2008). Planning for Change. Guidelines for National Programmes on Sustainable Consumption and Production. United Nations Environment Programme.

${ }^{6}$ Sustainable Consumption and Production and Sustainable Industrial Policy Action Plan \{SEC(2008) 2110\} \{SEC(2008) 2111\}, Brussels, 16.7.2008 COM(2008) 397 final

${ }^{7}$ Public procurement for a better environment (COM (2008) 400, published on 16 July 2008)

${ }^{8}$ Communication on Integrated Product Policy - Building on Life Cycle Thinking COM(2003) 0302 final, published on 18 June 2003)

${ }^{9}$ Europe 2020 Strategy: A European strategy for smart, sustainable and inclusive growth (COM (2010) 2020 final, 3 of March 2010). http://ec.europa.eu/eu2020/index_en.htm

${ }^{10}$ See report: "Procuring the Future. Sustainable Procurement National Action Plan: Recommendations from the Sustainable Procurement Task Force" to be downloaded at: www.defra.gov.uk/sustainable/government/documents/full-document.pdf

${ }^{11}$ See Procuring the Future, pages $66-68$.

${ }^{12}$ National GPP Policies and Guidelines, updated June 2010. Download: http://ec.europa.eu/environment/gpp/pdf/national_gpp_strategies_en.pdf

${ }^{13}$ National Audit Office. Addressing the Environmental impacts of Government Procurement. London 2009.

14 The GLA launched their Responsible Procurement Policy in 2006 as "Sustainable Procurement Policy"; it was renamed in 2008 .

${ }^{15}$ Getting Value for London. Using Procurement to make a positive difference for our city. Mayor of London. April 2009.

${ }^{16}$ The Mayor of London's Responsible Procurement Report. GLA, London, February 2008

${ }^{17}$ Mayor of London's green procurement code progress review October 2009: www.greenprocurementcode.co.uk/files/2009\%20Annual\%20Progress\%20Review\%20report.pdf 
${ }^{18}$ Mayor of London's green procurement code progress review October 2009: www.greenprocurementcode.co.uk/files/2009\%20Annual\%20Progress\%20Review\%20report.pdf

${ }^{19}$ see: www.tuc.org.uk/workplace

${ }^{20}$ The Environmental Sustainability of the London 2012 Olympic and Paralympic Games and documentation available on Olympics homepage

${ }^{21}$ See EIPRO report: most part of the $\mathrm{CO}_{2}$ emissions are related to housing, transport and food as the 3 major "need areas" of individual consumption

${ }^{22}$ Mayor of London's green procurement code progress review October 2009: www.greenprocurementcode.co.uk/files/2009\%20Annual\%20Progress\%20Review\%20report.pdf

${ }^{23}$ See DEFRA Change Behaviour Model through Policy Making - Enable, Encourage, Engage, Exemplify Motivating Sustainable Consumption - a review of evidence on consumer behaviour and behavioural change. www.sd-research.org.uk/documents/MotivatingSCfinal.pdf, Tim Jackson, 2005

${ }^{24}$ Low Carbon Construction. Innovation and Growth Team Emerging Findings. HM Treasury 2010

${ }^{25}$ Skills for a Low Carbon London. Final Report. LDA, June 2010.

${ }^{26}$ The Low Carbon Capital. London as a global leader of the low-carbon economy, LDA 2010

${ }^{27}$ Higher Education Response to the Low Carbon Economy; A discussion paper prepared for the London Low Carbon Forum - 13th September 2010.

${ }^{28}$ Martinez-Fernandez, C., C. Hinojosa and G. Miranda (2010), "Greening Jobs and Skills: Labour Market Implications of Addressing Climate Change", OECD Local Economic and Employment Development (LEED) Working Papers, 2010/2, OECD Publishing.

${ }^{29}$ Green Jobs: Towards decent work in a sustainable, low-carbon world Green Jobs: Towards Decent Work in a Sustainable, Low-Carbon World, UNEP/ILO/IOE/ITUC, September 2008 www.unep.org/labour_environment/features/greenjobs.asp

${ }^{30}$ Skills for a low-carbon and resource efficient economy. A review of Evidence. Pro Enviro Ltd. Commissioned by Defra 


\section{REFERENCES}

\section{GLA group member websites}

Greater London Authority - www.london.gov.uk/gla/tenders

London Development Agency - www.lda.gov.uk

London Fire and Emergency Planning Authority - www.london-fire.gov.uk/procurement.asp

Metropolitan Police Authority - www.mpa.gov.uk

Metropolitan Police Service - www.met.police.uk

Transport for London - www.tfl.gov.uk/sellingtotfl

\section{Responsible procurement links}

GLA Group Responsible Procurement Policy - www.london.gov.uk/rp

CompeteFor - www.competefor.com

The Mayor of London's Green Procurement Code - $\underline{\text { www.greenprocurementcode.co.uk }}$

Freight Operator Recognition Scheme (FORS) - www.tfl.gov.uk/fors

Skills for Low-Carbon Economy: http://skills4lowcarboneconomy.co.uk 


\title{
CHAPTER 6.
}

\section{ENABLING GREEN GROWTH IN LONDON}

\author{
By Mads Greaker
}

\begin{abstract}
In this chapter we analyse the prospects for green growth in London. This chapter includes a section with policy issues related to the green economy and an analysis of the London low-carbon actions. The chapter identifies barriers that hinder the development of a low-carbon economy and provides a set of recommendations to overcome these obstacles.
\end{abstract}

\section{Introduction}

The effect of Greenhouse Gas (GHG) emissions on global warming is independent of source and location. Countries have therefore aimed to tackle the climate challenge at an international level. Hence, any economic agent (firm, country or region) about to incur costs in order to reduce GHG emissions should reflect upon how its actions fit in with the actions taken internationally. The current international climate policy regime has many layers, ${ }^{1}$ which add important constraints to countries, cities and regions if they are to remain competitive.

The EU has reported its triple 20 target (the triple 20 target refers to a $20 \%$ reduction in GHG levels from 1990, increasing the renewable energy share to $20 \%$ and realising energy savings amounting to $20 \%$ reduction in energy usage) and intends to meet this commitment independent of whether there will be a second commitment period in the Kyoto treaty. Other countries also have targets, which are recorded in the Copenhagen Accord. Some of the countries, like Norway, also plan to reach their targets by use of the flexible mechanisms of the Kyoto Protocol.

In addition to countries setting emission reduction targets, municipalities within countries have also set their own GHG emission reduction targets. One such example is London. The city of London aims to reduce its carbon emissions by $60 \%$ from 1990 levels by 2025. Thus, for London the hierarchy of GHG emission reduction targets can be synthesised as follows:

Due to the flexible mechanisms in the Kyoto Protocol, any target fulfilment at a lower level tends to be counter-balanced by higher emissions at a higher level. For instance, the UK's emissions are a part of the EU's emissions. Hence, if the UK increases its emission reduction target from $34 \%$ to $40 \%$ without at the same time getting other EU members to agree on a stricter target, the increase in the reduction from the UK may lead to other EU member states seizing the opportunity to emit more. The same also holds for London versus the UK. If London reaches its ambitious emission reduction targets, businesses and households outside London may be able to emit more than they would have done with a less ambitious target for London (more in line with the target for the rest of the UK). In both cases the excessive GHG abatement by some countries/regions will free emission permits for the EU ETS market, and allow firms in other countries/regions to buy these at lower prices inducing them to abate less. 
Figure 6.1. Hierarchy of emission targets

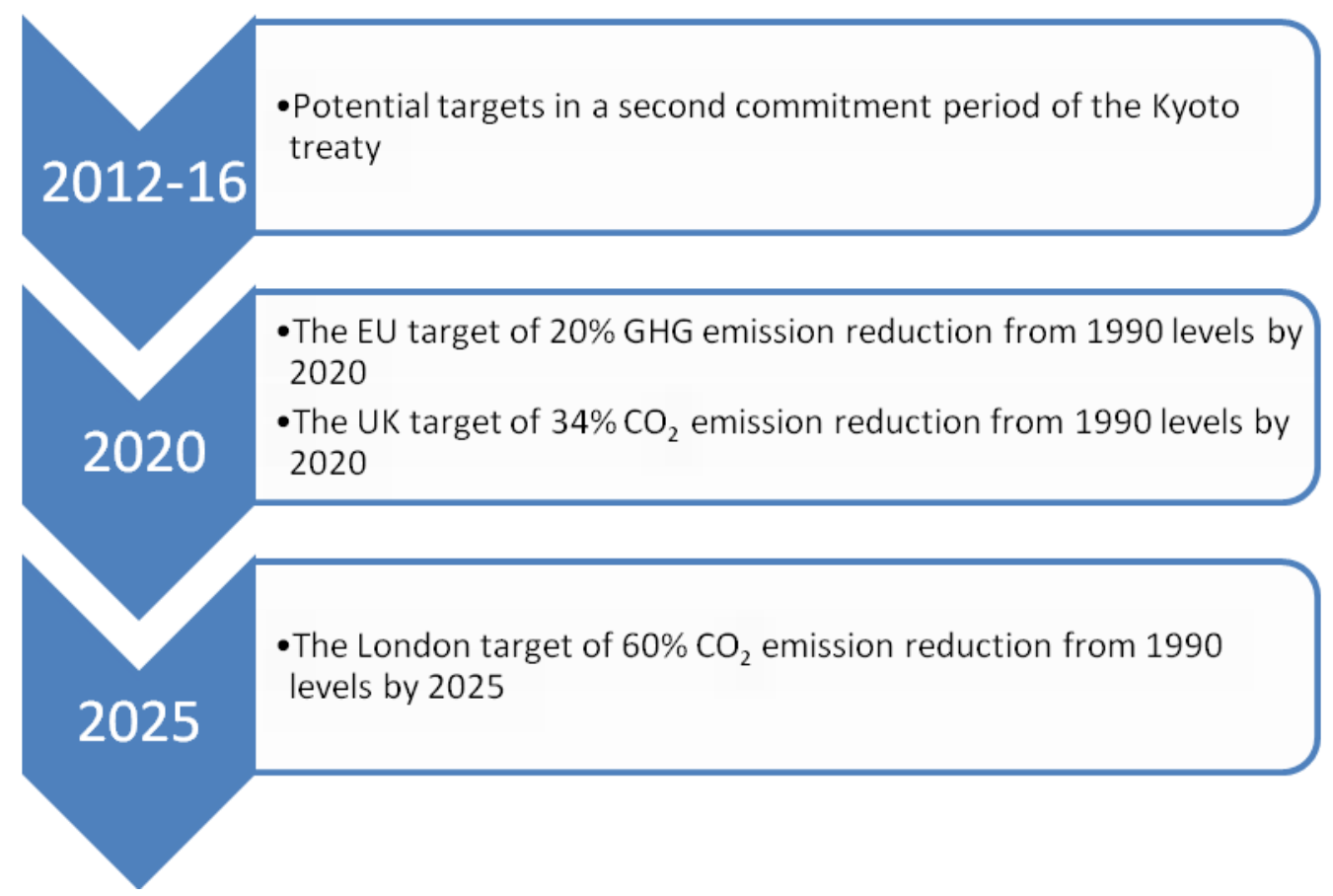

In reaching the emission reduction targets the EU, the UK, and London can choose among three key options:

- Carry out GHG abatement within own jurisdiction

- Acquire emission rights from the EU Emissions Trading System (EU ETS)

- Carry out Clean Development Mechanisms (CDM) projects

The city of London does not plan to use emission right acquisitions in the EU ETS or the CDM to reach its emission reduction target. Moreover, in order for the fulfilment of the emission reduction target to be considered successful, the Mayor also aims to have the following co-benefits realised:

- Growth in the number and size of so-called low-carbon firms i.e. an expansion of the green business sector

- A reduction in the rate of unemployment in the city of London (which is higher than for the rest of the UK)

A carefully designed skill development programme is seen as essential for the fulfilment of the cobenefits. A combined fulfilment of all three targets; 1) Emission reductions, 2) Expansion of the green sector, and 3) Reduction of unemployment will henceforth be referred to as "green growth". The focus of this chapter is to discuss how and to what extent green growth can be realised.

\section{Policy issues}

Keynesian counter business cycle policies

The financial crisis that hit the world in 2008 led to increased unemployment and reduced growth. According to Keynesian economic theory governments should then increase spending and run a counter business cycle policy. Many argued that governments at the same time should pay attention to green goals. 
That is, they should increase their total spending, but use the increase in spending to transform the economy in a greener direction (see e.g. Edenhofer and Stern, 2009). In order for Keynesian counter business cycle policy to work, total demand must increase. Moreover, the increased spending should ideally be directed towards labour intensive sectors.

Providing cheap loans for energy efficiency measures both in businesses and in residential homes is one way of increasing total demand. Moreover, even though some policy instruments like information campaigns do not increase total demand, demand may be spurred locally. That is, instead of spending their income on goods that are imported into London, households engage local firms for greening activities such as loft insulation etc. On the other hand, some of the policies planned in the UK and in London are not of the Keynesian type. For instance, feed-in tariffs leading to heavy instalment of PVs (solar photovoltaics) in private homes do not increase total demand as long as the feed-in tariffs are financed by higher electricity prices. Households may profit on the feed-in-tariff and hence, increase their spending, however, this will be counterbalanced by reduced spending in the sectors not benefitting from feed-in tariffs (i.e. electricity customers getting a higher energy bill, and hence, having to reduce their consumption on other goods).

\section{Increasing economic efficiency}

Many economists (and policy makers) do not believe in Keynesian counter business cycle policies. On the other hand, as long as policies unlock current inefficiencies in the economy, growth and demand will be spurred independent of whether total demand is increased. This is also pointed out by Edenhofer and Stern (2009) with respect to energy efficiency.

More recently, economists have come to understand additional market failures that may operate in the adoption and diffusion of new technology. For a number of reasons the cost or value of a new technology to one user may depend on how many other users have adopted the technology. This type of "increasing returns" may be created by learning-by-using, learning-by-doing or network externalities, and could be a feature of second generation energy saving products. Whenever successful diffusion implies increased economic efficiency, there may be a role for the state supporting the initial diffusion phase of the new technology.

Adoption of new technologies may also be hindered by principal-agent problems, and by cognitive costs (also coined bounded rationality i.e. consumers and firms do not act fully in their own self interest). For instance, if the purchaser of a new house has incomplete information about the energy use in houses, the builder may not be able to recover investments in energy saving building solutions. If made credible and understandable to consumers, an energy classification scheme could overcome this market imperfection. Cognitive costs may likewise lead house owners not to invest in profitable energy saving measures. Relevant types of cognitive costs in this respect are discounting the near future by a too high interest rate (hyperbolic discounting), and rules of thumb decision making not yet adapted to the new technology. ${ }^{2}$ Again the government may improve the workings of the economy by supporting the initial diffusion phase of the new technology. However, this need not be by providing various kinds of subsidies, but could be by information campaigns or by introducing new design standards.

A better transport system which reduces the time people spend in traffic jams may also improve economic efficiency and pollution levels. Transport is an important issue for world cities like London, and many alternatives are being sought in order to reduce the pressure on the environment and the economy. 


\section{The Porter hypothesis}

According to Porter (1991) and to Porter and Linde (1995) governments can tighten their level of environmental regulation, and firms will find that they become more competitive, not less. This has come to be coined the Porter-hypothesis. The Porter-hypothesis is disputed among economists; see for example Palmer, Oates and Portney (1995). The dispute seems partly to originate from different interpretations of the hypothesis, and some contributions in the economic literature indicate that a Porter-type mechanism may indeed exist - for instance, that a stringent environmental regulation could increase export output through more innovation. ${ }^{3}$ Moreover, an econometric study from Norway by Golombek and Raknerud (1997) suggested that a strong environmental policy spurred employment and induced a lower probability of exit from some industries, notably pulp and paper and iron, steel and ferroalloys.

Setting a more stringent environmental policy than comparable regions/nations, will also increase demand for environmentally friendly goods and services locally, and may constitute an opportunity for local firms. In particular, if the industry is characterised by strong learning-by-doing effects ("the more you have done, the cheaper you do it"), being a part of an initial wave may be necessary in order for the national sector to be a significant part of the international industry in the longer term. With respect to energy savings in homes and smaller businesses, there could also be a learning-by-using effect ("the more you have bought, the more you benefit from having it"). In this case establishing a highly skilled market, could attract firms wanting to further improve their services.

\section{Analysis of London}

\section{Climate policies}

London's GHG emissions are calculated by London Energy and Greenhouse Gas Inventory (LEGG). The compositions of emissions from London city are: Workplaces 43\%, Homes 36\% and Transport 21\% (see Chapter 3). Electricity use in London is translated into GHG emissions by LEGG. That is, electricity is produced outside London by a mix of coal, gas and nuclear plants, and the electricity usage is converted to emissions by some year specific factor. Partly, this is the reason why homes and workplaces have such high shares of emissions. Clearly, use of natural gas and other fossil fuels for all kinds of heating purposes is also important.

The emission reduction policy of London has three target areas:

1. Increase decentralised energy production in London by small scale renewable electricity installations and by generating heat and power from waste

2. Energy saving efforts such as better isolation of buildings, and reducing the energy use for other purposes than heating (boilers, electrical appliances etc.)

3. Reduce emissions from the transport sector by a transition from cars to bicycles and walking, and increasing the number of low-carbon vehicles

Target areas one and two will reduce emissions either directly through reduced use of fossil fuels for heating purposes or through reduced use of electricity which is produced outside London, partly by fossil fuels, but is calculated as emissions from London.

Within each of the areas there are a number of planned measures. Most of the measures will be introduced by the national government, and will also impact London's carbon emissions. However, some measures seem to be special for London (see the website of the UK Department of Energy and Climate Change and The Low-Carbon Capital, 2010). Table 6.1 lists the policies. 
Notice that very few measures are special for London. Most measures will be introduced on a country wide scale based on the UK Low-Carbon Transition Plan. However, some of the measures, for instance "interest free loans", "smart meters", "pay as you save schemes", "transport modal shifts" will only be successful if administered in a proper way by the local authorities. Herein, lays a major challenge for London. Finally, it should be noticed that specific carbon taxes are not in use in the UK. This also holds for natural gas which is a major contributor to London's carbon emissions.

\section{Energy efficiency measures}

Subsidising energy efficiency investments will likely lead to two types of faults. Firstly, energy efficiency measures that would have been carried out anyhow will receive subsidies, for instance as a cheap loan, which puts an unnecessary strain on public finances. Secondly, non-profitable energy efficiency measures which should not have been carried out, will be carried out. It is the latter which is the major problem since non-profitable measures do not increase economic efficiency. Likely, there exist very clever business models that can i) identify the real energy saving projects, and ii) provide financing models that targets the profitable projects that would not have been carried out without the subsidy (for instance, cheap loans). In order to craft such a model, one probably has to know more about the type of market imperfections and/or cognitive costs obstructing profitable investments from being carried out today. The green deal initiative of the new government looks very interesting in this respect (see The Green Deal, 2010).

Table 6.1. "List of climate policy measures"

\begin{tabular}{lcc}
\hline Measure/Coverage: & London & Great Britain \\
\hline Increase electricity production from low-carbon sources & $\mathrm{X}$ & $\mathrm{X}$ \\
\hline Feed-in tariffs (small scale renewable electricity production) & $\mathrm{X}$ & $\mathrm{X}$ \\
\hline Increase heat production from waste & $\mathrm{X}$ & \\
\hline Solar thermal water heating on roof & $\mathrm{X}$ & \\
\hline Interest free loan for energy saving & $\mathrm{X}$ & \\
\hline Installing smart meters in homes & $\mathrm{X}$ & $\mathrm{X}$ \\
\hline Piloting "pay as you save" for energy efficiency investment & $\mathrm{X}$ & $\mathrm{X}$ \\
(Green deal as announced by DECC, December 2010) & & $\mathrm{X}$ \\
\hline Introduce energy classification scheme for property & $\mathrm{X}$ & $\mathrm{X}$ \\
\hline EU ETS & & $\mathrm{X}$ \\
\hline Decrease emission intensity of private car transport & $\mathrm{X}$ & $\mathrm{X}$ \\
\hline Transport modal shift e.g. from cars to bikes & $\mathrm{X}$ & $\mathrm{X}$ \\
\hline Pilot the use of electric cars & $\mathrm{X}$ & $\mathrm{X}$ \\
\hline Decrease emissions from agriculture & & \\
\hline
\end{tabular}

\section{Transforming the labour market}

As analysed in Chapter 4, there are a number of barriers to adjusting the labour market to the demands of the low-carbon economy. Indeed, some new technologies require training and certain certificates such as certificates for the instalment of solar panels in homes eligible for feed-in tariffs. Others only require training such as solar thermal water heating.

Certification entails a cost for the firm. The cost consists of yearly fee plus a fee per instalment. These payments finance the certifying body. Of course, the fees also increase the end-user price of an instalment. In particular, the fee per instalment could lead to a non-optimal level of instalments since the cost to the 
certifier of an additional instalment is zero (as long as they do not check instalments, but only certifies the firms). Thus, it should be considered to only finance certifiers by a once and for all certification fee.

Manufactures may differentiate their systems with respect to design (to reduce competition) such that one type of training is not adequate for all systems. It also seems like manufacturers are resisting standardisation. There could be scale advantages in the skill attainment process which will be harder to realise due to lack of standardisation.

There is currently no definition of a "green job" or a "low-carbon" job, although some low-carbon sectors have been identified and a detailed breakdown of sub-sector activities has been provided in a report prepared for London (see DTZ, 2010). It also seems like "green skills" do not refer to any particular type of skill. However, green technologies may demand that artisans acquire cross-disciplinary skills. Many new technologies also rely more heavily on computers running heating, lightning etc., and are thus requiring a higher knowledge of computer usage. This may make it even harder for unskilled or lower skills to participate in the green economy.

It is hard to identify a particular, new type of skill being essential for the transformation to a lowcarbon economy. It is more about attitudes. Some skills in shrinking economic sectors may be well fitted to fill positions in emerging sectors in the low-carbon economy. A lot of the measures do not seem to require a radical shift of technological understanding. Job Centre Plus has not felt any special pressure in the area of green jobs yet. Some isolated training programmes have been put in place but there is no real strategy behind.

\section{Green industrial policies}

The most successful green business sector in London so far is the carbon finance sector. This sector helps firms trading in the EU ETS, and facilitates trading with other instruments such as CDM and JI (see above). In order to succeed in combating climate change, emission permit trading is regarded by most analysts as crucial. The abatement costs of reaching any global emission reduction targets skyrockets if extensive emission trading is not carried out (OECD, 2008).

The UK Department of Business has a low-carbon business team. This team targets green sectors other than the carbon finance sector. There is also a low emission vehicle department. The UK considers the following green sectors, other than the carbon finance sector, to be potential growth sectors: off-shore wind and electric vehicles. According to information provided with respect to electric cars, a potential "cluster" could be developing around Birmingham. Furthermore, the OECD team was informed that there is a quite successful firm that has developed a small scale "vertical axel" windmill in London. This windmill is not geared towards grid connection, but for direct building connection.

The UK Department of Energy finances an organisation called Carbon Trust. Their focus is to provide information to firms about business opportunities within the low-carbon economy both abroad and at home. In particular, they consult firms on how to reduce their energy bills, and provide inexpensive finance to energy saving projects. They also help entrepreneurs getting started with new carbon saving innovations.

There are firms specialising in homes insulation which retrofit homes with either loft insulation, external wall or inside wall insulation. A typical insulation job costs GBP 1500 and saves GBP 200 per year. Clearly, the house owner experiences some inconveniences during the process. These are real costs, but are normally not counted by engineers looking at energy saving projects.

Some of these firms have also started with solar PV due to the feed-in-tariff. A common business model is that firms agree with house owners to "rent" their roof for the installation. The house owner has 
no investments, and gets as much electricity as s/he wants from the PVs, while the installation firm gets most of the left over proceedings from sales.

\section{Business development in London}

There is a lot of innovative capacity in London that is currently not being exploited to its maximum. Indeed, there is evidence of the presence of large businesses and major economic sectors (e.g. finance) but there is a real lack of critical mass when it comes to smaller businesses, those that could be potentially linked to the activities of the larger corporations and supply the activities of low-carbon sectors in expansion. Two main reasons may be identified, one directly related to the lack of green entrepreneurship and a second one to the limited business support programmes.

On the green entrepreneurship side, universities, business centres and even Job Centre Plus may build capacities internally to better understand the opportunities arising in the low-carbon economy and, hence, provide quality advice to potential entrepreneurs (young people, jobseekers, etc.) who may be willing to venture in this sector. Building an entrepreneurial culture is the responsibility of both formal education systems and informal capacities (attitudes) that may be bred in the population. The former can be achieved in collaboration of $\mathrm{HE}$ and $\mathrm{FE}$ institutions, while the latter can benefit from a more effective communication strategy that highlights the market opportunities.

On the support schemes, R\&D subsidies and/or other forms of subsidies are very limited in London. These are widely used to help green sectors gain market shares in the early stages of their development. Whenever international markets are not perfectly competitive, government support of national firms will influence the international market structure, and could shift market shares and profits from foreign firms to domestic firms. R\&D subsidies have proved to be most robust to various forms of competition. A problem is of course that most nations and/or regions think in the same way. However, it is probably still a best response to provide subsidies for environmental R\&D. Another possibility is to provide subsidies to investments in the new industries. Subsidies may be given directly as cheap loans, direct public support etc., or indirectly through intervention in markets by instituting green certificates and other renewable standards. ${ }^{4}$

At the same time as we note these cases for subsidies, it is also necessary to point to a warning: there is a clear public choice problem, in that strong, concentrated interests will be in favour of financial support for specific industries, with largely invisible and spread out costs of these policies. For this reason, an independent perspective on these issues is especially important.

\section{Opportunities and Challenges for London}

\section{Strengths}

Spare capacity in the economy

Due to the financial crisis there is spare capacity in the economy (unemployment), which may be utilised in public sector projects such as district heating, bicycle highways, large scale home insulation etc.

\section{Highly educated and innovative population}

London has a highly innovative and well educated population which could generate the new ideas needed for the transition to a low-carbon economy. One challenge is to find business models that with limited state support unlock only the profitable energy saving measures, and is able to discriminate against profitable projects that would have been carried out anyway (see above). 


\section{London's strong position in carbon finance}

London has a very strong position in carbon finance, that is, facilitating buying and selling of emission permits in the EU ETS, in joint implementation (JI) projects and in CDM markets. These instruments are seen as essential for a global solution to the climate problem. As mentioned, Article 3.3 in the UNFCCC says that nations should aim to achieve the necessary global emission reductions at the lowest possible costs. However, London does not seem to plan to use this opportunity when fulfilling the emission targets.

\section{Weaknesses}

London's climate policy may not work as a "Keynesian demand" policy

The link between the current green firms located in London and the demand for new green solutions in London may be weak. That is, the current green firms in London may be geared towards demand from the sectors outside London i.e. the rest of the UK and internationally. This seems to hold for the large carbon finance sector of London which is geared at large firms covered by the EU ETS and nation states that plan to fulfil their emission reduction obligations by acquiring emission permits abroad. Moreover, the Mayor's emission reduction targets and the corresponding climate policy measures may be triggering the response of firms situated outside London. One example is solar PV firms which are called to supply PV panels to London's roofs. Another example is producers of consumer durables who may benefit from a surge in demand for more energy efficient appliances.

\section{Reaching the emission reduction target could prove to be prohibitively costly}

It is very hard to know in advance how costly it is to reach a given emission reduction target - GHG abatement costs are uncertain at the time of writing. Even if all profitable energy efficiency improvements are realised, it is unlikely that the emission reduction target will be reached. Thus, in order to reach the target, emission reduction projects with a net cost to the economy must also be carried out. These projects will only be carried out if supported by the London government, or if there is a cost to the firm of emitting (carbon tax). If firms expect the London government to back off from supporting emission reduction projects with a net cost, they may hesitate investing in the green economy. A target for the price of emission reductions may be more credible than an absolute emission reduction target. That is, it is possible to specify the target as: all emission reduction projects with a cost below GBP x per tonne GHG will be supported by the London government.

\section{Lack of measuring criteria}

There is no agreed opinion of what a "low-carbon economy" looks like for London. There is also no definition of "green jobs" in London, although some low-carbon sectors have been identified and a detailed breakdown of sub-sector activities has been provided in a report prepared for London (see DTZ, 2010). This lack of measuring criteria to identify what is "green" or what is considered "low-carbon" leads to confusion. Firstly, this makes it difficult to measure whether policy targets are met. Secondly, it makes crafting relevant green skills training programmes more difficult.

\section{Lack of clarity for businesses}

Likewise, there is a lack of clarity in the market prospective for green businesses. Thus, businesses may lack the necessary confidence to start investing or expand in the low-carbon sector. There may also be too many different funds, institutions, etc., and businesses could find it hard to afford the costs of finding the information and going through the application process. 


\section{Not making full use of businesses' potential}

Finally, green businesses with large growth potential located in London today have not been thoroughly identified. Clearly, artisan firms will be employed for home insulation, for installing energy efficient home equipment and for small scale electricity production at homes. However, there must be more opportunities; for instance, integrated firms that provide systems for so-called intelligent homes and buildings where all energy usage is monitored (referred to as "second generation energy efficiency" above).

Another potential growth business could be intelligent charging stations for electric cars. Electric cars may become a valuable resource for an electric power system especially when based on a large share of renewables. For instance, they could provide vehicle-to-grid services such as energy storage and peak hour supply. In a recent study with point of departure in the Texas power system, Sioshansi and Denholm (2010) show that a large fleet of plug-in-hybrids both provides significant benefits to the system and to the owners of the cars.

\section{Clarification of position towards carbon leakage}

London's emissions are monitored by London Energy and Greenhouse Gas Inventory (LEGG). They do not include emissions from the production of goods and services consumed in London except from electricity. Nearly all emission reduction measures taken in London will have leakage effects. For instance, if London reduces the "import of electricity" through roof based solar PV installation, emissions from London will be reduced. However, since the whole electricity sector in Europe is covered by the EU ETS, London's saving in emissions will be fully replaced by increased emission elsewhere. That is, if the UK electricity sector reduces its production due to London's initiatives, emission permits will be released to be used elsewhere. Moreover, if London increases the use of biofuels in transport, carbon emissions as measured by the LEGG, will decrease. However, according to recent research, also cited in The UK LowCarbon Transition Plan (2009), increased use of biofuels in the UK leads to increased emissions elsewhere. The leakage problems of London's Low-Carbon Capital plan could easily backfire. Businesses or consumer groups that dislike new climate policy measures will invoke leakage arguments for not carrying the measures out.

\section{Opportunities}

\section{First mover advantage}

London may gain a first mover advantage in the green business sector. This first mover advantage consists of many elements which should all be in place: London may attract high skilled people that prefer to live in a low-carbon society. Further, London may get a highly educated market, that is, many of the solutions for energy saving in building require quite skilled consumers (home owners). If London moves ahead here, it could attract innovative firms in this sector wanting to try out their products/systems in the most advanced market.

\section{Increasing economic efficiency}

Most experts on housing construction believe that there are plenty of profitable energy projects waiting to be carried out in both the business and private homes sector. These projects are profitable at current prices, and the riddle is why they are not carried out by the market forces. Several explanations exist: information asymmetries, myopic consumers, incentive structures in the housing market etc. If such market failures exist, policies that unlock them will lead to economic growth. For instance, every house owner that realises a profitable energy saving project will increase their lifetime income. This increase in 
income will, as long as not all is spent on increasing the amount of leisure, increase aggregate demand for investment and consumption.

\section{Other opportunities}

London will experience emissions reductions due to actions taken elsewhere. For instance, the UK aims at getting $40 \%$ of its electricity from carbon free sources by 2020 . This will automatically reduce emissions as measured by the LEGG.

\section{Threats}

\section{First mover disadvantage}

London is aiming to move ahead with respect to realising the low-carbon society. Moving ahead implies that you will have to pioneer many new solutions. This is in itself costly as most of the costs of the trial and error accrue to the first mover. Moreover, the first mover may end on a dead-end e.g. the first mover may choose technologies that are not chosen by the rest of the world when they later decide to go ahead. The French Mini-tell system, a pre-internet service, is one such example. The French had to abandon their system, and it does not seem like the Mini-tell gave the French a first mover advantage with respect to the internet of today.

\section{Sub-optimal climate policies}

The emission reduction obtained in London may result in increased emissions elsewhere in the UK and in the EU. London's efforts may be optimal for London, but sub-optimal for the UK as a whole. For instance, costly solution implemented by subsidies in London may displace less costly solutions elsewhere which will hurt the economy of the UK. One example could be investing in a waste heat plant. If in evaluating the investment the benefits of reduced carbon emissions are pivotal for the project to be carried out, we have an example of economic inefficiency. Carbon emissions will only be reduced by the way the LEGG calculates. However, as long as total carbon emissions from the UK are given by The UK LowCarbon Transition Plan (2009), there will be no real net reduction in emissions.

\section{Subsidising inefficient solutions and firms}

While there may be many profitable energy saving project, there are certainly also many unprofitable. If policy unleashes too many of the latter, the economy may not benefit from a net efficiency gain.

With respect to businesses, economists have long tried to persuade politicians from "picking winners" among future growth sectors and from channelling support to those winners. The problem is twofold. Firstly, it is hard for anyone to identify winners, and secondly, all kinds of firms will waste resources trying to convince politicians that they are the likely winners. The first priority of London should therefore be to choose the most efficient climate policy measures without looking at the business opportunities, and hopefully, new businesses will arise as the market shifts its demand to more green solutions. The Porterhypothesis is precisely about that: the government only needs to enforce an efficient environmental policy, and in many instances, it will find that businesses bloom.

\section{Public finances in the UK}

Public finances in the United Kingdom are in great strain. Budgets have to be significantly cut. In itself this will decrease demand, and may lead to increased unemployment across the UK. Moreover, it will be increasingly hard to use subsidies to kick-off the green economy. 


\section{Recommendations for London}

\section{Work towards realising only profitable energy saving projects}

\section{Unlock inefficiencies in the economy}

The essence of green growth is to unlock inefficiencies in the economy. Wasteful use of energy is very likely one such inefficiency. With generous subsidies to energy efficiency, investments such as free loans, pay-as-you-save schemes etc., there is a risk that also many unprofitable energy saving projects will be carried out. The Green Deal Initiative of the new government is aiming to deal with these issues, (see e.g. "the golden rule" in The UK DECC Green Deal, 2010). However, it could invoke high transaction costs in the process of identifying profitable projects and high financing costs due to the unusual way the investment is financed and the payments are administered. The London City administration should think of clever ways to support this initiative in its early stages.

\section{Better identification of growth sectors and training needs}

Even though London's government should be careful in trying to pick and channel support to likely "winners", it may still be of great value to present detailed future scenarios of what a greener London will look like. More work could be done in this area; for instance, how many full-time jobs of the different types will be created if a large share of London homes get improved insulation, a roof top solar PV and new boilers? Moreover, how many charging stations are needed if a significant share of London's cars is to become electric? And, what is the gain of making it possible for the cars to sell electricity to grid in times of shortages? What technology and skills are needed for this? What will it require to transform a certain share of London building into smart buildings in terms of skills, number of new jobs, costs etc.? It will reduce information costs in the private sector, and help investors allocating their capital. It can guide public training programmes; it will help students choose their study subject etc. The scenarios should be communicated widely.

\section{Remove barriers to green growth}

\section{Ensure that the climate policy targets are realistic}

As mentioned, if the emission targets are not realistic, businesses and professional investors will hesitate to invest in the green economy. One way of making the target more credible is to not have an absolute emission reduction target for the city, but rather a target price for emissions reductions and allow CDM projects to be counted. This will serve as a hedge towards being forced to abandon the target if costs prove too high. It should be possible to specify the target as: all emission reduction projects with a cost below GBP x per tonne GHG will be supported by the London government. Given that it is not possible to introduce a carbon tax, the support could be either subsidies or new mandatory standards.

London should also have a strategy towards carbon leakage as the lack of such a strategy may also weaken the credibility of the emission reduction targets. One possible strategy is of course to say that leakage should not be considered when choosing among climate policy projects. Another strategy is to say that measures with a high degree of carbon leakage should be avoided. This would require a method for calculating the extent of carbon leakage. Finally, London should have a rationale for why London might want to depart from global cost efficiency, that is, carry out GHG emission abatement projects that involves a higher cost per tonne emissions reduced than available projects outside London. One rational could be that London wants to promote a specified set of new technologies. 


\section{Consider realising projects abroad}

London should consider co-operating with one or more similar cities in Non-Annex 1 countries. London could utilise its large carbon finance sector to find suitable cities and CDM projects. Through this, London would take a more proactive stance towards the global dimension of climate change. According to the presentation given by the UK based Carbon Trust they are already working with China in this area. However, further work could be done by Carbon Trust to expand the market opportunities for Londonbased businesses abroad. Finally, London could provide real global GHG reductions. If London carries out CDM projects that are not counted as UK CDM projects, London's efforts will reduce global emissions i.e. have no leakage.

\section{Provide business support in the long term}

London may consider the installation of grants or subsidies for business creation and growth in the low-carbon economy. This, together with good quality advice/guidance, may support the development of businesses in the low-carbon economy, reaching a critical mass needed to grow the well established lowcarbon sectors and enable the emergence of new other sectors. Procurement measures can be also applied for business-to-business trade. London may also directly support businesses and individual consumers with subsidies, tax incentives or other benefits for purchasing particular eco-products and services such as renewable energy, energy-efficient electronics and green buildings in order to stimulate demand (OECD, 2010). This is an approach to proactively use demand support measures to shift the course of technology and product development. However, it would be important to engage in such support schemes in the longer term as "changing minds" is damaging for businesses already established, as well as for business creation as it causes uncertainty. 


\section{ENDNOTES}

${ }^{1}$ First, there is the UN Framework Convention on Climate Change from year 1992 (UNFCCC). The convention has as its ultimate objective to stabilize concentrations of green house gasses (GHGs) in the atmosphere at a level that prevents dangerous anthropogenic inferences with earth's climate system. The UNFCCC also sets forth some central principles: Article 3.1 states the principle about common but differentiated responsibilities, which is understood as demanding that in an initial phase of GHG mitigation the developed countries must bear a lion's share of the mitigation costs. Moreover, Article 3.3 says that nations should aim to achieve the necessary global emission reductions at the lowest possible costs.

In the next layer, the Kyoto protocol was negotiated under the UNFCCC. The Kyoto protocol sets a common quantitative GHG emission ceiling for the period 2008 to 2012 for the developed countries listed in Annex I to the UNFCCC (henceforth called the Annex 1 countries). The Kyoto protocol also distributes the "allowed emissions" among the Annex I signatories to the protocol such that each of these Annex 1 countries has an assigned amount of emission rights. Developing countries like for instance India, Brazil and China, are referred to as Non-Annex 1 countries, and do not have any ceiling on their emissions in the Kyoto protocol.

The final layer in the international climate policy regime is the institutions established by the Kyoto treaty in order to facilitate cost efficient emission reductions by the Annex I countries. In short, they can either abate emissions from their own territory by national climate policy measures or use the flexible mechanisms built into the Kyoto protocol. These are buying and selling emission rights among the Annex I countries through markets for emission rights like the EU ETS or through so-called Joint Implementation (JI) projects, and by buying emission rights from Non-Annex I countries through the Clean Development Mechanism (CDM).

It is currently unsure whether the Kyoto protocol will be extended beyond 2012. Emission quota trading between Annex I countries will however continue. For instance, the EU has already set targets for the allocations of emission permits to the EU emission permit market (EU ETS), for the period 2012 to 2020. Moreover, it is likely that the CDM institution will continue as long as countries use it. Beyond 2012 there may be a regime in which countries and regions set their own GHG emission reduction targets. A hint in this direction is the Copenhagen Accord. In the Copenhagen Accord (2009) a majority of the signatories to the UNFCCC agreed to set a target of no more than 20C temperature increase. Moreover, they were asked to report their national GHG emission reduction target.

${ }^{2}$ See Thaler and Sunstein (2008) for an introduction to cognitive costs.

${ }^{3}$ See Greaker (2006) for an example of a Porter-type mechanism.

${ }^{4}$ See Greaker and Rosendahl (2008) for an analysis of strategic trade policy in the case of environmental goods and services. 


\section{REFERENCES}

DTZ (2010), Skills for a Low-Carbon London, DTZ, London

Edenhofer O. and Stern N. (2009), Towards a global green recovery, Report submitted to the G20 London summit

Golombek R. and Raknerud A. (1997), Do Environmental Standards Harm Manufacturing Employment?, Scand. J. Econom. 99(1), p. 29-44

Greaker M. and Rosendahl K. E. (2008), "Environmental policy with Upstream Pollution Abatement Firms", Journal of Environmental Economics and Management 56, p.246-259.

Greaker M. (2006), "Spillovers in the Development of New, Pollution Abatement Technology: A New Look at the Porter Hypothesis", Journal of Environmental Economics and Management 52, p. 411420 .

London Development Agency (2010), The Low-Carbon Capital, London

IPCC (2007), A Summary for Policymakers. In: Climate Change 2007: The Physical Science Basis. Contribution of Working Group I to the Fourth Assessment Report of the Intergovernmental Panel on Climate Change, Solomon, S., D. Qin, M. Manning, Z. Chen, M. Marquis, K.B. Averyt, M.Tignor and H.L. Miller (eds.). Cambridge University Press, United Kingdom and New York, USA.

Palmer K, Oates W. E. and Portney P. R., Tightening Environmental Standards: The Benefit-Cost or the No-Cost Paradigm?, J. Econom. Perspec., 9, p. 119-132 (1995)

Porter M. E., America's Green Strategy, Scientific American, Apr., p. 168, (1991).

Porter M. E. and C. von der Linde (1995), Green and Competitive, Harvard Business Rev., Sep-Oct 1995.

OECD (2010), Eco-Innovation in Industry: Enabling Green Growth, Paris

OECD (2008), World Environmental Outlook 2008, Paris

Sioshansi R. and Denholm P. (2010), The value of Plug-In-Hybrid Electric Vehicles as Grid Resources, Energy Journal 31, p. 1-19.

Stern Review Report (2006): The Economics of Climate Change, HM Treasury, London, (available online at: www.hmtreasury.gov.uk/independent_reviews/stern_review_conomics_climate_ change/stern_review_report.cfm.)

Thaler R. H. and Sunstein C. R. (2008), "Nudge", Penguin Books.

UK Department of Energy and Climate Change (2010), The Green Deal: A summary of the government's proposals. 


\section{ANNEX A: LEARNING MODELS}

This section provides some practical examples (learning models) to the London authorities to illustrate some of the approaches and recommendations suggested in the report. These models cannot necessarily be replicated in London as the local context needs to be taken into consideration. However, these models do intend to provide some practical guidance on how similar challenges were dealt with in other places that could be of inspiration for London. The following examples are included in the annex:

Table A.1. Synthesis of learning models

\begin{tabular}{|c|c|c|}
\hline Model & Region (country) & Recommendation/Approach \\
\hline ‘Cool City Sakai' Plan & Sakai (Japan) & $\begin{array}{l}\text { Strengthen collaboration with large businesses. } \\
\text { Involve HE and FE in larger low-carbon projects. }\end{array}$ \\
\hline A ‘Demonstration’ city & Baoding (China) & $\begin{array}{l}\text { Grow your market internationally in collaboration } \\
\text { with the private sector }\end{array}$ \\
\hline The Wise Group & Glasgow (UK) & $\begin{array}{l}\text { Support government actions through social } \\
\text { enterprises }\end{array}$ \\
\hline TransverS'AL & Alsace (France) & $\begin{array}{l}\text { Identify transferrable skills and make the } \\
\text { information available to a wide audience }\end{array}$ \\
\hline Green Public Procurement & Basque Country (Spain) & $\begin{array}{l}\text { Definition and implementation of common GPP } \\
\text { criteria in collaboration with the private sector }\end{array}$ \\
\hline $\begin{array}{l}\text { Green Skills in Vocation } \\
\text { Education and Training, TAFE }\end{array}$ & New South Wales (Australia) & Green training for private and public sector actors \\
\hline EcoBuy & Vienna (Austria) & $\begin{array}{l}\text { Develop criteria for GPP and involve all of the } \\
\text { public sector in the process }\end{array}$ \\
\hline Eco-primes & Paris (France) & $\begin{array}{l}\text { Stimulate the use of RE:NEW programme by home } \\
\text { owners through incentives }\end{array}$ \\
\hline Cap-and-Trade Programmes & New York (USA) & Using market instruments instead of direct controls \\
\hline $\begin{array}{l}\text { Flexible approach to GHG } \\
\text { emission reduction targets }\end{array}$ & Norway & $\begin{array}{l}\text { Assess the current GHG emission targets and } \\
\text { adjust the actions to meet the target }\end{array}$ \\
\hline
\end{tabular}

\section{'Cool City Sakai’ Plan (Sakai, Japan)}

\section{Description of the Model}

Sakai is located on the edge of Osaka Bay and at the mouth of the Yamato River and has been historically connected to foreign trade and investment. For many years Sakai was a major trading port with major dockyards and a reliance on international trade. In the $18^{\text {th }}$ and $19^{\text {th }}$ centuries it was an autonomous city run by its merchants. Faced with industrial decline, Sakai is reinventing itself as 'Cool City Sakai' with a plan to create a low-carbon metropolis that provides its citizens with 'sustainable prosperity and living comfort'.

The plan depends on Sakai with its traditions of adaptability and trade taking advantage of a rapid shift to low-carbon industries and the creation of world leading technologies and industries. Like London there are ambitious carbon reduction targets $-15 \%$ by 2030 and $60 \%$ by 2050 and like London there are leading financial services clusters and scientific and industrial expertise. To take advantage of both of these, the city has invested significantly in new institutions and demonstrator projects.

The Sakai 'Eco University' has been opened to support new low-carbon clusters. In association with Osaka University it is offering research and tuition specialisms in renewable energy sources such as solar 
and water as well as broader STEM subjects. The universities, government and technology businesses in Sakai have collaborated to invest in a Coastal Low-Carbon Energy Centre Showcase and also to help Sharp build two huge solar arrays - the largest of their kind in the world. Sharp and Kansai are two key large scale businesses and Sakai is hoping that their presence and the clustering of their supply chains in the area will do much to drive further investment and growth in the area.

\section{Relevance to London}

The relevance of the Sakai case study to London relates to focus, investment and branding. Whilst Sakai should not be considered a comparison to London in terms of its size, industries or historical significance, it does show how other cities are delivering massive investment and major long-term economic development aspirations in the global low-carbon economy.

This case shows how such cities (and countries) are investing heavily in market leading green technologies and the research and science that underpin them. Where cities are making such a concerted effort, often in co-operation with the private sector, investing heavily and already beginning to develop a global reputation, it is clear that London should look at how targeted and specific ambitions are playing out. Sakai's is not a 'laissez faire' approach. It is a conscious and significant attempt to pin its industrial future on low-carbon knowledge and technologies. London's low-carbon clusters and knowledge bases are competing globally with such approaches.

\section{Results of the approach}

The two solar plants built in partnership with Kansai Electric Power and used primarily to help power Sharp's factories and other production facilities in the area is called the 'Sakai City Waterfront Mega Solar Power Generation Plan' and the two plants generate 10000 kilowatts and 18000 kilowatts respectively, for a combined maximum output of 28000 kilowatts. This has resulted in a reduced cost of electrical bills for Sharp's factories, raising profits and productivity, creating more jobs and a strengthening of Sakai's and Sharp's 'green' brand and promotion of the city as a location for 'green' technologies.

In March 2010, Sharp also started operations at its new thin-film solar cell plant in Sakai - powered by the solar array. This plant produces thin-film solar cells with a structure in which thin layers of silicon are accumulated onto a glass substrate, enabling a dramatic reduction in the amount of silicon used, to approximately one hundredth the amount used in other solar cells currently in production around the world. The production processes are simpler, thereby lowering production costs. For this reason, the demand for thin-film solar cells, especially for use in large scale photovoltaic power generation, has been steadily increasing throughout the world. The thin-film solar cell plant in Sakai will serve as a model plant for future Sharp thin-film solar cell plants around the world. Sharp will continue to accumulate and enhance its proprietary production technology and its know-how, to meet the world's growing demand for solar cells. The production of these solar cells has also resulted in the creation of more jobs in Sakai and in stronger collaboration projects between the university, Sharp and other related factories enhancing the ecoinnovation system locally.

\section{Reasons for success}

Sakai's ambitions are based on major public and private investment plans and the solar array. The coastal energy centre and the eco-university are all funded by partnerships between national, local governments and leading private sector businesses such as Sharp and Kansai. This investment has been driven by generous tax incentives and generous grants, in turn framed by the Japanese and Sakai governments desire to develop and sustain a global technological advantage in these specific aspects of low-carbon industry. Alongside, the Sakai government has developed a co-operative framework with its 
22 finance institutions in so that they will support and invest in low-carbon businesses spinning out of the universities and the larger industrial supply chains.

\section{Considerations for adoption in London}

This is the level of commitment that London is competing with when it aims to be a world leader in low-carbon industry. In Sakai, it is highly targeted, with significant investment and major new facilities and technologies are in mass production today as a direct result. London should consider making use of its relationships with universities and other actors to build a stronger partnership around the Low-Carbon London initiative. London may also consider further involving the private sector in its activities, building on the presence of large companies in the city and a strong supply chain. London can also take inspiration from Sakai to better brand its plan and communicate more clearly its ambitions to other public and private actors, as well as to its population in general. This will help to strengthen global perceptions of London as a green city and as a home to green industries, technology and 'know how.' Other initiatives that London may consider from Sakai's approach are the definition and implementation of long-term grants and other incentives to drive the market towards a low-carbon economy.

\section{Further information}

Further information on Sakai and its businesses can be found at www.japanfs.org/en/pages/027202.html http://sharp-world.com/corporate/news/080623_1.html

\section{A 'Demonstration' city (Baoding, China)}

\section{Description of the Model}

The Chinese city of Baoding, in the heavily industrialised Hebei province, is attempting to become China's first low-carbon city, with an ambition of creating around 20000 green jobs from its emerging renewable energy industries. Baoding is located around 140 kilometres south of Beijing. It is nearly halfway between Beijing and Shijiazhuang, the capital of Hebei province. Like other Chinese cities, Baoding owes more to a heritage of factory smoke stacks and industrial pollution - relying heavily on coal for its energy consumption - but has been increasingly attracting newer, green tech firms in recent years.

But Baoding represents a focus for Chinese industrial ambitions. They - like London and the UK want to develop world leading expertise, businesses and jobs that will service domestic and global demands for green technologies. Baoding represents China's ambitions - specifically on renewable energy and has seen investment in its colleges, universities and business facilities to that effect.

\section{Relevance to London}

The focus and scale of investment in Baoding is extremely significant. The Chinese authorities alongside many state owned businesses are prepared to invest in the low-carbon opportunities in order to develop a global competitive advantage in knowledge and new technologies. In the case of Baoding they are prepared to open entire new education and research institutions such as the North China Electric Power University in order to boost capacity and applied knowledge. In this sense London is competing with active industrial policy, backed by major investment in countries where competitive advantage in the global low-carbon economy is a clear and sustained policy imperative.

Baoding has eight universities including the recently established North China Electric Power University - designed to bolster knowledge and skills in the green energy sector. Again the contrast with London and the UK is striking. In China (as in Japan) cities are able to secure the resources and investment 
to open brand new universities dedicated to low-carbon industries in very short time. The scale and speed of their reactivity should be a salutary reminder to London as in order to seize opportunities in the lowcarbon economy London has to be able to adjust quicker and to compete with positioning and investments of this kind.

\section{Results of the approach}

Baoding has become China's new 'power valley', attempting to transform itself into a low-carbon city, and becoming an industrial base for the production of clean and renewable energy related technology and products. Yingli Solar in Baoding is one of the leading manufacturers of photovoltaic products in China. When it first opened the company had 30 employees. Today, the company employs a workforce of around 7000 . With a successful exporting business to the US and Europe, the company was listed on the New York Stock Exchange in 2007, and the following year their total turnover rose to an equivalent of around USD 1.2 billion and profits close to USD 200 million. The year 2009 saw growth reach $91.5 \%$ compared to the previous year.

Baoding city has one of China's biggest plants which manufacture blades used in wind turbine generators, catering mainly to the domestic market. The state owned Tianwei Wind Power Technology is one of the three main plants in Baoding that produces wind turbine generators. It wheeled out its first 20 turbines in 2008 and it will produce 150 units in 2009 and another 500 in 2010 and further growth to 1500 per year in the future. China has also surpassed the United States as the world's largest market for wind turbines, and during the past four years it has been doubling installations each year - with much of the output based in Baoding and its surrounding areas.

\section{Reasons for success}

As with so much of China's investment and rapid growth, it is difficult to know how successful the city of Baoding's approach will be in the short or longer term. However, it is clear that there is a major effort taking place, backed with enormous effort and political will, to make Baoding a global centre for green energy and technology. This is a major attempt to establish global market share and reputation in the green economy and a lesson for London.

\section{Considerations for adoption in London}

London should recognise that this is the type of approach in place in countries like China (and Japan above) is attempting to develop similar concentrations of green industry, research and development and technology at the level of global leadership. London is much better known as a city and has much longer and better established universities with very strong research and technological reputations. But this alone will not necessarily guarantee a lead in the low-carbon economy. London should decide whether it wishes to be a leader amongst existing 'world' cities such as New York, Paris and Sydney or whether to compete for the industrial leadership in low-carbon technologies with emerging cities such as Baoding or Sakai.

\section{Further information}

For more information see:

www.twbb.com/web/einfo.asp (information on Baoding Tianwei Power)

www.channelnewsasia.com/stories/eastasia/view/439950/1/.html http://english.cctv.com/programme/newshour/20091212/101357.shtml

www.huffingtonpost.com/2009/08/21/baoding-china-worlds-firs_n_265411.html (for background information.) 


\section{The Wise Group (Glasgow, UK)}

\section{Description of the model}

'We increase job and training opportunities for people, contribute to the regeneration of communities, and help create a fairer and greener society. The Wise Group works with partners to make a positive difference to people's lives through employment because we believe paid work is the best route to independence, health and wellbeing for most people.' Wise Group Mission Statement

The Wise Group is a social enterprise with a reputation for the getting long-term unemployed back into sustainable jobs. Their relevance in this learning model comes in several ways. Firstly it shows how a city council can procure services from social enterprises with a twin focus of providing environmental skills and services and getting residents into green jobs. Secondly it shows that such initiatives can quickly develop to a scale and level of expertise that puts them in a central position for delivering government welfare to work programmes.

The Wise Group rapidly diversified into other council contracts - 'Treewise' and ' Landwise' were environmental subsidiaries offering remediation and cleaning up of 'back courts' in Glasgow's post war peripheral housing estates. By 2000 - the Wise Group had expanded into England - mainly in the North East - and had delivered several thousands of workless trainees into jobs - using the contracts as the basis for an intermediate labour market model. By this stage, Wise Group was also one of the largest Scottish providers in Labour's New Deal programme.

\section{Relevance to London}

The relevance to London comes on several levels related to innovation in public service delivery. Firstly, the Wise Group shows that a social enterprise aimed at improving employment opportunities for workless residents is a model that can work on a large scale. Secondly it demonstrates that it can be financed and organised through the procurement of 'city' services (in this case home insulation of social housing in Glasgow) and contracts. Thirdly, the Wise Group also shows that such processes can also be adapted to provide skills and training that could help to build green skills (and a green curriculum) to further embed opportunities in the workforce.

\section{Results of the approach}

Launched in 1983 as 'Heatwise' they secured a Glasgow Council Social Housing contract to draughtproof and insulate Glasgow's then directly owned and managed social housing stock. This was a bold procurement decision by the council but one that has paid off many times over. By 1986, over 300 trainees were in full time work and over 25000 homes had been insulated through loft insulation and draughtproofing.

The Wise Group also developed key qualifications and training programmes offering trainees nationally recognised qualifications in associated areas including engineering, construction, building services and environmental activities. Today the Wise Group is one of the largest accredited training providers in Scotland and post Lord Freud's welfare review was the winner of the 'Flexible New Deal' prime contract for Scotland. It is likely to win the same role in the Coalition Government's Work Programme. 


\section{Reasons for success}

The Wise Group has used key procurement and regulation at the level of a UK city to drive green jobs and to increase employment in disadvantaged groups. This model began with the cost of improving social housing stock - a similar environmental challenge to that in London. The outcomes show clear improvements in employment and environmental performance - two major goals for London today.

\section{Considerations for adoption in London}

London could be as focused in Glasgow in the way that it has used its own procurement practices and budgets to drive training and job creation and to improve basic 'green' skills in the labour force. The Wise Group and Glasgow City Council approach is much more direct than the techniques and processes in evidence in London.

\section{Further information}

Further information can be found at: www.thewisegroup.co.uk/content www.scotland.gov.uk/Publications/2007/06/13132224/1 (an evaluation of one Wise Group project.)

\section{TransverS'AL (Alsace, France)}

\section{Description of the approach}

The employment office of Mulhouse (MEF Mulhouse) undertook a mapping of existing sectors, the diagnostic of the opportunities in the low-carbon economy and the identification of potential or emerging sectors. This was combined with the distillation of the skills in each of the sectors (shrinking and expanding) and the potential use of these in the context of the green economy. The platform is open to the public and is a very innovative tool to facilitate the reorientation of workers or unemployed towards green opportunities in the labour market.

The MEF Mulhouse serves a territory made up of 38 communes and about 270000 inhabitants, with the city of Mulhouse itself having a population of around 120000 people, within a larger travel-to-work area (bassin d'emploi). MEF Mulhouse has been working with partners on labour market issues covering a much wider territory within south Alsace, however, bringing together four labour market areas comprising 240 communes and around 460000 inhabitants.

South Alsace has a working population of 129000 (35\% in the service industry, 28\% in business, $9 \%$ in construction and 28\% in manufacturing). Since 2003, 8000 manufacturing jobs have been lost in the automobile, chemical, food processing and machine construction/electronics industries in the region. MEF has worked with partners on a "horizontal approach" (demarche transversale) to better support the transition of workers to more stable career paths within emerging sectors.

The mission of the MEF was established in legislation in February 2008, following the reform of the public employment service. To begin with, the focus was on the emergence of new jobs, particularly in the construction industry, where a number of local building firms came together to form a new "low-carbon" sustainable construction cluster. MEF Mulhouse undertook a number of related studies, including an analysis of the shifting labour market within the region to better identify the local destruction and creation of jobs. A study on the impact of the car industry in the region was carried out to examine not only the local importance of the sector and its travel to work area, and but also the transferable skills possessed by its workers. Following a wave of redundancies, the textile sector and the CFDT union also asked the MEF 
to redouble its efforts in tackling unemployment in the sector, through facilitating a transfer of skills to other sectors.

\section{Relevance to London}

London does not have a proper identification of the skills needed in the low-carbon economy. There is an opportunity to process the information that Job Centre Plus receives daily from jobseekers in London to identify the skills available in the labour market. Working with trade unions and other sector federations, it should be possible to identify the skills needs in the medium and long term in order to categorise them and facilitate the identification of "bridges" to move from one sector to another with a certain amount of training targeted to this population. This would also enable the VET system to prepare customised programmes to meet the demands of the businesses in expanding economic sectors.

\section{Results of the approach}

In response to some labour market readjustments, MEF sought to open dialogue within the region by creating a platform for communication and exchange on industrial change, employment and skills. A fourmonth period of consultation took place with relevant local and regional actors in order to analyse the principle challenges facing the region, including economic change, the recognition and valorisation of the skills possessed by local people, and the need to define a common strategy for employment development which would make local career pathways more sustainable.

Fifteen objectives were developed and shared by the different actors, around four themes: research and analysis, co-operation with companies, training, and communication. Specific objectives included anticipating the future needs of businesses arriving in the region, better matching skills to future demand, and making people more aware of potential areas of future employment growth, including opportunities in the low-carbon sector.

Specific examples of the work carried out include:

- A joint advertising campaign and information service was launched to better inform employees, business owners and human resources personnel on the adult and professional training programmes available in the region.

- A series of studies were carried out to help to identify those sectors which were precarious and those which were likely to have a greater future in the region.

- A website was set up to enable professionals and businesses to better understand the horizontal career paths which could allow people to pass from declining to emerging sectors.

Reasons for success of the approach

The key reason for the success of TransverS'AL is the dialogue with social partners in the various sectors and the work in partnership (see Figure A.1). Most of the research is based on work already prepared by the some of the networks in place, for instance the association of professional training for adults (AFPA). The analysis of the sectors was carried out by the employment office in collaboration with the trade unions and the sector federations. The actors of the VET system are also involved in the process as they provide the training available to update any skill or provide a suitable training to meet the skills demands in expanding sectors. For instance, the pilot study for the project was called TEXBAT (acronym for Textile to Building sectors). It was prepared in collaboration with the federation of training in the 
textile sector (FORTHAC). Many other analyses like this one have been undertaken for shrinking sectors in the region, such as steel and the automobile.

Figure A.1. TransverS'AL work in partnership

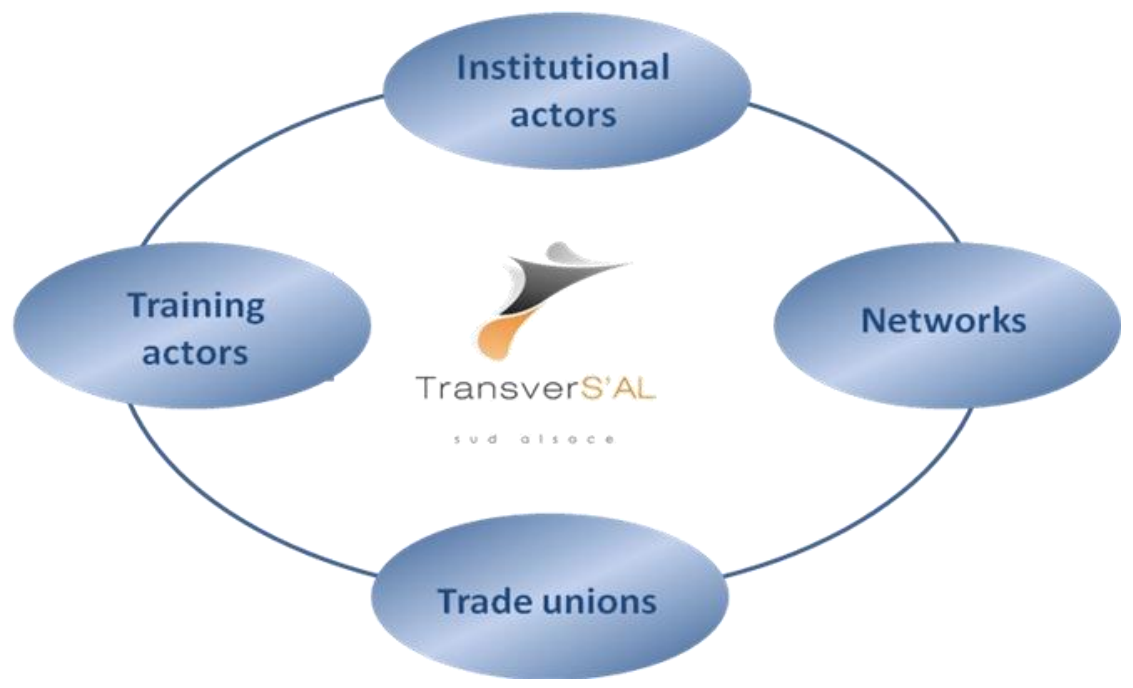

Source: Translated from the presentation made on 6 July 2010 in Paris by Mr. Olivier Olivier Pihan, deputy-director of the Maison de l'Emploi et de la Formation (MEF) du Pays de la région mulhousienne

This online platform will be easily accessible to everyone at www.monmetierdedemain.com. Today, there are over 500 "bridges" identified in the platform, providing a wide range of alternative jobs to workers in shrinking economic sector and to unemployed.

\section{Obstacles faced and response taken}

One of the obstacles was the availability of data as well as the anticipation of the sectors requirements. These obstacles were faced in two ways. For the first one, a thorough project was developed in collaboration with social partners. The regional authorities made a long-term commitment and provided the resources (human and financial) needed to obtain the data needed for analysis. For the second one, the employment office of Mulhouse approached the businessmen in the region and undertook a series of interviews to identify their needs. This takes time as trust should be built, but it eventually happened.

\section{Considerations for adoption in London}

London may consider to adopt this kind of approach through its Job Centre Plus offices. However, it would be important to involve social partners in the process in order to build synergies and trust. Also, a long-term commitment regarding human and financial resources will be needed in order to gather sufficient data to build a platform. It would also be important to work with the unions and the sector federation to make an accurate audit of the skills required and to identify the transferable skills from sector to sector.

\section{Further information}

For further information, please visit: www.transversal-sudalsace.fr www.mef-mulhouse.fr 


\section{Green Public Procurement (Basque Country, Spain)}

\section{Description of the model}

GPP was first and has been mainly implemented by local authorities. As the EU has acknowledged the importance of implementing GPP at EU level, many national governments have developed or are developing National GPP Action Plans. However, many of the National Plans only involve the central government or are not deeply enough linked to the municipal context. The Basque Government believes that regional and local governments also play an important role in promoting GPP in local and regional organisations in order to achieve environmental relief, including climate protection.

In the Basque Country, two strategic plans started in 2006 which set the objective to reach a $40 \%$ GPP by 2010. To achieve that, the Department for the Environment, Spatial Planning, Agriculture and Fisheries of the Basque Government through Ihobe (its Public Agency of Environmental Management) started implementing a GPP programme that same year to support all public authorities of the region in the implementation of GPP. The GPP programme has been in place since 2006 with the support of a technical assistance service.

The five main action lines of the Basque GPP programme are the following:

1. Development of tools and green procurement criteria

Focus has been made on the development of a "flexible framework" to implement gradually GPP in public administrations, and of green procurement criteria for certain product groups in line with the EC GPP-Toolkit, which has been adapted to the Basque reality. The instruments are compiled in the "Practical Manual for Green Public Procurement" (in Spanish and Basque) and in the section of Ihobe's website that deals with this topic and which is regularly updated. At present, green criteria for 18 product groups covering more than 30 single products are available for all public authorities. The product groups are: Office paper; Computer equipment; Office furniture; Cleaning services in buildings; Cars and vans; Organisation of events; Gardening services; Catering services (including vending services); Courier service; Publications; Textile products; Travel management services; Consultancy services; Office materials; Absorbent materials; Lighting; Public works and construction. New product categories are in development.

2. Support to public administrations

Even though the development of tools is very important in the promotion of GPP, it is not enough for a real uptake of GPP by public authorities. Therefore special emphasis is made on the GPP programme to encourage and help public administration start the implementation of GPP practices. It has been conducted through:

- The organisation of training seminars and awareness raising activities for procurement practitioners and other relevant staff.

- The maintenance of permanent working groups in the three provincial capitals, the three provincial governments and the Department of Economy and Finance of the Basque Government.

- The provision of direct, personalised guidance and support both for the implementation of GPP strategies and for tender greening and support with the documentation through two standardised services: "Expert Answer" and "Expert Environmental Advice". For the 
provision of these services, a group of consultants have been trained by Ihobe's technical assistance in order to transfer their knowledge and increase the number of people who can provide qualified support to public authorities.

- The collection of a database of green products, third-party certified, that complies with the GPP criteria in varying degrees. Administrations interested in knowing the number of green products available in the Basque market can contact Ihobe for that information. This is especially relevant for small authorities that can do direct procurement.

Apart from the demands for the product groups covered in the manual, other product groups for which administrations have asked for support are:

- Energy and electric installations

- Fuels and electricity

- Urban cleaning and waste management services

- Maintenance services
- Other vehicles

- $\quad$ Public works

- $\quad$ Security services

- $\quad$ Moving services

- Cosmetic products

In Ihobe's website there is a list of more than 50 green procurement practices by Basque administrations with different demand levels for several product groups, the tender documents of which can be obtained from Ihobe.

3. Dissemination and communication activities

In order to encourage the participation of as many public authorities as possible, several dissemination activities are conducted alongside with the rest of the programme's measures. They include the regular publication of news and good practices conducted by Basque public administrations in Ihobe's website, the dissemination of relevant information through a mailing list, etc.

Until 2009, almost 40 best practices have been identified and compiled in the website, which illustrates successful cases of procuring with the green criteria developed in the programme, as well as other relevant practices in relation to GPP (political agreements, training seminars, electronic procurement, etc).

4. Dialogue with the market

As mentioned above, a successful GPP strategy also needs to promote the exchange and greening of the market. To do so, within Ihobe's GPP programme, discussion forums with manufacturers and suppliers and communication activities are conducted to raise awareness on this subject and accelerate the introduction of greener products in the market.

The discussion forums are organised with the aim to:

- Inform the private sector about GPP criteria that will be promoted by all public authorities in the Basque Country. 
- Establish a common ground for discussion and exchange to gather their concerns and to provide a common definition of the level of demand (since GPP criteria are divided into three levels, from basic to excellent), and thus avoid being too exacting before the market is ready.

- Offer information to the private sector so that they can prepare themselves and be ready for all the GPP demands from the Basque administrations

5. Development and testing of GPP monitoring systems

In order to be able to evaluate the level of achievement of the objective set for the Basque Country, as well as the commitment from the Basque Government to implement GPP in all their procurement activities, two monitoring methodologies have been tested in the Basque administrations.

One of them was applied only in the Basque Government (Departments and its Public Companies) to monitor in general terms the level of implementation of GPP.

The other methodology to measure GPP in the Basque Country was based on the one developed for the EC, but adapted to a smaller scale and context. In order to test it before extending it to all Basque administrations, a pilot test of the methodology has been conducted with a group of public authorities with which Ihobe has been working since 2006, namely the three provincial capitals, the three provincial governments and the Department of Economy and Finance of the Basque Government. The results of the process will be shared with the European Commission and other interested organisations to participate in the definition of a standard monitoring system for the European Union.

\section{Relevance to London}

The GPP programme of the Basque Country is both focused on the demand and the supply sides, understanding business and industry as consumers, and not only as producers (like in the MLGPC). The main objectives of the programme are:

- To provide the necessary tools, resources and support to the Basque administrations so that they can reduce their needs and implement environmental criteria in their procurement activities

- To inform, discuss and prepare the Basque manufacturing sector (i.e. companies) so that they can offer environmentally friendlier products and services

Normal strategies focus only on public authorities (the demand side), setting targets, developing tools, etc. However, in order to really move the market, it is important to promote environmentally friendlier companies and products as well (the offer side). That is why the Basque GPP programme deploys a coordinated strategy that focuses on both the demand side (public administrations) and the offer side (providers and manufacturers). Specific industry strategies, such as an Ecodesign certification have been developed and are recognised in public tendering procedures as proof of compliance of certain environmental criteria.

This approach recognises the starting point for the local and regional industry, and it is designed to achieve at the same time a push in demand and supply. The implication of local and regional industry in the development of environmental criteria for tender could be an interesting point for London. 


\section{Results of the approach}

In some industry sectors based in the Basque Country, such as office furniture, the evidence shows that green products are more competitive than the no-green alternatives. Indeed, in various tendering procedures of the Basque Government for products like furniture or office materials, the winning offers had both the highest environmental score and the cheapest price.

Until 2009, a total of 14 discussion forums had been organised in which almost 150 people from different companies participated. In figures, a total of 12 training sessions were organised between 2008 and 2009 with the participation of 151 people from 73 different public organisations. In terms of direct support, since 2006, 142 demands have been answered, of which there were 112 related to greening tenders and the remaining 30 related to other issues.

\section{Reasons for success}

Reasons for success are the complementary work in the offer and demand sides; the establishment of common green procurement criteria with 3 levels of ambition, based on a consultation process involving both the industry and the public purchasers.

\section{Obstacles faced and response taken}

As in most of the European GPP initiatives, the process of implementation is relatively slow and gradual. Regular communication, training and networking activities, as well as the establishment of a GPP helpdesk for Basque administrations help to foster the implementation of GPP.

\section{Considerations for adoption in London}

A similar process of defining GPP criteria with the participation of both the demand and the supply sides, especially for works and service contracts, could be set up (in line with national GPP activities and in consultation with private sector actors). A diagnostic about service sectors with a high demand from the public bodies, and also about specific London-based service offers should be carried out beforehand.

\section{Further information}

Contacts: compra.verde@ihobe.net; gorane.ibarra@ihobe.net.

All information and tools developed within the programme can be downloaded from Ihobe's website www.ihobe.net, Areas of Action, Green Public Procurement.

\section{Green Skills in Vocational Education and Training, TAFE (NSW, Australia)}

\section{Description of the model}

In December 2009 the Council of Australian Governments endorsed the National Agreement on Green Skills, an agreement between the Australian Government and the state and territory governments. The Agreement includes 4 objectives: the development of national standards in green skills in Vocational Education and Training (VET); training of VET teachers in skills for sustainability; revision of Training Packages to embed green skills; and implementation of a strategy to teach vulnerable workers in the transition to a low-carbon economy ${ }^{1}$. The Green Skills Implementation Plan was presented to the Ministerial Council on Tertiary, Education and Employment (MCTEE) in June 2010. 
A number of actions have been taken or are ongoing at the national level, like the revision of Training packages by Australia's 11 Industry Skill Councils, or the Clean Sustainable Skills Package (CSSP). The CSSP is a AUD 94 million investment in 50000 green jobs and training opportunities focused on young or disadvantaged Australians'; the Teaching and Learning Capital Fund for Vocational Education and Training (VET) provided during 2009 - 2010 AUD 500 million for modernisation and improvement of the quality of teaching and learning across the vocational education and training sector.

One of the elements of the Programme is the Training Infrastructure Investment for Tomorrow AUD 200 million is available for TAFE institutes and consortia led by TAFE institutes to apply for competitive grants of up to AUD 10 million for infrastructure projects to: adjust to the emerging training needs of the local economies in which they operate; and support the national training system to address industry's emerging green skills requirements. ${ }^{3}$

The state of North South Wales (NSW) approved the "Green Skills NSW Strategy" in 2008. The NSW Technical and Further Education Commission (TAFE NSW) is recognised as a key provider of green skills training. In Australia, operating through 10 institutes and 130 campuses; TAFE NSW accounted for $89.5 \%$ of VET training hours.

\section{Relevance to London}

This programme is relevant to London in various aspects. The programme tackles the development of green skills in a broad and systematic way. For London, lack of green skills have been identified in different sectors, for example in Energy Management and Maintenance of buildings; London has also identified the need to distinguish between up-skilling in terms of specific professional competence for specific jobs and up-skilling of environmental awareness and embedding sustainability in everyday work.

London still needs to define standards for Low-Carbon Skills in specific sectors. The involvement of the private sector in the development and delivery of green curricula is one option, and, in this combined industry approach to VET education, NSW's experience is very relevant. One of the major challenges London is facing is the integration of a large number of low-skilled workers and long-term unemployed people into the Low-Carbon Economy. The Australian experience includes all of these threats. The time to adjust in London is lengthy and the NSW experience shows how the reactiveness of TAFE has been essential to ensure the skills availability in the green economy.

\section{Results of the approach}

The NSW Green Skills Strategy Implementation Plan 2008-10 prepares and monitors the progress in implementing the NSW Green Skills Strategy. The Strategy partners are the NSW Board of Vocational Education and Training (BVET), which has funded the Green Workforce Training Guide and other strategy elements, and the NSW Department of Environment and Climate Change (DECC). Industry priorities have been selected based on "their potential to contribute to environmentally sustainable industry and commerce and the potential for the vocational education and training (VET) sector to meet the anticipated skill requirements".

The strategy includes five elements: prioritise funding for training related to environmental sustainability; build the capacity of trainers and training organisations to provide environmentally related training; establish green industry partnerships identifying businesses and training opportunities in green markets; publish a green workforce business guide containing information and advice for employers and workers on green skills; and implement skills strategies for NSW Government environmental programmes. All elements, especially the last one, could be replicated in London (related the RE:FIT, RE:NEW and similar programmes). 
The priority industries have been analysed in terms of key environmental challenges and opportunities, key VET-related occupations and related government environmental targets; actions and planned actions for the five strategy elements; and Units of Competence relating to environmental sustainability in a number of Training Packages ${ }^{4}$.

TAFE NSW Sydney started in 2009 to develop strategies to deliver best practice training in sustainability skills. TAFE NSW Sydney offers currently 59 sustainability skills courses and 129 courses with sustainability skills modules. The areas of expertise are: Building \& Construction; Electronics \& Communications; Information \& Communication Technology; Property Services; and Transport \& Logistics 5 .

In terms of embedding sustainability in everyday work, the NSW State Training Services launched subsidies for training to integrate sustainability into business operations; the Green Skills Business Incentives are available for short courses to integrate sustainability into business planning and operations; to develop and manage environmentally sustainable business practices, and to develop innovative sustainable products and services. A "Green Skills Business Guide" was designed for SMEs ${ }^{6}$, focusing especially on Farming, Tourism and Hospitality, Building and Construction, Printing, Clerical and Office, Transports and Logistics. The Green Skills NSW Course Finder includes 9 industry sectors and a huge number of occupations ${ }^{7}$.

TAFE NSW institutes developed new training programmes for green jobs: for example, they developed a new green skills programme GSmart for the Tourism and Hospitality industry to provide businesses with skills in environmental sustainability (Hunter Institute ${ }^{8}$ ); the Y Green programme provides young Aboriginals with skills for sustainability and qualifies them to conduct home sustainability assessments under the Commonwealth Government's Green Loans Scheme (North Coast Institute); the agri-skills centre of Western Sydney Institute will provide training in sustainable practices in agriculture and horticulture and new and emerging industrial green collar skills 9 .

A performance report showed that, in the year 2008, 23018 students were undertaking green skills training ( $4 \%$ of the total $)^{10}$.

\section{Reasons for success}

Green Skills are not limited to some industry sectors: "Skills policy cannot focus merely on the development of green jobs; sustainability principles will need to be diffused throughout all sectors of the economy that influence greenhouse gas emissions. This may involve a lifecycle approach, from schools through universities and TAFE through to life-long learning and retraining. (...) Skills will be needed at all levels and across existing and emerging industries. This requires training which covers practical skills for trades in installation and maintenance of low-emission, energy-saving and recycling equipment, as well as programmes which provide the skills required of managers in planning, energy and carbon management, and reporting. Others such as retailers and those in the property market will require information and rising of awareness of issues related to product sourcing and land use. No one will be unaffected." $" 1$ 
Figure A.2. Skills for sustainability, TAFE

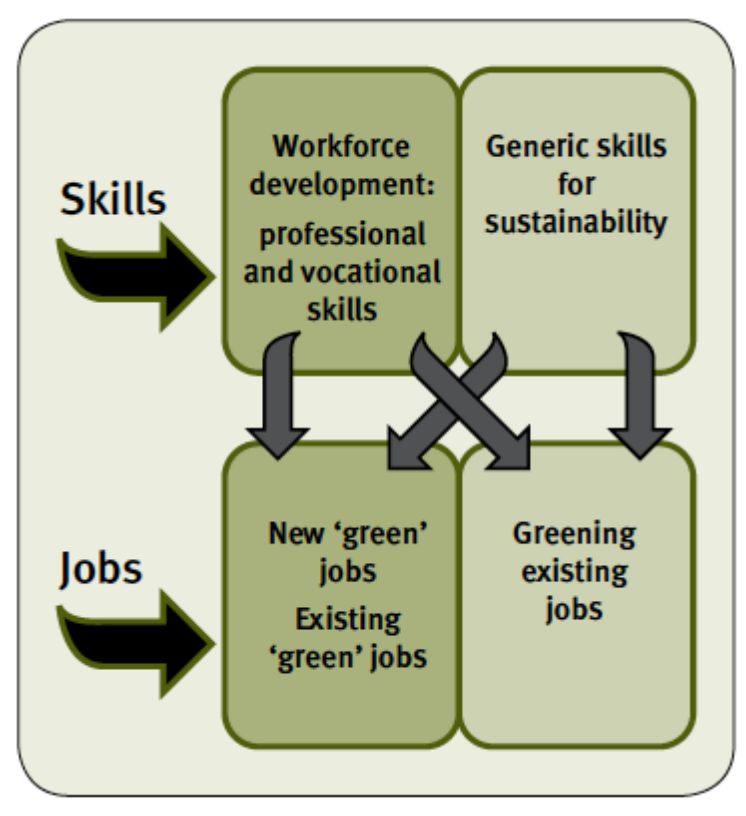

Skills for sustainability will be needed in new "green jobs", such as renewable energies, but also in all sectors of traditional industries and services. The National VET Sector Sustainability Action Group developed a definition of "Skills for sustainability" which includes technical and generic skill areas, understanding "Skills for sustainability" generically as "the skills needed to support sustainable development".

Leadership in implementation of sustainable everyday practices: TAFE NSW combines training on green skills with its internal environmental and energy efficiency policies. 2010 was declared as Year of Learning for Sustainability for NSW Public Schools, TAFE NSW campuses, state offices and staff. Sustainability education and management at TAFE NSW institutes is based on proactive initiatives, for example the development of new centres and skills at TAFE NSW Sydney Institute, including a "Sustainable design programme" in partnership with the Australian Graphic Design Association, assisting small and medium enterprises in the selection of soya inks, paper stock, packaging and triple bottom line printers or the establishment of a Sustainable Hydraulic Trade centre which provides interactive student learning and has enabled the delivery of training in best practice green building skills with a focus on hydraulic trades, including waste water treatment and reuse, evacuated tube water heating and rain water harvesting. TAFE NSW centres are implementing also the "Sustainable Advantage Recognition Scheme" promoted by the NSW Department of Environment and Climate Change.

\section{Obstacles faced and response taken}

Identification of priority sectors for Green Skills

A report of the Green Skills NSW Taskforce identified a number of systemic issues to be addressed in the future: (a) reliable information is needed for effective resource allocation, and therefore the development of scenarios to anticipate or drive demand will improve resource allocation; (b) "better coordination of planning across government is needed to ensure that resources are strategically mobilised to support a Green State"; (c) there is also a need to "consider centres of excellence in emerging areas of sustainability and/or locating these centres in regions where there is the potential for growth"; (d) Government assistance is required to ensure a quick development of quality training courses tailored to the 
specific needs in priority industries and in emerging green technologies; (e) showcase the work of business "champions" and case studies demonstrating the financial benefits of sustainable business practice; (f) support young people to gain career opportunities in a green economy ${ }^{12}$.

Quality Standards for green skill provider

The National Quality Council for VET established in 2009 the "Skills for Sustainability Standards Framework" as a voluntary framework of standards against which Registered Training Organisations (RTOs) can demonstrate their capacity and capability to teach and assess skills for sustainability. The following key principles were identified: Institutional leadership and institution-wide capacity are crucial; Skills for sustainability are generic, and also specific; Educating for sustainability calls for a range of delivery techniques; Collaboration and networks are important; Knowledge and skills of staff are critical. The "Skills for Sustainability Standards Framework" defines 5 quality criteria, which are aligned with AQTF Excellence Criteria (Leadership; Learning and Assessment; People Development; Relationship Management; and Integrated Information Management).

"Green Skills" - sustainable practice in Vocational Education \& Training (VET)

The Green Skills Workshops are providing professional development and support for VET trainers and managers, "The workshops support the NSW BVET Green Skills strategy by developing the capacity of training providers to meet environmental awareness and skills development needs in key industry sectors ${ }^{13 \%}$.

\section{Considerations for adoption in London}

The systematic approach taken by the NSW Government, as well as the allocation of funding for TAFE NSW and other VET providers, could be replicated in a similar way in London. One of the first steps would be the revision of existing training, with the differentiation between generic green skills for existing jobs and up-skilling of key sectors of the Low-Carbon Economy. It would also be important to define the criteria of a "green" training and to make the system more flexible so that the time to put a training in place is in line with the market needs. The codes for identifying the skills that could be useful in the low-carbon economy (transferrable skills) are not identified in the classification system. London could take inspiration from TAFE NSW to achieve this.

\section{Further information}

Homepage of the Department of Education, Employment and Workplace Relations of the Australian Government: www.deewr.gov.au/Skills/Programs/WorkDevelop/ClimateChangeSustainability

NSW Green Skills initiative: https://www.training.nsw.gov.au/programs_services/not_funded/greenskills

TAFE NSW: www.tafensw.edu.au

NSW Green Skills Business Guide and Course Finder: www.greenskills.nsw.gov.au

Background information and detailed case studies can also be found in:

Rafferty, M. and S. Yu (2010), "Skills for Green Jobs in Australia: Unedited Background Country Study", International Labour Office, Skills and Employability Department, ILO, Geneva. www.ilo.org/skills/lang--en/index.htm 


\section{EcoBuy (Vienna, Austria)}

\section{Description of the model}

In 1999, the City of Vienna was one of the first local authorities in Europe to implement a Green Public Purchasing Programme, called "ÖkoKauf Wien" ("EcoBuy Vienna"), as a substantial contribution to reach the targets of Vienna's Climate Protection Programme "KliP". The annual volume of Vienna's purchasing budget is approximately 5 billion Euros, corresponding to about "five times the total amount spent by the city's private households on home furniture and furnishings, food and drink, clothing, hygiene and cleaning. The City Administration aims to use its influential role in the market to promote the further development and wider availability of eco-friendly products, thus providing a positive example for consumers, retailers and the business community in general."

The programme is carried out in collaboration between the City Council Departments and Public Enterprises, (like the Vienna Hospital Association) headed by a steering group and 3 consultative Committees. About 180 persons, including both internal staff and external experts, are participating on the different working groups and committees. 18 thematic working groups (building construction, food, cleaning, paper, electrical appliances, fleet of vehicles, events, winter services, etc) are developing environmental criteria for specific products and services. Research and pilot projects are also part of the programme.

\section{Relevance to London}

"ÖkoKauf Wien" has a very strong component of developing common environmental criteria in collaboration between different City Council departments; this aspect could be of interest for London, as London's procurement activities could have a wider impact in the market if they were based on common environmental criteria. An efficient communication strategy to inform both private consumers and local business is also part of Vienna's programme. Pilot projects and specific research are focused on effective implementation of the environmental criteria, keeping in mind the availability of green products and services on the market.

\section{Results of the approach}

Until now, about 60 sets of environmental criteria for different product groups have been developed. By decree of the Chief Executive Director of the Vienna City Administration, the set of criteria are mandatory for purchasing. Savings of about $103000 \mathrm{t}$ of $\mathrm{CO}_{2}$ and 45 million Euros have been achieved since 2004.

The results of the programme relate to the environmental criteria included in tender documents elaborated in different working groups: in the case of organic food, public catering services are actually offering 50\% organic food in kindergartens, $30 \%$ in public schools and public hospitals and $18 \%$ organic food in senior homes; the installation of water saving gate valves in public buildings achieved a cost reduction of 1,5 million Euro every year. Besides, the integration of environmental criteria in calls for tenders in cleaning products saves 10\% of the costs (1999/2000: about EUR 581 000/year) and 23\% of the amount of cleaning products used (1999/2000: 297 tons/year) ${ }^{14}$.

Awareness rising for everyday sustainability at work is another component of the programme. "The "ÖkoKauf Wien" project further includes substantial PR work to publicise the methods and objectives of ÖkoKauf Wien within the City of Vienna, among the business community and the local population. The public at large is informed via media conferences, press releases and news articles. Films, brochures, info folders and posters are available on specific topics, and even working materials and games for kindergartens and schools have been produced. A key aim of the project consists in informing as many 
people as possible on the importance of "buying green", both as a private customer and as a bulk purchaser for the City of Vienna, and on clear-cut criteria that every single person can apply to be more eco-friendly in daily life.

Some of the additional benefits of ÖkoKauf Wien are cost reductions for private consumers (in the case of organic food); positive effects on health; improved cooperation between departments and long-term savings.

\section{Reasons for success}

The development of research and pilot projects regarding specific targets of the programme has been essential for the results achieved. One example is the development of a database of disinfectants. In the case of organic food, a feasibility study to maximise the use of organic food in canteens of the Vienna Hospital Association analysed not only ecological effects, but also financial and market specific aspects. The Steering Committee also developed position papers, for example those regarding the economical and ecological benefits of the use of drinking water (instead of bottled water).

Some elements of success identified are the cooperation regardless hierarchy and shared values between participants; the establishment of "hybrid learning forums" combining scientific and public relations knowledge, user's and purchaser's knowledge; "commitment to radical experimentalism" and "seamless political support"15.

\section{Obstacles faced and response taken}

Training of the staff -for example, in the case of cleaning staff-, and internal information campaigns -for example, to reduce paper consumption-, are considered as essential for the success of the programme.

"There persisted, and still persists, the common preconception that ecological (organic) products and services are more expensive than conventional ones -a prejudice, which could not be eliminated in all spheres. Due to the direct implementation of the results developed within the programme in the City of Vienna's procurement practices, this preconception was proved wrong in virtually every case. (...)

The reservations of the business sector about the efforts to enhance the environmental compatibility of products and services, which could be felt in few cases, could be eliminated by intensive contacts, sound arguments and the consistent implementation of the programme results in the City of Vienna's procurement activities. ${ }^{16 "}$

\section{Considerations for adoption in London}

The criteria development process, based on thematic long-term working groups, could be of interest for London's Procurement activities. The communication of results and awareness raising activities towards citizens and business community is also applicable in London.

\section{Further information}

Some information in English can be found at the homepage of the programme: www.oekokauf.wien.at

A detailed description of the process of implementation of "ÖkoKauf Wien" is available at the UN-Habitat Best Practices Database in Improving the Living Environment: www.unhabitat.org/bestpractices/2010/mainview.asp?BPID=2298 


\section{Eco-primes for energy efficiency (Paris, France)}

\section{Description of the model}

"Le Grenelle Environnement" is a five-year French plan for nationwide sustainability created in 2007 through the new Ministry of Ecology and Sustainable Planning. A key strand of the plan is the Building Plan which seeks to put an end to energy-intensive buildings and cities through the thermal renovation of existing buildings and the construction of energy-positive buildings. Approximately EUR 208 billion has been allocated to cutting the energy consumption of existing buildings by at least $38 \%$ by 2020 . Buildings and housing currently generate $18 \%$ of greenhouse gas emissions in France.

Various provisions are contained within the Finance Law to increase financing for energy efficiency investments. One such provision is the zero-interest eco-loan programme for energy-efficient renovation activities. The aim of this programme is to create energy savings which cover the repayment of the loan's capital. Providing that the property was built before January 1990, a loan of up to EUR 30000 can be applied for, with repayments over a 10 year period.

Activities that can be covered under the loan include:

- Thermal insulation for roofs, exterior walls, and exterior glass surfaces

- Installation, regulation or replacement of heating or hot water systems

- Installation of heating or hot water systems using renewable energy.

A range of additional measures have also been introduced as part of the national Building Plan. Tax credits of up to EUR 16000 are available which allow households to deduct a percentage cost of certain energy improvements from their income tax, regardless of whether they are the owner or the tenant of the property. These tax credits can be used in conjunction with, or in addition to the eco-loan.

In line with the national strategy, the City of Paris has put in place the "Eco-primes" [eco-loan] finance scheme. Under this scheme, loans are granted under certain conditions to residential property owners in the city who are willing to undertake refurbishment works to improve energy efficiency. This scheme, created in September 2009 by the City Council, is co-financed by the National Agency for Housing. The loans range from EUR 500 to EUR 4000 . They are granted on the basis of certain criteria including the owner's income, the level of refurbishment and whether or not the owner occupies in the apartment.

For low income owner-occupiers, a loan of up to EUR 1500 can be granted for works which create a $30 \%$ reduction in energy consumption. Middle income owner-occupiers are eligible for up to EUR 500 for the same type of work. Landlords willing to undertake this type of work can apply for a loan of up to EUR 4000 . Across all cases, the work must improve the property's energy efficiency classification by a minimum of 2 categories (achieving a minimum rating of category D, between A to G) and must meet current building code efficiency requirements.

\section{Relevance to London}

Such a scheme could be applied in London in order to encourage home owners, landlords and tenants to take steps to increase the energy efficiency in their homes, notably in the context of the RE:NEW Programme. As a majority of London housing is rental properties, a targeted approach towards landlords who have few or no incentives to improve the energy efficiency of their properties could be beneficial. 


\section{Results of the approach}

Eco-loans are continuing to grow in popularity and recent figures show more than 100000 successful applicants. According to the French Banking Federation (FBF), since the scheme started in April 2009 the average amount of eco-loans was roughly EUR 17 000. In Paris, the success of the eco-loan has meant a large share of the Parisian housing stock has undergone energy efficiency related work. The one-stop-shop online platform www.apc-paris.com created by the Paris City Council is increasingly visited.

\section{Reasons for success}

For the national support schemes, the key reasons for success are:

- The eco-loan is not means-tested, which means that anybody can apply provided that the intended property development meets certain requirements.

- A thermal study costing between EUR 1000 and 2500 is covered by the loan, as well as any other project management and insurance costs.

- This eco-loan can be combined with tax credits under certain conditions.

- The eco-loan has not been introduced as a standalone measure but as part of a much wider range of interventions including: a 5.5\% VAT rate on installation, maintenance and renovation work in housing; incentive schemes for the purchase of "low consumption" housing, and a "low consumption" standard for new housing, public and tertiary buildings, and; a "social housing ecoloan" to improve the energy performance of social housing.

For the Paris eco-prime, the main reason for its success has been due to a broad communication campaign and that the scheme is easily accessible to both tenants and owners.

\section{Obstacles faced and response taken}

The system has been criticised as being overly complex which may dissuade potential beneficiaries. While there is no means testing, there are many restrictions. In addition to the loans only applying to properties built before 1990, multiple renovation projects must be carried out simultaneously. That is, it is not sufficient to just replace a property's windows to qualify, but rather a minimum of two to three different renovations must be carried out from an approved list. Furthermore the works must result in a minimum improvement of global energy performance and be completed within two years of the loan being granted. According to the Fédération Bancaire Française, the authorities did not provide sufficient clarification of eligibility requirements needed to stimulate the number of applications when the project was launched. The French Agency for Environment and Energy Management reacted by launching an information campaign about the eco-loans explaining that although the system may be complex, the principle is simple: "It's about subsidising the most efficient and coherent works, and avoiding the patchup jobs. There's no point in replacing the windows if the rest of the house leaks energy".

To facilitate the access to the various tax incentives and eco-loans offered specifically to Parisians, the Paris City Council has created a one-stop-shop styled website that provides both owners and tenants with the relevant information on the one website. The Paris City Council has also created the Agence Parisienne du Climat (Paris Climate Agency) which collates and disseminates the city's strategy to meet its ambitious GHG reductions. The online platform is available at www.apc-paris.com 


\section{Considerations for adoption in London}

The conditions of a zero-interest eco-loan (such as maximum loan amount; time frame for completion; works covered under the loan; or other eligibility criteria) would need to be suitably adapted to both the pressing requirements of the London housing stock and the needs of occupants. London could also look towards the Paris example of setting up a one-stop-shop style platform. Not only would it clearly communicate it's strategy and raise awareness, it would also present Londoners with the support schemes available for them to contribute to meeting the ambitious energy efficiency targets set by London.

\section{Further information}

Agence Parisienne du Climat (n.d.), www.apc-paris.com [in French], accessed 01 March 2011.

Marie de Paris (n.d.), "Les espaces info-énergie”, www.paris.fr [in French], accessed 01 March 2011.

Invest in France Agency (IFA) (2009), "Opportunities to invest in "green growth, What France has to offer: France's "Green New Deal"”, www.invest-in-

france.org/Medias/Publications/152/Argumentaire\%20Grenelle_UK.pdf, accessed 01 March 2011.

\section{Using market instruments instead of direct controls (Norway and United States)}

\section{Description of the approach}

According to Porter (1991) and to Porter and Linde (1995), innovation is only spurred by stringent environmental policies if policies are flexible with respect to technology choice. In this learning model, examples from two countries are used to demonstrate the Porter hypothesis.

Soon after the 1987 UN Report "Our Common Future" was released, Norway along with other industrialised countries, set themselves bold GHG emission reduction targets. However, as these countries gradually discovered that achieving the targets would be much more costly than expected, the targets were silently abandoned. The GHG emission reduction target in Norway led to modest changes in the Norwegian economy even though it was only officially upheld for several years. Interestingly, the carbon tax which was introduced later in 1991, was never abandoned. This suggests that emission pricing is more credible that emission reduction targets. The tax started at the high rate of USD 51 per metric ton of $\mathrm{CO}_{2}$ on gasoline, and has since been increased. The tax was also applied to diesel and mineral oil for heating purposes. It is now among the highest carbon taxes across the OECD.

The second example is the US $\mathrm{SO}_{2}$ cap and trade programme. The Acid Rain Programme (ARP) as part of the 1990 Clean Air Act Amendments, set a cap on $\mathrm{SO}_{2}$ emissions in order to limit $\mathrm{SO}_{2}$ emissions from utilities. It then distributed the emission rights among the utilities and allowed trading in emission rights.

\section{Relevance to London}

Even though London already has most parts of its policy package in place, it is not immediately clear how the policy package will work to sort and offset emission reduction projects with net costs. There is a risk selecting emission reduction projects based on technology and not on costs. Moreover, it should be considered that by picking emission reduction projects based on technology, innovation may not be spurred by stringent environmental policies. 


\section{Results of the approach}

The carbon tax in Norway was also applied to emissions of $\mathrm{CO}_{2}$ from the production of oil and gas offshore. As a result, it is likely that this tax led the Norwegian oil industry to investigate how carbon could be stored in former offshore oil and gas reservoirs. At the Sleipner field about 250 kilometres (160 mi) west of Stavanger, the first such project was started in 1996 and today as much as 12 million tons of $\mathrm{CO}_{2}$ are stored at the field. The experience from the Sleipner field will be crucial for the success of carbon capture and storage technologies, and may have given Norway first-mover advantage in this area.

According to Burtraw and Palmer (2003), the main savings from the US $\mathrm{SO}_{2}$ cap and trade programme were due to increased competition between abatement suppliers, and not from differing abatement costs amongst polluters. When regulation changed from a technology standard to tradeable emission quotas, upstream industries such as railroad transportation, scrubber manufacturing and coal mining companies were thrown into competition with each other in a race to supply the electricity generating industry with low cost compliance strategies. This lead the price of low sulphur coal to fall by $9 \%$ even though total supply increased by $28 \%$. Further, coal transportation prices fell from 20-26 mills (one mill is the thousandth of a US dollar) per ton-mile to 10-14 mills per ton-mile. Lastly, the efficiency of scrubbers were enhanced, leading to a drop in the price of scrubbing measured as emission reduction per dollar.

\section{Reasons for success/failure of the approach}

It has been impossible for the Norwegian government to implement the tax in all sectors. In particular, internationally competitive industries have been sheltered. It is very likely that the tax would have had a much higher impact on emissions if applied universally.

Although the US $\mathrm{SO}_{2}$ cap and trade programme is considered to be a success, it has proven very difficult to get political acceptance for a similar $\mathrm{CO}_{2}$ cap and trade programme in the US. Again, competiveness concerns seem to play a crucial role.

\section{Obstacles faced and response taken}

In Norway, the threat of the tax could have induced some of the sheltered industries to sign agreements with the government which also has led to significant emission reductions.

A general issue with cap and trade programmes is overallocation (McAllister, 2009). This occurs when a cap is set to a level that sources of emissions have no incentive to reduce their emissions. The Acid Rain Programme has been accused of "early overallocation" during Phase I which allowed emission sources to "bank" their allowances for future years. As the ARP allowed unlimited "banking" of allowances, this meant sources could draw down their banked allowances in future phases.

\section{Considerations for adoption in London}

The two main lessons for London are firstly, in order to promote change, the climate policy must be credible. Secondly, it is very hard to predict what kind of innovations that will be induced from a strict climate policy. Introducing a tax on GHG emissions do not imply picking any particular clean technology.

In its approach to climate policy London should strive to keep the flexibility of market based instruments. Even if London cannot implement a carbon tax or a cap and trade programme, it could ensure that the policy measures are technology neutral. For instance, it could be possible to specify the target as "all emission reduction projects with a cost below GBP x per tonne GHG will be supported by the London government". Clearly, limitations in public budget could also make this strategy impossible. 


\section{Further information}

Bruvoll A. and B. Larsen (2004), “Greenhouse gas emissions in Norway: do carbon taxes work?”, Energy Policy 32(4), 493-505.

Burtraw D. and K. Palmer (2003), "The paparazzi take a look at a living legend: The SO2 cap and trade program for power plants in the United States", Discussion Paper 03-15, Resources for the Future.

McAllister, L.K. (2009), "The Overallocation Problem in Cap-and-Trade: Moving toward Stringency", Columbia Journal of Environmental Law, Vol. 43, San Diego Legal Studies Paper No. 08-076, pp. 395-445.

OECD (2000), "Rapporteur's Report in Innovation and the Environment", from Workshop on Innovation and the Environment, 19 June, OECD, Paris.

\section{Flexible approach to GHG emission reduction targets (Norway)}

\section{Description of the approach}

In 2008 the Norwegian parliament set bold GHG emission reduction targets for Norway. By 2030 the net GHG emissions of Norway should be zero i.e. all remaining emissions from Norwegian territory should be compensated by emission reduction abroad (financed by Norway). Note that it was not accurately specified how much GHG abatement that would be carried out within Norway's jurisdiction.

It could be problematic to have national emission reduction targets for sectors covered by the EU ETS, that is, any additional national abatement effort in these sectors will show up as increased emissions in other parts of the EU ETS since the EU ETS emission cap is given. Moreover, it is hard to know GHG abatement costs for non-EU ETS sectors up front. Reaching a national emission reduction target could therefore turn out to be excessively expensive.

The Norwegian parliament therefore decided not to have an absolute target for emission reductions from Norwegian territory, but instead intends to use the Clean Development Mechanisms (CDM) to the extent necessary to reach its target. Further, it has initiated and financed large projects within developing countries aimed at tropical forest conservation as a part of its GHG emission reduction strategy. These projects do not yet count as CDM projects, and thus cannot be accounted for when considering Norway's net emissions, that is, emissions from own jurisdiction subtracted off-sets from the flexible mechanisms in Kyoto. However, Norway is taking a proactive approach, and is working in parallel to get forest conservation projects integrated into a future climate treaty.

\section{Relevance to London}

It is very hard to know in advance how costly it is to reach a given emission reduction target for the Mayor of London if all emission reductions are to be carried out within London. Promoting profitable energy efficiency improvements are likely not sufficient to reach the bold emission reduction target. In this case also emission reduction projects with a net cost to London's economy must be carried out. If these projects turn of too be costly, London could profit greatly by carrying out projects in developing countries.

\section{Results of the approach}

As mentioned, the Norwegian parliament has did not accurately specify how much GHG abatement that would be carried out within Norway's jurisdiction. Instead, the government has made detailed emission reduction scenarios for every emission sector in Norway, and calculated how much emissions are 
likely to be reduced at various carbon prices and costs. For instance, the macro analysis showed that with a carbon tax as high as USD 250 per tonne; Norway can cut its 1990 emissions by $12 \%$ (this constitutes a $25 \%$ reduction from business as usual emissions in 2020).

\section{Reasons for success/failure of the approach}

The programme has just started, but clearly the policy depends on the legitimacy of the flexible mechanism in the Kyoto i.e. emission quota trading, CDM etc. Norway has also made its emission reduction ambitions contingent on other countries taking action. Hence, if other countries do not take action, Norway will no longer consider the country to be bounded by the target of having zero net emissions in 2030.

\section{Obstacles faced and response taken}

Even though the analysis has been criticised for being too optimistic on technology development, the analysis shows that it can be very costly to reach ambitious GHG reduction targets within a short time span. Thus, in order to reach its emission reduction targets Norway must most likely acquire CDM emission rights from developing countries. Some political parties oppose this as they believe that this is unethical, and that it only shows that Norway is not really committed to fight climate change. However, the alternative, not using CDM, probably implies that the target will not be reached. If a target is too ambitious, most economic actors will expect the target never to be fulfilled, and hence, not take the wanted action. An expert commission advised the Norwegian government to set a target price for emission reduction projects. Such a target price would help the private sector to invest in the right kinds of GHG abatement technologies.

\section{Considerations for adoption in London}

London could use the Norwegian report on GHG abatement costs and emission reduction potentials as an example for how to make more detailed emission reduction scenarios. Moreover, if London carried out a similar analysis, it could say something about the realism of London's target.

London could also consider using CDM projects for reaching its emission reduction targets. London could also consider emission reduction projects in other cities not yet certified as CDM projects, but which could constitute a development model for the CDM mechanism. London could work together with its experienced carbon trading sector in order to develop new models that could be implemented in London and elsewhere i.e. not project-based, but sector-based such as city transport in a particular city.

\section{Further information}

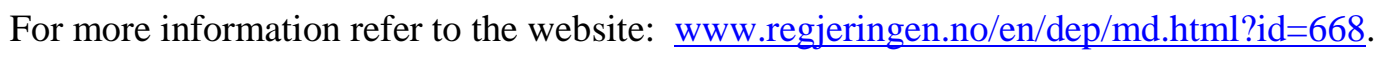

An English summary of the report can be obtained from: bestilling@klif.no. Ask for "Climate Cure 2020, Measures and instruments for Achieving Norwegian Climate Goals by 2020”. 


\section{ENDNOTES}

${ }^{1}$ Green Skills Agreement, Council of Australian Governments

${ }^{1}$ www.deewr.gov.au/Skills/Programmes/WorkDevelop/ClimateChangeSustainability/Pages/default.aspx

${ }^{2}$ Clean Sustainable Skills Package, see: www.deewr.gov.au/Skills/Programmes/WorkDevelop/ClimateChangeSustainability/Pages/default.aspx

${ }^{3}$ www.deewr.gov.au/Skills/Programmes/WorkDevelop/ClimateChangeSustainability/Pages/default.aspx

${ }^{4}$ NSW Green Skills Strategy Implementation Plan 2008-2010

${ }^{5}$ www.sit.nsw.edu.au/courses/?Media_Index_ID=1690

${ }^{6}$ www.greenskills.nsw.gov.au/

${ }^{7}$ http://coursefinder.greenskills.nsw.gov.au

${ }^{8}$ www.hunter.tafensw.edu.au/industry/food_bev/Pages/GSmart.aspx

${ }^{9}$ Annual Report 2009, NSW Department of Education and Training. Sydney, 2010.

${ }^{10}$ NSW Board of Vocational Education and Training, Annual Report 2009-2010

${ }^{11}$ Skills for Sustainability NSW Department of Education and Training, 2009

${ }^{12}$ NSW Jobs Summit: Report of the Green Skills NSW Taskforce.

${ }^{13}$ Green Skills Agreement Implementation Plan 2010-2011 for Ministerial Council for Tertiary Education and Employment; June 2010

14 "ÖkoKauf Wien: How to make use of 5 billion Euro purchasing power" Eva Persey, presentation at Ecoprocura 2006.

${ }^{15}$ Transdisciplinary Research and Sustainable Innovations: The Case of EcoBuy Vienna. Günter Getzinger IFZ Inter-University Research Centre for Technology, Work and Culture, Graz, Austria. Dubrovnik, 15 September 2010

16 "ÖkoKauf Wien"- Vienna buys ecologically, UN-Habitat best practice database, www.unhabitat.org/bestpractices/2010/mainview.asp?BPID=2298 


\section{ANNEX B: ABOUT THE AUTHORS}

\section{Gabriela Miranda, OECD project manager}

Gabriela Miranda, Mexican, is a policy analyst with the OECD Local Economic and Employment Development (LEED) Division, where she works since 2002. Her work comprises analysis and recommendations of public policy approaches notably on entrepreneurship and innovation, clusters, green growth, and the Latin American region. Before joining the OECD, Gabriela worked in Mexico as a consultant for SME development within the TEC-FUNDES Programme. For over two years, she also comanaged a project with indigenous communities in Mexico, where she defined and implemented tailored strategies for entrepreneurial, social and local economic development, with a specific focus on ethnic minorities and women.

Gabriela is the manager of the project on Climate Change, Employment and Local Development, which is a key contribution of LEED to the horizontal OECD Green Growth Strategy In LEED, Gabriela has led and contributed to various analytical studies in OECD and Latin American countries and has coauthored several reports. She has also participated as an expert in various events and with partner organisations, including the ILO, the IADB, the EC and CAF. Gabriela holds a BSc in business and economics with a specialisation on SME development from ITESM University in Mexico, and an MSc in international economics from Paris Dauphine University.

\section{Kris Krasnowski, London diagnostic report}

Kris Krasnowski, British, is a Senior Policy and Research Manager leading the Labour Market Strategy Team at the London Development Agency. Kris has successfully set up the LDA's Labour Market Research Series and is the Series Editor. In addition, he is also responsible for labour market policy advising the LDA, the Mayoral team and London Skills and Employment Board. Kris is also Vice-Chair of the London Skills and Employment Observatory.

$\mathrm{He}$ is in his second stint at the LDA following a year long absence to advise a Welfare to Work Company in the US and to help set up their UK business. Prior to working at the LDA Kris worked in Whitehall for five years at the HM Treasury on European Economic Reform and at DWP and DfES on employment and skills policy.

Whilst working in central and city-level Government Kris has led and contributed to a wide range of comparative studies and publications including London's first Skills and Employment Strategy, a Mayoral report on Increasing Employment in London, the Social Bridges series on meeting the social challenges of globalisation and he also led the labour market strand of ECOFIN's mid-term review of the EU's Lisbon Strategy. Most recently Kris led the LDA's research on Green Skills and he is about to publish a policy paper on applying behavioural economics to tackling worklessness.

\section{Andy Westwood, expert on topic (1) The labour market}

Mr Andy Westwood is chairman of the OECD Forum on Social Innovations and a former adviser to ministers in the Department of Communities and Local Government. Andy has also worked as a special adviser to John Denham at the Department for Innovation, Universities and Skills and at the UK Treasury. 
He has worked in education and employment policy for many years including as a team member of the Leitch Review of Skills and the Foster Review of Further Education. Prior to that Andy worked in Further Education and as Head of Policy Research at the Work Foundation and a director of the Centre for Economic and Social Inclusion.

He has written widely on many subjects including vocational education and training, urban regeneration, economic development, welfare to work and city policy and is a visiting professor in local economic development at London's South Bank University, a visiting professor in business at the University of Buckingham and a Fellow at London University's Institute of Education.

\section{Bettina Schaefer, expert on topic (2) Greening the workplace}

Ms Bettina Schaefer, Austrian, is a founding member of Ecoinstitut Barcelona with 17 years of professional experience. She studied architecture and urban planning in Vienna and Stuttgart (1993). Her main areas of expertise include: green public procurement, ecological assessment methods and resource efficiency in construction and urban planning, environmental policy instruments. Her projects focus on strategic approaches for the gradual implementation of green and social procurement in public organisations, including legal advice, criteria development for product groups and services, keeping in mind the market specific preconditions; and also on methodology development and implementation of sustainable consumption policies, like the FP7 project EUPOPP (European Policies to Promote Sustainable Consumption Patterns) and projects related to the Basque Sustainable Consumption Action Plan.

She has been working as a consultant on Local Agenda21 and ecological urbanism for the City of Barcelona since 1997. As an expert she participated in the elaboration of the "Spanish Green Book on the Urban Environment". She participates in Catalonian advisory councils and expert commissions, e.g. Barcelona's Municipal Council on the Environment and Sustainability, or the Catalonian Strategy for Environmental Education. She is also the Vice-president of the Association Architecture and Sustainability (Catalonian Chamber of Architects).

\section{Mads Greaker, expert on topic (3) Enabling green growth}

Mr Mads Greaker, Norwegian, holds a PhD from the Department of Economics, University of Oslo. He also has a Master of Science from the Norwegian Institute of Technology, Trondheim. He is currently engaged as Head of research for the Section for Economic Growth and Environmental Economics at the Research Department in Statistics Norway. In addition, he holds a position as part time Assistant Professor in Environmental Economics at Department of Economics, Gothenburg University, Sweden.

Mads Greaker's research includes analyzing the relationship between environmental regulation and firm competitiveness (Porter hypothesis), technology policy and climate change, robustness of international environmental agreements and sustainable development indicators. He has published his work in leading journals such as Journal of Environmental Economics and Management, Environmental and Resource Economics and Resource and Energy Economics. He also regularly does consultancy work for the Norwegian Ministry of Finance, The Swedish Ministry of Finance, The Nordic Council of Ministers and the like. 


\section{Climate Change, Employment m and Local Development in London, UK}

London and the UK are far from immune from the impacts of climate change. The UK is already experiencing the effects of climate change in the form of increased sea-surface temperature and rising sea levels. If global GHG emissions continue unabated, London in particular, will be vulnerable to floods, droughts and heat waves.

To achieve ambitious emission-cutting targets, the Mayor of London has developed a range of programmes that will stimulate demand for the low-carbon economy in London. However, some challenges still need to be addressed in order to ensure that enough jobs will be created and that those jobs created in the low-carbon economy will be accessible for Londoners.

This report examines the impacts of climate change (including through its effect on policy and regulations) on the London labour markets, with a focus on the creation of jobs and the development of a skilled workforce to meet the needs of the greener economy. The report also contains a set of policy recommendations for London to meet its ambitious low-carbon agenda while creating jobs.

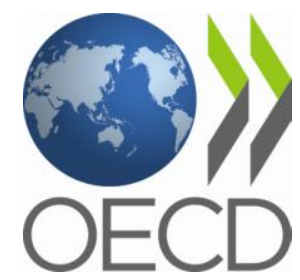

